Tese apresentada ao Hospital de Reabilitação de Anomalias Craniofaciais da Universidade de São Paulo para a obtenção do título de DOUTOR em Ciências. Área de Concentração: Distúrbios da Comunicação Humana. 


\section{IDENTIFICAÇÃO AUDITIVA EM CRIANÇAS DE 3 A 12 MESES DE IDADE COM FISSURA LABIOPALATINA.}

SILVIA HELENA ALVAREZ PIAZENTIN-PENNA

Orientador: Prof. Dr. José Alberto de Souza Freitas

Tese apresentada ao Hospital de Reabilitação de Anomalias Craniofaciais da Universidade de São Paulo para a obtenção do título de DOUTOR em Ciências.

Área de Concentração: Distúrbios da Comunicação Humana. 


\section{UNIVERSIDADE DE SÃO PAULO \\ HOSPITAL DE REABILITAÇÃO DE ANOMALIAS CRANIOFACIAIS}

R. Silvio Marchione, 3-20

Caixa Postal: 1501

17043-900 - Bauru - SP - Brasil

Telefone: (14) 235-8000

Prof. Dr. Adolpho José Melfi - Reitor da USP

Prof. Dr. José Alberto de Souza Freitas - Superintendente do HRAC-USP

Autorizo, exclusivamente, para fins acadêmicos e científicos, a reprodução total ou parcial desta tese.

Silvia Helena Alvarez Piazentin-Penna

Bauru, 10 de outubro de 2002

Piazentin-Penna, Silvia HA

P577i Identificação auditiva em crianças de 3 a 12 meses de idade com fissura labiopalatina. /Silvia Helena Alvarez Piazentin-Penna. Bauru, 2002. 157p.; il.; $30 \mathrm{~cm}$.

Tese (Doutorado - Ciências) - HRAC-USP cópia revisada em 22/11/2002

Orientador: José Alberto de Souza Freitas. Descritores: 1.Fissura labiopalatina 2.Criança 3.Audição.4 Avaliação Audiológica 5 EOAT 


\section{FOLHA DE APROVAÇÃO}

Dissertação apresentada e defendida por

SILVIA HELENA ALVAREZ PIAZENTIN-PENNA

e aprovada pela Comissão Julgadora em 21/11/2002

Profa. Dra. Diná Olivetti de Carvalho Hubig
Universidade de São Paulo - USP

Universidade de São Paulo - USP

Profa. Dra. Renata Motta Mamede Carvalho

Universidade de São Paulo - USP

Profa. Dra. Mariza Ribeiro Feniman

Universidade de São Paulo - USP

Prof. Dr. Orozimbo Alves Costa Filho

Universidade de São Paulo - USP

Prof. Dr. José Alberto de Souza Freitas

Universidade de São Paulo - USP (Orientador)

Profa. Dra. Inge Elly Kiemle Trindade

Presidente da Comissão de Pós-Graduação do HRAC-USP

Data de depósito da dissertação junto à SPG: 10/10/2002 


\section{Silvia Helena Alvarez Piazentin-Penna}

02 de novembro de 1963

Rio Claro-SP

1981-1984

1984

1987-1989

1994

1997

$1998-2002$

\section{Nascimento}

Curso de FonoaudiologiaUniversidade do Sagrado Coração-Bauru-SP.

Fonouadióloga do HRACUSP-Bauru.

Curso de Pós-Graduação

em Distúrbios da

Comunicação, ao nível de Mestrado, na Pontifícia Universidade Católica de São Paulo.

Encarregada de Setor Técnico (Ambulatório) do HRAC USP-Bauru.

Título de Especialista em Audiologia pelo Conselho Regional de Fonoaudiologia.

Curso de Pós-Graduação em Distúrbios da Comunicação Humana, ao nivel de Doutorado, no HRAC USP-Bauru. 
Ao meu pai José, que já não está mais conosco, pelo exemplo de familia, trabalho e honestidade dispensado em toda sua existência;

À minha mãe Bela, por seu jeito de me ensinar e encorajar, sempre com muita fé e amor;

Ao Fábio, meu amor, por compartilhar minhas alegrias, tristezas e preocupações e sempre com muito amor, impulsionando minha vida. 
Ao Prof. Dr. José Alberto de Souza Freitas (Tio Gastão), exemplo de persistência, dedicação e amor ao trabalho

Benditas sejam as dificuldades que nos agridem e fazem pensar.

Benditas sejam as horas que gastamos em função do bem eterno.

Bendito seja quem nos maltrata à primeira vista e nos ajuda a melhorar.

Bendito seja quem não nos conhece e não acredita em nós.

Bendito seja quem nos compara com vagabundos e indolentes.

Bendito seja quem nos expulsa, como párias ou fanáticos.

Bendito seja a mão que nos nega o cumprimento.

Bendito seja quem quer nos esquecer, impaciente.

Bendito seja quem nos nega o pão de cada dia.

Bendito seja quem nos ataca por ignorância e covardia.

Bendito seja quem nos experimenta no correr do tempo.

Bendito seja quem nos faz chorar nos caminhos.

Bendito seja quem não agrada no momento.

Bendito seja quem exige de nós a perfeição.

Benditos sejam os que nos maltratam o coração porque, verdadeiramente, são estes, meus filhos, os nossos vigilantes e os que nos ajudam a seguir o Cristo com maior segurança, pois Deus, através deles, nos ajuda na auto educação, de maneira que fiquem abertas todas as portas para o Amor Universal. 
À Profa Dra Mariza Ribeiro Feniman, que vivencia muitos momentos de minha vida, desde a graduação, sempre me ensinando e incentivando a vencer meus desafios.

"Que você aceite o tempo seja ele qual for.

Que sinta serenidade na espera necessária.

Para que a semente plantada brote no tempo certo.

E apesar das dificuldades, e de algumas tristezas que insistem,

Que o sol possa ser seu presente mais doce”. 
A Deus pela minha vida, minha saúde, minha família, meus amigos e meu trabalho;

À Mariana, Sueli e Candinho, pelo carinho e apoio sempre presentes;

À Profa Dra Inge Elly Kiemle Trindade, presidente da Pós-Graduação do HRAC-USP, pelo exemplo de garra e determinação no trabalho;

Ao Prof. Dr. Orozimbo Alves Costa Filho, meu orientador no curso de Mestrado, pelos ensinamentos sempre dispensados;

À fonoaudióloga Maria Cristina Zimmermann, chefe do setor de Fonoaudiologia do HRAC-USP, pelo companheirismo e constante incentivo;

À minha amiga Renata, companheira de muitos momentos de minha vida acadêmica, profissional e pessoal;

Às colegas setor de Fonoaudiologia do HRAC-USP: Andréa, Cristianne, Cristina Guedes, Giovana, Jacilene, Janaina, Lourdes, Rosana, Vera, bolsitas, alunas e estagiárias, pelo apoio e convivio diário;

Aos pacientes que tanto me ensinam;

Aos professores e colegas do curso de Pós-Graduação em Distúrbios da Comunicação Humana do HRAC-USP;

Ao Prof. Dr. José Roberto Pereira Lauris pela análise estatística deste trabalho; 
Ao Prof. Dr. José Benedito Pinto, pela revisão da língua portuguesa;

Ao Prof. Dr. Roberto Loureiro Maringoni, por suas sugestões no trabalho;

Aos funcionários da secretaria de Pós-Graduação do HRAC-USP, pela presteza e competência com que sempre me atenderam;

Aos funcionários da Unidade e Pesquisa do HRAC-USP, pelo profissionalismo e dedicação que sempre me atenderam;

À todos que direta, ou indiretamente colaboraram e tornaram possivel a realização deste trabalho. 


\section{SUMÁRIO}

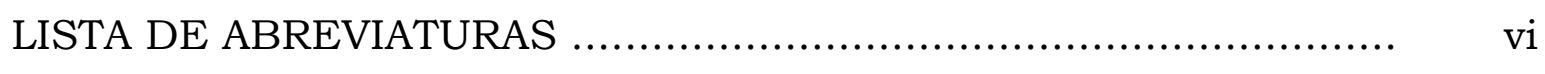

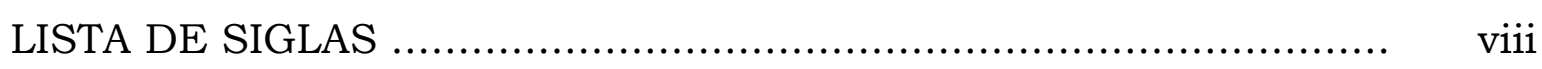

LISTA DE FIGURAS ................................................... ix

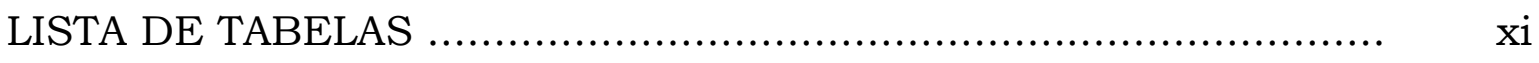

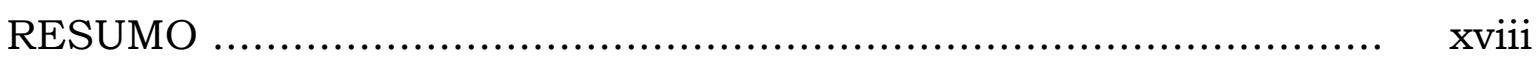

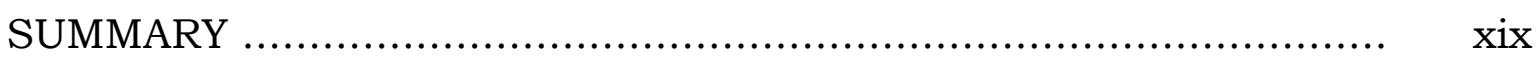

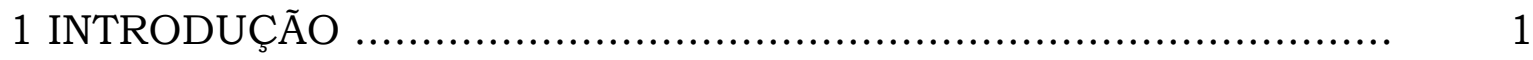

2 REVISÃO DE LITERATURA .......................................... 4

3 OBJETIVO ............................................................ 33

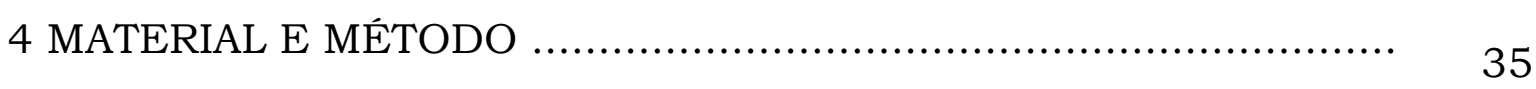

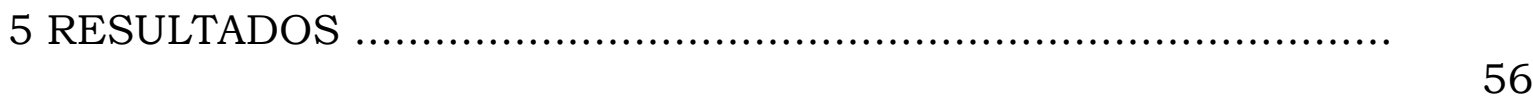

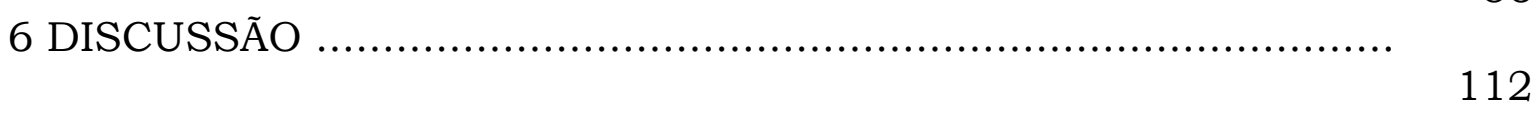

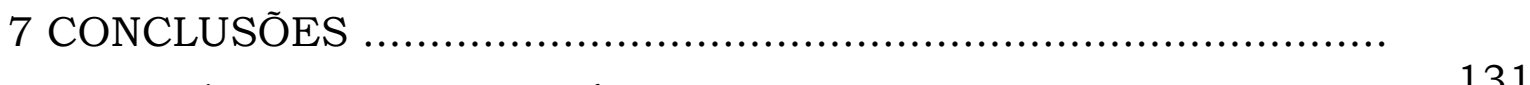

8 REFERÊNCIAS BIBLIOGRÁFICAS ...................................... 131

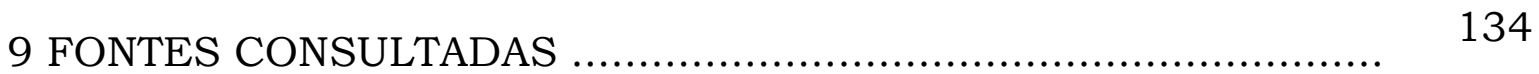

$\begin{array}{ll}\text { ANEXOS } & 156\end{array}$ 


\section{LISTA DE ABREVIATURAS}

dB - Decibel

dBNA - Decibel nível de audição

dBNPS - Decibel nível de pressão sonora

daPa - Deca Pascal

$\mathrm{Hz}-\mathrm{Hertz}$

$\mathrm{KHz}$ - Kilohertz

$\mathrm{cm}$ - centímetro

ms - milissegundos

EOA - Emissão otoacústica

EOAT - Emissão otoacústica evocada por estímulo transiente EOAPD - Emissão otoacústica evocada produto de distorção

PAETE - Potencial auditivo evocado de tronco encefálico

TIB - fissura transforame incisivo bilateral

TIUD - fissura transforame incisivo unilateral direita

TIUE - fissura transforame incisivo unilateral esquerda

PÓS-COM - fissura pós-forame incisivo completa

PÓS-IN - fissura pós-forame incisivo incompleta

PRÉ BI - fissura pré-forame incisivo bilateral

PRÉ DIR - fissura pré-forame incisivo unilateral direita

PRÉ ESQ - fissura pré-forame incisivo unilateral esquerda

FPSM - fissura de palato submucosa

MASC - masculino

FEM - feminino

$\mathrm{m}$ - meses

OM - orelha média

OD - orelha direita

$\mathrm{OE}$ - orelha esquerda

RCP - reflexo cocleopalpebral

MAE - meato acústico externo 
$\mathrm{S}$ - reação de sobressalto

A - atenção à fonte sonora

$\mathrm{PF}$ - procura da fonte sonora

LL - localização da fonte sonora

E.A. -Entrevista audiológica

IMIT- Medidas de imitância acústica

VRA - Audiometria de reforço visual

AOC - Audiometria de observação comportamental

IVAS - infecções de vias aéreas superiores

OMS - otite média secretora 


\section{LISTA DE SIGLAS}

HRAC - Hospital de Reabilitação de Anomalias Craniofaciais USP - Universidade de São Paulo

ILO - Institute of Laryngology and Otology 


\section{LISTA DE FIGURAS}

Figura 1 - Fissura transforame incisivo unilateral....................... 37

Figura 2 - Fissura transforame incisivo bilateral ....................... 37

Figura 3 - Fissura pós-forame incisivo incompleta ..................... 38

Figura 4 - Fissura pós-forame incisivo completa ......................... 39

Figura 5- Fissura pré-forame incisivo incompleta bilateral .......... 40

Figura 6 - Fissura pré-forame incisivo completa unilateral .......... 40

Figura 7 - Fissura de palato submucosa ................................ 41

Figura 8 - Registro das EOAT de uma criança ............................. 53

Figura 9 - Distribuição da porcentagem de orelhas segundo o critério tipo de curva timpanométrica de crianças de 3 a 6 meses do grupo 1

Figura 10 - Distribuição da porcentagem de orelhas segundo o critério tipo de curva timpanométrica de crianças de 6 a 9 meses do grupo 1

Figura 11 - Distribuição da porcentagem de orelhas segundo o critério tipo de curva timpanométrica de crianças de 9 a 12 meses do grupo 1

Figura 12 - Distribuição da porcentagem de orelhas das crianças de 3 a 6 meses do grupo 1, quanto ao critério presença ou ausência de EOAT

Figura 13 - Distribuição da porcentagem de orelhas das crianças de 6 a 9 meses do grupo 1, quanto ao critério presença ou 
ausência de EOAT

Figura 14 - Distribuição da porcentagem de orelhas das crianças de 9 a 12 meses do grupo 1, quanto ao critério presença ou ausência de EOAT

Figura 15 - Distribuição da porcentagem de orelhas segundo o critério tipo de curva timpanométrica das crianças de 3 a 6 meses do grupo 2

Figura 16 - Distribuição da porcentagem de orelhas segundo o critério tipo de curva timpanométrica das crianças de 6 a 9 meses do grupo 2

Figura 17 - Distribuição da porcentagem de orelhas das crianças de 3 a 6 meses do grupo 2, quanto ao critério presença ou ausência de EOAT.

Figura 18 - Distribuição da porcentagem de orelhas das crianças de 6 a 9 meses do grupo 2, quanto ao critério presença ou ausência de EOAT

Figura 19 - Distribuição da porcentagem de orelhas segundo o critério tipo de curva timpanométrica do grupo 3

Figura 20 - Distribuição do número de orelhas das crianças do grupo 3, quanto ao critério presença ou ausência de EOAT 


\section{LISTA DE TABELAS}

Tabela 1 - Distribuição de pacientes do grupo 1, do grupo 2 e do grupo 3, quanto ao gênero

Tabela 2 - Distribuição de pacientes do grupo 1, do grupo 2 e do grupo 3 quanto à faixa etária

Tabela 3 - Distribuição de pacientes do grupo 1, do grupo 2 e do grupo 3, quanto ao tipo de fissura

Tabela 4 - Distribuição dos indicadores de risco, além da fissura labiopalatina, referidos pelos pais e/ou responsáveis das crianças do grupo 1

Tabela 5 - Distribuição da freqüência de ocorrência de respostas a sons instrumentais, nas crianças de 3 a 6 meses do grupo 1

Tabela 6 - Distribuição da freqüência de ocorrência de respostas a sons instrumentais, nas crianças de 6 a 9 meses do grupo 1

Tabela 7 - Distribuição da freqüência de ocorrência de respostas a sons instrumentais, nas crianças de 9 a 12 meses do grupo 1 ....... 66 Tabela 8 - Distribuição da ocorrência dos niveis de respostas para tons puros obtidos para as freqüências de $500 \mathrm{~Hz}, 1000 \mathrm{~Hz}, 2000 \mathrm{~Hz}$ e $4000 \mathrm{~Hz}$ para o lado direito e esquerdo das crianças de 3 a 6 meses do grupo 1

Tabela 9 - Distribuição da ocorrência dos niveis de respostas para tons puros obtidos para as freqüências de $500 \mathrm{~Hz}, 1000 \mathrm{~Hz}, 2000 \mathrm{~Hz}$ e $4000 \mathrm{~Hz}$ para o lado direito e esquerdo das 
crianças de 6 a 9 meses do grupo 1 .

Tabela 10 - Distribuição da ocorrência dos níveis de respostas para tons puros obtidos para as freqüências de $500 \mathrm{~Hz}, 1000 \mathrm{~Hz}$, $2000 \mathrm{~Hz}$ e $4000 \mathrm{~Hz}$ para o lado direito e esquerdo das crianças de 9 a 12 meses do grupo 1

Tabela 11 - Associação dos dados da EOAT com os dados da entrevista audiológica, das 17 crianças de 3 a 6 meses do grupo 1 que realizaram os procedimentos bilateralmente

Tabela 12 - Associação dos dados da EOAT com os dados da entrevista audiológica, das 7 crianças de 6 a 9 meses do grupo 1 que realizaram os procedimentos bilateralmente

Tabela 13 - Associação dos dados da EOAT com os dados da entrevista audiológica, das 7 crianças de 9 a 12 meses do grupo 1 que realizaram os procedimentos bilateralmente

Tabela 14 - Associação dos dados da EOAT com os dados das medidas de imitância acústica, por orelha testada, das 17 crianças (34 orelhas) de 3 a 6 meses do grupo 1 que realizaram os exames bilateralmente

Tabela 15 - Associação dos dados da EOAT com os dados das medidas de imitância acústica, por orelha testada, das 7 crianças (14 orelhas) de 6 a 9 meses do grupo 1 que realizaram os procedimentos bilateralmente.

Tabela 16 - Associação dos dados da EOAT com os dados das medidas de imitância acústica, por orelha testada, das 7 crianças 
(14 orelhas) de 9 a 12 meses do grupo 1 que realizaram os procedimentos bilateralmente

Tabela 17 - Associação dos dados da EOAT com os dados da audiometria de reforço visual, por orelha testada, das 17 crianças (34 orelhas) de 3 a 6 meses do grupo 1 que realizaram os exames bilateralmente

Tabela 18 - Associação dos dados da EOAT com os dados da audiometria de reforço visual, por orelha testada, das 7 crianças (14 orelhas) de 6 a 9 meses do grupo 1 que realizaram os exames bilateralmente

Tabela 19 - Associação dos dados da EOAT com os dados da audiometria de reforço visual, por orelha testada, das 7 crianças (14 orelhas) de 9 a 12 meses do grupo 1 que realizaram os exames bilateralmente

Tabela 20 - Associação dos dados da EOAT com os dados da audiometria de observação comportamental, das 17 crianças de 3 a 6 meses do grupo 1 que realizaram os exames bilateralmente ..... 78 Tabela 21 - Associação dos dados da EOAT com os dados da audiometria de observação comportamental, das 7 crianças de 6 a 9 meses do grupo 1 que realizaram os exames bilateralmente Tabela 22 - Associação dos dados da EOAT com os dados da audiometria de observação comportamental, das 7 crianças de 9 a 12 meses do grupo 1 que realizaram os exames bilateralmente ...... Tabela 23 - Distribuição dos indicadores de risco, além da fissura 
labiopalatina, referidos pelos pais e/ou responsáveis das crianças do grupo 2

Tabela 24 - Distribuição da freqüência de ocorrência de respostas a sons instrumentais, nas crianças de 3 a 6 meses do grupo $2 \ldots \ldots$.

Tabela 25 - Distribuição da freqüência de ocorrência de respostas a sons instrumentais, nas crianças de 6 a 9 meses de idade do grupo 2

Tabela 26 - Distribuição da ocorrência dos níveis de respostas para tons puros obtidos para as freqüências de $500 \mathrm{~Hz}, 1000 \mathrm{~Hz}$, $2000 \mathrm{~Hz}$ e $4000 \mathrm{~Hz}$ para o lado direito e esquerdo das crianças de 3 a 6 meses do grupo 2

Tabela 27 - Distribuição da ocorrência dos níveis de respostas para tons puros obtidos para as freqüências de $500 \mathrm{~Hz}, 1000 \mathrm{~Hz}$, $2000 \mathrm{~Hz}$ e $4000 \mathrm{~Hz}$ para o lado direito e esquerdo das crianças de 6 a 9 meses do grupo 2

Tabela 28 - Associação dos dados da EOAT com os dados da, entrevista audiológica, das 16 crianças de 3 a 6 meses do grupo 2 que realizaram os exames bilateralmente

Tabela 29 - Associação dos dados da EOAT com os dados da entrevista audiológica, das 4 crianças de 6 a 9 meses do grupo 2 que realizaram os exames bilateralmente

Tabela 30 - Associação dos dados da EOAT com os dados das medidas de imitância acústica, por orelha testada, das 16 crianças (32 orelhas) de 3 a 6 meses do grupo 2 que realizaram os exames 
bilateralmente

Tabela 31 - Associação dos dados da EOAT com os dados das medidas de imitância acústica, por orelha testada, das 4 crianças (8 orelhas) de 6 a 9 meses do grupo 2 que realizaram os exames bilateralmente

Tabela 32 - Associação dos dados da EOAT com os dados da audiometria de reforço visual, por orelha testada, dos 16 crianças (32 orelhas) de 3 a 6 meses do grupo 2 que realizaram os exames bilateralmente

Tabela 33 - Associação dos dados da EOAT com os dados da audiometria de reforço visual, por orelha testada, dos 4 crianças ( 8 orelhas) de 6 a 9 meses do grupo 2 que realizaram os exames bilateralmente

Tabela 34 - Associação dos dados da EOAT com os dados da audiometria de observação comportamental das 16 crianças de 3 a 6 meses do grupo 2 que realizaram os exames bilateralmente Tabela 35 - Associação dos dados da EOAT com os dados da audiometria de observação comportamental das 4 crianças de 6 a 9 meses do grupo 2 que realizaram os exames bilateralmente Tabela 36 - Distribuição da freqüência de ocorrência de respostas a sons instrumentais, nas crianças do grupo 3 Tabela 37 - Distribuição da ocorrência dos niveis de respostas para tons puros obtidos para as freqüências de $500 \mathrm{~Hz}, 1000 \mathrm{~Hz}$, $2000 \mathrm{~Hz}$ e $4000 \mathrm{~Hz}$ para o lado direito e esquerdo das criança do 
grupo 3

Tabela 38 - Associação dos dados da EOAT com os dados da entrevista audiológica, das 5 crianças de 3 a 6 meses do grupo 3 que realizaram os exames bilateralmente

Tabela 39 - Associação dos dados da EOAT com os dados das medidas de imitância acústica, por orelha testada, das 5 crianças (10 orelhas) do grupo 3 que realizaram os exames bilateralmente .. Tabela 40 - Associação dos dados da EOAT com os dados da audiometria de reforço visual, por orelha testada, das 5 crianças (10 orelhas) do grupo 3 que realizaram os exames bilateralmente ..

Tabela 41 - Associação dos dados da EOAT com os dados da audiometria de observação comportamental das 5 crianças do grupo 3 que realizaram os exames bilateralmente

Tabela 42 - Associação dos dados da EOAT de orelhas de crianças de 3 a 6 meses do grupo 1, grupo 2 e grupo 3 que realizaram os exames bilateralmente, em relação ao total de orelhas testadas .....

Tabela 43 - Associação dos dados da EOAT de orelhas de crianças de 6 a 9 meses do grupo 1 e do grupo 2 que realizaram os exames bilateralmente, em relação ao total de orelhas testadas

Tabela 44 - Associação dos dados da entrevista audiológica de crianças de 3 a 6 meses do grupo 1, do grupo 2 e do grupo 3 106 Tabela 45 - Associação dos dados da entrevista audiológica de crianças de 6 a 9 meses do grupo 1 e do grupo 2 Tabela 46 - Associação dos dados das medidas de imitância 
acústica de crianças de 3 a 6 meses do grupo 1, do grupo 2 e do grupo 3 que realizaram os exames bilateralmente, de acordo com a orelha testada

Tabela 47 - Associação dos dados das medidas de imitância acústica de crianças de 6 a 9 meses do grupo 1 e do grupo 2 que realizaram os exames bilateralmente, de acordo com a orelha testada

Tabela 48 - Associação dos dados da audiometria de observação comportamental de crianças de 3 a 6 meses do grupo 1, do grupo 2 e do grupo 3

Tabela 49 - Associação dos dados da audiometria de observação comportamental de crianças de 6 a 9 meses do grupo 1 e do grupo 2

Tabela 50 - Associação dos dados da audiometria de reforço visual de crianças de 3 a 6 meses do grupo 1, do grupo 2 e do grupo 3 que realizaram os exames bilateralmente, de acordo com a orelha testada

Tabela 51 - Associação dos dados da audiometria de reforço visual de crianças de 6 a 9 meses do grupo 1 e do grupo 2 que realizaram os exames bilateralmente, de acordo com a orelha testada 
Piazentin-Penna SHA. Identificação auditiva em crianças de 3 a 12 meses de idade com fissura labiopalatina (tese). Bauru: Hospital de Reabilitação de Anomalias Craniofaciais, Universidade de São Paulo, 2002.

Objetivos: Verificar a ocorrência de emissões otoacústicas evocadas por estímulo transiente (EOAT) em crianças com fissura labiopalatina (FLP) e associar esses resultados com os da entrevista audiológica (EA), medidas de imitância acústica (IMIT), audiometria de observação comportamental (AOC) e audiometria de reforço visual (VRA).

Local: Setor de Fonoaudiologia e de Genética Clínica - HRAC - USP.

Participantes: 82 crianças com FLP não operada, de ambos os gêneros, idade entre 3 e 12 meses.

Intervenções: EA, meatoscopia, AOC, VRA, IMIT, EOAT.

Resultados: Os achados mostraram: presença de indicadores de risco, além da FLP, em $77 \%$ das crianças do grupo 1 (fissura transforame e pós-forame incisivo, $\mathrm{N}=48$ ), $52 \%$ do grupo 2 (fissura pré-forame incisivo, $\mathrm{N}=29$ ) e $40 \%$ do grupo 3 (fissura de palato submucosa, $\mathrm{N}=5$ ); maior ocorrência de alteração na IMIT nas crianças com fissura transforame e pós-forame incisivo e a partir dos 6 meses de idade; AOC alterada em $50 \%$ das crianças do grupo 1 e $14 \%$ do grupo 2; maior ocorrência de alteração na VRA nas crianças do grupo 1, seguidas pelo grupo 2; ocorrência de EOAT em 1\% das crianças do grupo 1, 55\% do grupo 2 e $70 \%$ do grupo 3 .

Conclusões: verificamos maior ocorrência de EOAT nas crianças com fissura de palato submucosa e pré-forame incisivo; a associação entre os resultados da EOAT com os dos outros procedimentos, mostrou diferença estatisticamente significante na associação das EOAT com as IMIT das crianças de 3 a 6 meses de idade dos grupos 2 e 3 ; o uso das EOAT não mostrou ser um método adequado para a avaliação da audição de bebês com fissura de palato não operada.

Descritores: fissura labiopalatina, criança, audição, avaliação audiológica, EOAT. 
Piazentin-Penna SHA. Hearing identification in 3- to 12-month-old children with cleft lip and palate (thesis). Bauru: Hospital de Reabilitação de Anomalias Craniofaciais, Universidade de São Paulo, 2002.

Objectives: To determine the occurrence of transient evoked otoacoustic emissions evoked (TEOA) in infants with cleft lip (CL)and palate (P) and to correlate these results with those of the audiologic interview (AI), acoustic imitance (IMIT) measurements, behavioral observation audiometry (BOA), and visual reinforcement audiometry (VRA).

Place: Sector of Speech Pathology and Audilogy and Clinical Genetics HRAC - USP.

Participants: 82 infants of both sexes with non-operated CLP aged 3 to 12 months.

Interventions: AI, meatoscopy, BOA, VRA, IMIT, TEOA.

Results: The findings showed the presence of risk indicators in addition to CLP in $77 \%$ of group 1 infants (CLP, N=48), $52 \%$ of infants of group 2 $(\mathrm{CL}, \mathrm{N}=29$ ) and $40 \%$ of children in group 3 (submucous cleft, $\mathrm{N}=5$ ); a more frequent occurrence of altered IMIT in children with CLP and CP and starting at 6 months of age; altered BOA in $50 \%$ of group 1 children and $14 \%$ of group 2 children; a more frequent occurrence of altered VRA in group 1 children, followed by group 2; occurrence of EOAT in 1\% of group 1 children, in $55 \%$ of group 2 children, and in $70 \%$ of group 3 children.

Conclusions: we detected a more frequent occurrence of EOAT in children with submucous and CL. TEOA was significantly correlated with IMIT in children aged 3 to 6 months of groups 2 and 3; the use of TEOA did not prove to be an adequate method to assess the hearing of babies with non-operated CP.

Key words: cleft lip-palate, infants, hearing, audiologic evaluation, TEOA. 


\section{INTRODUÇÃO.}

A associação entre perda auditiva e fissura labiopalatina tem sido conhecida há muitos anos. Embora existam desacordos na prevalência de perda de audição em indivíduos com fissura labiopalatina, existe um consenso de que esta perda auditiva, geralmente do tipo condutiva e bilateral, ocorre mais freqüentemente nas crianças com fissura do que naquelas que não a apresentam.

A efusão da orelha média tem sido apontada como um fator desencadeante dessa perda auditiva em indivíduos com fissura labiopalatina, em virtude da malformação anatômica e da deficiência funcional da musculatura da tuba auditiva com aquela do palato mole.

Sabe-se que a audição é de importância fundamental para o desenvolvimento normal da linguagem, pois a criança que ouve normalmente regula a qualidade de articulação das palavras mediante o controle aferencial através do feedback auditivo. Uma perda auditiva, por menor que seja, pode comprometer a aquisição da fala e da linguagem das crianças, pois estas serão privadas de experiências verbais, por não terem o padrão auditivo correto para imitar, levando a um pobre desenvolvimento de fala e linguagem.

Assim, detectar o mais cedo possivel os distúrbios de audição nesta população tem sido uma das metas dos fonoaudiólogos, juntamente com outros membros de uma equipe interdisciplinar, pois sabe-se que as perdas auditivas e a história de otite média nos 
primeiros anos de vida podem ser indicadores de risco para o desenvolvimento alterado da linguagem, da fala, do aprendizado e do processamento auditivo, visto ser este o período crítico em que a criança aprende como ouvir.

Muitos métodos para detectar as perdas auditivas em crianças pequenas têm sido desenvolvidos, porém opiniões divergem no que diz respeito a sua viabilidade e confiabilidade. O uso das emissões otoacústicas (EOA), no entanto, tem se mostrado um procedimento promissor, visto sua forma de realização ser simples, rápida, objetiva e não invasiva.

A literatura tem relatado a ocorrência das EOA em indivíduos com audição normal e um decréscimo ou ausência das mesmas, em casos de perda auditiva condutiva ou neurossensorial.

Devido a grande ocorrência de alterações auditivas e otológicas encontradas na população com fissura labiopalatina, é recomendado que se detecte essas alterações o mais cedo possivel. Isto permite o encaminhamento e o tratamento adequados evitando-se, muitas vezes, que uma deficiência auditiva se instale, levando à privação sensorial auditiva da criança, com prejuízo para o desenvolvimento da fala, da linguagem e das habilidades cognitivas. 


\section{REVISÃO DE LITERATURA.}

Há muito tempo, os problemas auditivos e otológicos que a fissura palatina podem acarretar a um indivíduo têm despertado atenção por parte de pesquisadores.

O primeiro autor que descreveu a repercussão da fissura palatina na audição foi Alt (1878), citado por Heller (1979 p.100) o qual observou melhora na audição após o tratamento da otorréia associada à fissura palatina.

Em 1892, Thorington, citado por Heller (1979 p.100), relatou um caso de destruição quase total do véu palatino, o qual foi substituído por um palato mole artificial, resultando, não somente, em grande melhora da fala, como, também, em melhora da audição.

Gutzmann A. e Gutzmann H. (1893) e Gutzmann H.(1894), citados por Hirschberg (1986 p.238), chamaram a atenção para a freqüente ocorrência de perda auditiva em indivíduos com fissura palatina. No primeiro estudo, relataram que quase $50 \%$ de seus pacientes com fissura de palato apresentavam perda auditiva.

Em 1901 Lannois, citado por Heller (1979 p.100), foi o primeiro a descrever alterações patológicas na orelha média e relacioná-las à fissura palatina. A partir de então, inúmeros trabalhos têm sido desenvolvidos, procurando esclarecer essas alterações.

Grande parte da literatura é unânime em afirmar que a fissura labiopalatina acarreta problemas audiológicos e otológicos (Sataloff e 
Fraser 1952, Hayashi et al 1961, Shimo 1972, Mattucci 1979, Strupler 1980, Webster 1980, Ribeiro 1987, Piazentin 1989, Paradise e Elster 1994, Costa Filho e Piazentin 1997 e Kemker 1997), causados, provavelmente, por uma alteração no funcionamento da tuba auditiva.

Moller (1981) examinou 261 pacientes com fissura de palato, com idades entre 1 mês e 20 anos (idade média de 7 anos), por um período de 3 anos. Foram realizados a otoscopia, a timpanometria e a audiometria. Os resultados mostraram que a otite média serosa foi um achado dominante nas crianças abaixo de 5 anos, portadoras de fissura de palato e que, aos 3 anos de idade os achados otoscópicos e timpanométricos freqüentemente começaram a mudar. Relatou ainda, que partir dos 6 anos de idade foi ocorrendo clara normalização da otoscopia e da pressão da orelha média.

Freeland e Evans (1981) pesquisaram 2 grupos de crianças com fissura de palato, até os 4 anos de idade. No grupo 1 as crianças não tinham tido avaliação otológica de rotina ou tratamento otológico. No grupo 2 as crianças foram regularmente observadas através da otoscopia, no período anterior à palatoplastia, aos 6 meses de idade. Caso os indivíduos do grupo 2 apresentassem otite média com efusão, 3 meses após a cirurgia era realizado novo exame, e inserido tubo de ventilação. Nesse grupo, o objetivo era manter a ventilação da orelha média até os 4 primeiros anos do desenvolvimento da fala e da linguagem. Concluíram que a incidência de otite média com efusão, de perfurações e de retrações da membrana timpânica foi maior no 
grupo 1. Quanto à avaliação da fala e da linguagem durante os 4 anos, não houve diferença significativa entre os dois grupos. Os autores reforçaram a importância da avaliação otológica de rotina, para permitir o tratamento da efusão persistente nessa população.

Kono et al (1981) estudaram 71 casos de fissura de palato submucosa (FPSM) clássica associada à fissura de palato primário. Verificaram que $78 \%$ apresentaram alterações de orelha média. Dos indivíduos com FPSM clássica, 45\% apresentaram alterações de orelha média.

Croft et al (1981) referiram que nos casos de FPSM as otites podem estar ocorrendo pela própria fissura.

Too-Chung (1983) realizou timpanometria em crianças com fissura de lábio e palato desde o nascimento. Verificou que todas elas tinham aeração normal da orelha média por ocasião do nascimento e as complicações começaram a aparecer com 17 semanas de vida. Enfatizou que o fechamento do palato aos 4 meses de idade ou antes, poderia evitar essas complicações e, a partir do momento em que se observasse fluído na orelha média, deveria ser indicada a inserção de tubos de ventilação juntamente com a cirurgia do palato.

Kinnebrew e Mc Tigue (1984) referiram a presença de otite média na FPSM como conseqüência da hipoplasia da tuba auditiva. Sugeriram que a intervenção otológica com os tubos de ventilação não seria efetiva nos casos de FPSM, a menos que a musculatura do palato fosse reorientada através da palatoplastia. 
Frable et al (1985) instituíram um programa para realizar a correção do palato mole e miringotomia, com inserção bilateral de tubo de ventilação no mesmo procedimento cirúrgico, em trinta e seis pacientes com fissura de palato duro e mole que realizaram a palatoplastia entre os 12 e 15 meses de idade. Os autores notaram uma grande diminuição dos problemas auditivos, pois a incidência de otite média foi reduzida de quase $100 \%$ para $17 \%$, e nestes foi necessária a repetição de miringotomia e colocação de tubos de ventilação.

Hubbard et al (1985) realizaram um estudo com individuos que apresentavam fissura de palato, para verificar as conseqüências dos problemas de otite média. Os achados indicaram que a otite média recorrente na infância, pode resultar em prejuizo da audição e da fala, porém, não confirmaram a hipótese de que a otite média precoce pode afetar o desenvolvimento cognitivo, social, emocional e da linguagem.

Kitajiri et al (1985) estudando 20 ossos temporais de crianças com idade entre 45 minutos e 12 meses, procuraram definir a relação entre a ocorrência de otite média com efusão e a disfunção da tuba auditiva em crianças com fissura de palato. Para comparação, realizaram um estudo similar em crianças com palato ogival. Foi observada otite média em 17 dos 20 ossos temporais, sendo que 16 apresentavam efusão. A otite média foi mais grave nas crianças com fissura de palato, assim como a inflamação da orelha média e da tuba auditiva pareceram mais pronunciadas em crianças mais velhas, particularmente nas com fissura de palato. 
Doyle et al (1986) realizaram um estudo longitudinal em 24 crianças com fissura de palato para verificar a função da tuba auditiva e a ocorrência otite média. Em todas as crianças entre os 3 e 6 meses de idade, inseriu-se tubo de ventilação, bilateralmente, como profilaxia da otite média. Os resultados indicaram que $88 \%$ das orelhas testadas antes da palatoplastia, realizada entre os 14 e 18 meses de idade, apresentavam habilidade para dilatar a tuba auditiva ativamente durante a deglutição e essa porcentagem permaneceu a mesma após a palatoplastia. Antes da cirurgia, a resistência ao fluxo aéreo e à pressão peritubal estavam anormalmente altas; após a cirurgia voltaram ao limite normal. Os autores afirmaram que crianças com fissura de palato são consideradas de alto risco para desenvolver uma perda auditiva leve e flutuante.

Fria et al (1987) descreveram achados de potencial auditivo evocado de tronco encefálico (PAETE) num grupo de 23 crianças (3 a 36 meses de idade) com fissura de palato, que foram submetidas à miringotomia com colocação de tubo de ventilação. Os resultados mostraram que a otite média com efusão, usualmente, resulta em alguma perda auditiva pois, das 46 orelhas testadas, 40 apresentaram perda auditiva e dessas, 39 (98\%) tinham efusão na orelha média.

Helias et al (1988) estudaram 23 crianças entre 0 e 14 meses de idade, com fissura palatina. Foi realizada otoscopia, timpanometria e PAETE, antes da palatoplastia, aos 18 meses. Em 19 crianças detectouse perda auditiva condutiva moderada. Os autores concluíram que o 
problema auditivo aparece precocemente em crianças com fissura palatina e que está diretamente relacionado à malformação do palato.

Velasco et al (1988) estudaram 108 indivíduos com FPSM clássica com idade acima de 4 anos. Verificaram que 57 indivíduos apresentavam inadequação velofaríngea e destes, 4 apresentaram perda auditiva neurossensorial profunda, 41 perda auditiva condutiva e 12 apresentaram audição normal. Referiram que as perdas auditivas, principalmente as do tipo condutivo encontradas neste tipo de fissura, devem-se à malformação da musculatura do véu palatino.

Piazentin (1989) realizou um estudo com 64 crianças entre 3 e 10 anos de idade, com fissura labiopalatina, por meio da otoscopia, audiometria e medidas de imitância acústica, no período pré e póspalatoplastia. Verificou que, antes da cirurgia, todas as crianças apresentaram algum tipo de alteração auditiva condutiva e, após a mesma, houve melhora quanto aos aspectos otológicos e audiológicos; entretanto, a maioria não atingiu a normalidade.

Gould (1990) com o objetivo de examinar as mudanças nas condições auditivas e o efeito da idade, da raça e do sexo em uma população com fissura labiopalatina, realizou um estudo em que analisou 1699 audiometrias de 480 pacientes. Verificou que ocorreu uma melhora significativa na condição auditiva quando tratamentos precoces (melhora das condições gerais de saúde, monitoramento otológico e audiológico, uso de tubos de ventilação), foram administrados e que crianças mais velhas demonstraram reduzida 
prevalência de perda auditiva. Não houve relação entre o tipo de fissura ou sexo e a freqüência da dificuldade de audição. No entanto, observou relação entre a raça e a incidência de dificuldade auditiva (maior na raça negra, seguida pela raça branca e amarela), podendo estar relacionada a indicadores sócio econômicos.

Moss et al (1990) citaram que a incidência de patologias de orelha média na FPSM é tão alta como na fissura de palato aberta, entre 59 a $93 \%$.

Examinando os efeitos da cirurgia do palato na orelha média, Robinson et al (1992) verificaram que não existe melhora real na condição da orelha média após a palatoplastia. Em relação à idade durante a cirurgia, ou o tipo de fissura palatina, também não foi observada nenhuma diferença.

Rynnel-Dagoo et al (1992) investigaram os antecedentes médicos, as condições da orelha média, a competência imunológica e a habilidade auditiva de 44 crianças com idade média de 37 meses de idade, com fissura labiopalatina operada. Realizaram entrevista sobre a ocorrência de otite média secretora, otoscopia, audiometria e exames de imunidade. $\mathrm{O}$ estudo mostrou que crianças com fissura palatina não apresentam imaturidade do sistema imunológico, mas sim um pequeno aumento de infecções purulentas da orelha média e entre 3 e 4 anos , a maioria das crianças avaliadas (82\%) apresentaram audição normal. 
Todd e Krueger (1992) estudando 35 cadáveres adultos com FPSM verificaram que nenhum deles apresentou evidências clínicas de otite média.

Paradise e Elster (1994) referiram que a maioria das crianças com fissura labiopalatina apresentam sucção não produtiva, requerendo alimentação por meios artificiais. Sugerem que o leite materno assim ministrado, provê variável proteção contra o desenvolvimento de otite média com efusão em crianças com fissura labiopalatina, com efeito protetor similar ao do leite materno em crianças não fissuradas. Duncan et al (1993) sugeriram que a alimentação exclusiva por meio do leite materno durante 4 meses ou mais protege a criança de episódios de otite média simples e recorrente.

Nunn et al (1995) realizaram um estudo retrospectivo de 19 crianças que realizaram a palatoplastia com 1 mês de vida. Após a cirurgia $72 \%$ necessitaram de colocação de tubos de ventilação. Enfatizaram a necessidade de avaliação otorrinolaringológica e audiológica antes e após a cirurgia assim como avaliação da fala e da linguagem e seguimentos a longo prazo para determinar o resultado final quanto à audição e crescimento facial.

Para determinar os efeitos da avaliação otológica na audição e na função da orelha média, assim como a relação entre a inserção de tubos de ventilação e a cirurgia da fissura, Broen et al (1996) avaliaram, em intervalos trimestrais, 28 crianças com fissura palatina e 29 sem fissura, dos 9 aos 30 meses de idade. Concluíram que as crianças com 
fissura palatina que colocaram o tubo de ventilação mais tardiamente apresentaram perda auditiva, com função anormal da orelha média.

Handzic-Cuk et al (1996) encontraram 59,7\% de perda auditiva condutiva ao comparar os niveis de audição de 243 pacientes de 1 a 34 anos (média de 6 anos) com fissura labiopalatina uni e bilateral e com fissura isolada de palato. O estudo mostrou que, independente do tipo de fissura, até os 6 anos os pacientes apresentaram perda auditiva condutiva moderada a severa. Na puberdade e na idade adulta, a maioria apresentou limiares até $20 \mathrm{~dB}$, sem tendência à completa normalização em repetidas avaliações, pois o critério de normalidade adotado foi de $10 \mathrm{~dB}$, em pelo o menos 2 freqüências da fala.

Jury (1997) estudou 1120 crianças com fissura labiopalatina do nascimento aos 14 anos, através da audiometria, imitânciometria e nos casos de suspeita de deficiência auditiva neurossensorial foi realizado PAETE. O estudo ressaltou a importância do tratamento interdisciplinar completo, pois, das 1015 crianças que foram tratadas desde o nascimento, apenas 4\% desenvolveram otite média crônica e as crianças restantes descontinuaram o tratamento retornando posteriormente com doenças de orelha média.

Feniman (1998) estudou 100 sujeitos com fissura pré-forame incisivo, por meio da audiometria e medidas de imitância acústica. Os resultados mostraram que a média dos limiares de condução aérea e das medidas de imitância acústica estão dentro do que tem sido 
considerado limite normal. A autora concluiu que a fissura pré-forame não interferiu na sensibilidade auditiva da população estudada.

Seagle et al (1998) compararam os resultados da avaliação audiológica de crianças que realizaram palatoplastia e colocação de tubo de ventilação no mesmo ato cirúrgico, com crianças que realizaram apenas a palatoplastia. Não observaram diferenças substanciais dos limiares auditivos entre os 2 grupos. Os autores sugerem uma atitude mais conservadora em relação à avaliação da efusão da orelha média em crianças com fissura labiopalatina, devendo ser identificados os pacientes que, realmente, se beneficiariam com a colocação precoce do tubo de ventilação e aqueles que podem ser tratados sem os mesmos.

Brandão e Genaro (1998) estudaram 50 sujeitos entre 3 e 41 anos de idade com fissura de palato submucosa e verificaram que esse tipo de fissura pode contribuir para a ocorrência de alterações auditivas devido ao funcionamento deficiente da tuba auditiva. Enfatizaram a importância da avaliação da audição o mais cedo possivel, evitando-se a privação sensorial, que pode contribuir para um atraso de linguagem.

Feniman et al (1999) verificaram a ocorrência de perda auditiva entre crianças de 4 a 18 anos de idade, com fissura de lábio e fissura de palato, por meio da audiometria por via aérea. O estudo concluiu que pacientes com fissura de palato apresentaram valores médios dos limiares aéreos piores de que os de fissura de lábio, sugerindo que a presença da fissura palatina é um importante fator a ser considerado, 
uma vez que a fissura de lábio não interferiu na sensibilidade auditiva da população estudada.

Schonweiler et al (1999) em um estudo com 370 crianças com fissura labiopalatina $(284 \mathrm{com}$ perda auditiva condutiva e $86 \mathrm{com}$ audição normal), observaram que alterações na fonologia, morfologia, sintaxe, percepção auditiva e compreensão de fala são significantemente mais freqüentes em crianças com perda auditiva do que naquelas com audição normal, indicando que a função da fala e da linguagem em pacientes com fissura labiopalatina está predominantemente relacionada ao estado auditivo.

Güneren et al (2000) realizaram um estudo em 26 crianças com fissura de palato, quando compararam os efeitos de duas técnicas cirúrgicas para a correção do palato (Veau-Wardill Kilner e Furlow), na abertura da tuba auditiva. As cirurgias foram realizadas em crianças com idade entre 1 e 10 anos (média de 3,2 anos) e as crianças avaliadas por meio da timpanometria, antes e após as cirurgias. Os resultados não mostraram diferenças significativas entre as duas técnicas cirúrgicas na função da tuba auditiva, uma vez que encontraram 69\% de otite média secretora antes da cirurgia. Após a mesma, encontraram $77 \%$ de otite média secretora nas crianças submetidas à técnica de Veau-Wardill Kilner e 62\% naquelas submetidas à técnica de Furlow.

Fernandes et al (2000) analisaram avaliações timpanométricas, no período anterior à queiloplastia (entre 3 e 6 meses de idade) e à palatoplastia (entre 9 e 12 meses de idade ou 15 e 18 meses de idade), 
de 169 crianças entre 3 meses e 2 anos de idade, com fissura transforame incisivo unilateral. Verificou-se que, antes da queiloplastia, $57,4 \%$ das orelhas testadas apresentaram alterações e, antes da palatoplastia 90\% delas apresentaram-se alteradas, demonstrando piora nas condições da orelha média quando no período prévio à palatoplastia.

Handzic-Cuk et al (2001) realizaram timpanometria, audiometria tonal e otomicroscopoia em 239 pacientes com fissura labiopalatina e idade superior a 1 ano (média de 6 anos). Verificaram que timpanometria do tipo B é a mais freqüentemente encontrada entre as crianças de 1 a 7 anos de idade, em todos os tipos de fissura. Com o aumento da idade existe uma tendência de diminuição dessa freqüência.

Fernandes et al (1999), Feniman e Piazentin-Penna (2002) estudando crianças com fissura labiopalatina verificaram, por meio da timpanometria, condições normais de orelha média entre 3 e 6 meses de idade. A partir dessa idade foi notada a presença de timpanometria do tipo B na maioria das crianças avaliadas.

Hanson et al (2002) relataram a importante proteção da alimentação por meio do leite materno, reduzindo a ocorrência de várias doenças como a septcemia neonatal, infecções do trato respiratório, alergias e otite média, dentre outras; especialmente em crianças de alto risco. 
Aniansson et al (2002) analisaram a incidência de otite média secretora e otite média aguda e alimentação com leite materno e o uso do tubo de ventilação em crianças com fissura de lábio e de palato, comparando com um grupo controle. Verificaram significante correlação durante os primeiros 18 meses de vida entre a longa duração do aleitamento materno e baixa incidência de otite média nos grupos estudados. Sugeriram que a cessação prematura do aleitamento materno pode contribuir para um aumento da otite média.

Oliveira (2002) estudando crianças com FPSM entre 20 e 47 meses de idade, observou 42,5\% (17 casos) de queixa auditiva relatada pelos pais daquelas que apresentavam FPSM assintomáticas para a fala. Para as crianças que apresentaram FPSM sintomáticas para a fala a porcentagem de queixas auditivas foi de $70 \%$ (7 casos).

Vários autores atribuem o fato da alta ocorrência de perda auditiva na população com fissura labiopalatina, a uma inadequação da musculatura do véu palatino, principalmente o músculo tensor do véu palatino, com conseqüente interferência no mecanismo de abertura da tuba auditiva ( Cantekin et al 1980, Cantekin et al 1983 e Matsune et al 1991).

Doyle et al (1980) referiram que o maior fator responsável pela ocorrência de otite média com efusão, na população com fissura labiopalatina, está relacionado à inabilidade do músculo tensor do véu palatino em dilatar a tuba auditiva durante a deglutição. 
Por meio da nasofaringoscopia, Shprintzen e Croft (1981) observaram, em indivíduos com fissura labiopalatina, que além da hipoplasia do toro tubário, ocorre uma diminuição do orificio da tuba auditiva. Verificaram ainda que o músculo tensor do véu palatino não é o único músculo responsável pela função tubária e que o músculo levantador do véu palatino também contribui para a abertura da tuba auditiva, pois encontra-se hipoplásico nesta população e atuam conjuntamente sobre a tuba auditiva.

Gopalakrishna et al (1984) concluíram em seu estudo com pacientes portadores de fissura palatina, que o funcionamento da tuba auditiva em indivíduos não operados é insuficiente e, com a correção cirúrgica até os 6 anos de idade, a incidência de melhora no seu funcionamento aumenta. Com relação à otite média serosa, verificaram que a incidência é alta nos indivíduos com fissura de palato, em todas as idades, mas não é afetada significantemente pela correção cirúrgica do palato, persistindo a perda auditiva na maioria dos indivíduos após essa cirurgia.

Filkelstein et al (1990) com o objetivo de verificar se o músculo levantador do véu-palatino apresenta papel funcional no mecanismo da tuba auditiva, analisaram 30 pacientes entre 4 e 24 anos, com fissura de palato submucosa, fissura oculta e com paralisia congênita unilateral do músculo levantador do véu palatino, todos sem intervenção cirúrgica. Foi realizada uma correlação entre anomalia do músculo levantador do véu palatino, anomalia do orifício da tuba 
auditiva e alterações na ventilação da orelha média. Os resultados mostraram que a ventilação da orelha média foi normal em $77 \%$ dos indivíduos estudados, $10 \%$ apresentaram pressão negativa na orelha média, otite média crônica em 3\% e 3\% com otite média com efusão. Os autores concluíram que o músculo levantador do véu palatino não tem função no mecanismo de abertura da tuba auditiva, considerado apenas como um músculo da válvula velofaríngea, enquanto o músculo tensor do véu palatino é o músculo dilatador da tuba auditiva.

Bütow et al (1991) desenvolveram um estudo com 39 crianças com fissura labiopalatina entre 3 e 36 meses de idade, divididas em 2 grupos. No primeiro grupo realizaram veloplastia intravelar e no segundo grupo, uma modificação na técnica da veloplastia, através da criação de uma tensão cirúrgica em torno do músculo tensor do véu palatino. A comparação entre os grupos mostrou que a modificação teve influência positiva na função da tuba auditiva, podendo beneficiar os casos com fissura labiopalatina e otite média crônica.

Matsune et al (1991) analisaram ossos temporais, incluindo a tuba auditiva e suas estruturas, de 10 crianças com fissura palatina e 20 crianças sem a malformação. O estudo sugeriu que a pobre inserção ou a não inserção do músculo tensor do véu palatino na cartilagem da tuba auditiva é uma das causas da obstrução funcional da tuba auditiva nos casos com fissura palatina e que, freqüentemente, leva à otite média com efusão. 
Goldman et al (1993) relataram que a criança com palato não operado tem um mecanismo anormal de abertura da tuba auditiva, demonstrada pela radiografia, permanecendo alterado mesmo após a cirurgia. Apontam esse fator como a causa primária para a alta incidência de problemas da orelha média em indivíduos com fissura de palato. Defendem a necessidade de avaliação otológica contínua e cautelosa para a prevenção de doenças crônicas de orelha média nessa população.

Takasaki et al (2000) salientaram o importante papel da tuba auditiva na ventilação e proteção da cavidade da orelha média e afirmaram que a imaturidade da cartilagem da tuba auditiva em crianças com fissura palatina, especialmente, da lâmina lateral, pode ser um significante fator de risco para o desenvolvimento da otite média com efusão.

O problema da otite média não é exclusivo de indivíduos com fissura labiopalatina. A literatura relata alta ocorrência de otite média com efusão em crianças, podendo comprometer o desenvolvimento lingüístico, cognitivo, escolar e interpessoal.

Wallace et al (1988) referiram que crianças com otite média recorrente durante o primeiro ano de vida, mostraram déficit na linguagem expressiva e redução da sensibilidade auditiva quando comparadas com crianças que não apresentavam otite. 
Stenströn e Ingvarsson (1995) realizaram um estudo com 88 crianças que apresentaram mais de 11 episódios de otite média aguda até os 3 anos de idade. Verificaram que crianças com predisposição a otites, com freqüentes episódios de otite média aguda ou otite média serosa durante os primeiros 2 ou 3 anos de vida, freqüentemente, continuam a sofrer de problemas de orelha média durante a idade escolar e, também, estão sujeitas a miringotomia (com ou sem colocação de tubos de ventilação) e adenoidectomia. Os autores defendem a opinião de que crianças predispostas a otites deveriam ser tratadas e continuamente seguidas por um otorrinolaringologista até a normalização da orelha média.

Roberts et al (1995) estudaram 61 crianças negras de 6 a 12 meses de idade, por meio da otoscopia, da timpanometria, da audiometria de reforço visual, de testes padronizados para avaliar habilidades comunicativas e cognitivas e da avaliação da qualidade do ambiente familiar e do ensinamento das mães. Concluíram que a perda auditiva causada por otite média com efusão tem associação indireta com a linguagem expressiva e receptiva e com o desenvolvimento cognitivo e de comunicação no primeiro ano de vida. Crianças com perda auditiva, freqüentemente, tendem a ter mães e ambientes familiares menos responsivos. Os resultados salientaram a importância do estudo da multidisciplinariedade de indicadores que afetam o desenvolvimento das crianças. 
Gravel et al (1996) em um estudo longitudinal realizado com um grupo de 74 crianças, verificaram que a otite média e a perda auditiva leve, podem influenciar no processamento auditivo a longo prazo. A perda auditiva condutiva presente nos primeiros anos de vida influencia as habilidades auditivas, tendo importância no desempenho escolar e comportamental a longo prazo.

Vernon-Feagans et al (1996) em um estudo com 36 crianças entre 12 e 36 meses de idade que freqüentavam creches, verificaram relação entre a otite média nos primeiros anos de vida e atraso comportamental na idade escolar. Freqüentemente são crianças que têm interações verbais pobres e brincam mais sozinhas, quando comparadas com crianças que não têm otite média crônica. Uma perda auditiva leve pode refletir em dificuldade para distinguir a fala/linguagem em ambiente ruidoso, como é o caso de creches.

Hubig e Costa (1997) referiram que a otite média é considerada como a doença mais comum na infância, devendo ser encarada como um problema básico de saúde. Procedimentos quanto a sua identificação e seu tratamento devem ser adotados o mais cedo possivel, prevenindo os períodos de privação sensorial e suas graves conseqüências.

Um dos indicadores de risco para o desenvolvimento da otite média é o fumo passivo. Estudos mostram que crianças expostas à fumaça do tabaco, ou com mães fumantes, têm risco maior de doenças 
respiratórias nos primeiros anos de vida, incluindo otite média com efusão (Etzel et al 1992, Lubianca Neto et al 1996 e Ilicali et al 1999).

Hubig e Costa (1997) referiram que além do fumo passivo, existem outros indicadores de risco para o desenvolvimento da otite média, citando os antecedentes familiares e tendências pessoais, baixo nível sócio-econômico, não aleitamento materno, condições ambientais e de higienização, processos alérgicos, variações sazonais, entre outros. Os autores reforçam a necessidade de exames periódicos para a identificação da otite média em seus estágios iniciais para o controle das condições auditivas e imediata adoção de condutas preventivas.

Azevedo (1997) indicou que a avaliação audiológica comportamental e o acompanhamento audiológico do desenvolvimento auditivo no primeiro ano de vida permitem a identificação tanto das alterações da acuidade auditiva, quanto das alterações do processamento auditivo. Enfatizou, dentre outros casos, a importância dessa avaliação no primeiro ano de vida naqueles com história de perda auditiva transitória (otites recorrentes ou persistentes, deformidades anatômicas e outros distúrbios que afetam a função da tuba auditiva, como é o caso das lesões labiopalatinas).

Sih (1999) referiu que o fumo passivo provoca a hiperplasia das células caliciformes, com hipersecreção mucosa e a diminuição do transporte mucociliar, alterando mecanismos de defesa inespecífica, podendo produzir estado de hipersensibilidade (Kós e Soares 1999). 
Gravel e Wallace (2000) realizaram bimensalmente otoscopia pneumática, audiometria e timpanometria em 114 crianças entre 5 e 36 meses de idade e verificaram que aquelas que apresentaram otite média com efusão bilateralmente nas idades de 1, 2 e 3 anos tinham audição significantemente pior do que as que não tiveram otite bilateral nestes mesmos períodos. Com relação ao sexo, nível sócio-econômico e condições de nascimento, os autores não encontraram relação com a audição.

Stockard-Pope (2001) relatou que qualquer tipo de perda auditiva pode trazer sérios efeitos permanentes no desenvolvimento da criança. A otite média crônica durante o período crítico do desenvolvimento de linguagem pode resultar na produção e percepção alterada das consoantes da fala. A autora salientou a importância do diagnóstico e do tratamento adequado para todos os tipos de alterações auditivas.

Diante do exposto acima, vemos a grande necessidade de se avaliar a audição das crianças o mais cedo possivel, principalmente daquelas com fissura labiopalatina, pois são consideradas de alto risco sob o aspecto auditivo.

Além dos métodos de avaliação da audição de crianças, já citados anteriormente, encontramos também o da Emissão Otoacústica (EOA). Seu uso tem importância clinica baseada no meio direto, rápido, simples e não invasivo de se avaliar a audição, demonstrando êxito para avaliação, também, em crianças pequenas. 
Entre os quatro tipos de EOA reconhecidos na literatura, a evocada por estímulo transiente (EOAT) foi primeiramente demonstrada no órgão vestíbulo-coclear humano por Kemp (1978). A partir daí, seu registro tem sido investigado por muitos pesquisadores. A literatura pesquisada mostrou-se escassa no que diz respeito à EOA e fissura labiopalatina. Dessa forma procuramos descrever trabalhos com EOAT realizados com crianças sem fissura labiopalatina e com alterações da orelha média, acreditando que semelhante explicação pode ser atribuída à população com fissura labiopalatina.

Como demonstrou a literatura, as EOAT estão ausentes quando existe uma perda auditiva superior a 30 dB (Bonfils e Narcy 1989, Gattaz e Cerruti 1994, Lopes Filho 1996, Kemp 1997, Lopes Filho e Carlos 1997, Coube e Costa Filho 1998).

Johnsen et al (1983) mostraram que as EOAT puderam ser registradas em todas as orelhas, em um estudo piloto com 20 recémnascidos com suposta audição normal. Em estudos posteriores, Elberling et al (1985) puderam confirmar tal fato quando detectaram EOAT em 199 orelhas de 100 recém-nascidos.

Experimentos em que foram medidos e comparados os limiares do PAETE e as EOAT em crianças relataram a presença de $100 \%$ de EOAT quando limiares da onda $\mathrm{V}$ do PAETE foram melhores ou iguais a 30dBNPS. Ao contrário, em crianças, consideradas de alto risco para a audição, cujos limiares do PAETE se mostraram acima de 40dBNPS, as EOAT estavam ausentes (Bonfils et al 1988 e Bonfils e Narcy 1989). 
Bray (1989) relatou que das 139 orelhas testadas de 75 crianças na faixa etária de 10 meses a um ano, 65 tinham audição normal, sendo que em 55 destas foram detectadas EOAT.

Norton e Widen (1990) a fim de verificar a existência de mudanças significativas nas EOAT relacionadas à idade, estudando indivíduos na faixa etária de 17 dias a 30 anos, com audição dentro dos padrões de normalidade e com história médica e otológica negativas, encontraram EOAT em todas as orelhas testadas. Relataram que tais emissões em recém-nascidos e em crianças pareceram mais fortes e maiores em amplitude do que as encontradas em adultos e adolescentes (Bray 1989 e Kemp et al 1990).

Uma porcentagem de $98 \%$ de EOAT foi conseguida por Bonfils et al (1990) nas 100 orelhas testadas de um grupo de recém-nascidos com audição normal. Foi possivel identificar com clareza 97\% das EOAT em um grupo de recém-nascidos saudáveis e com história de desenvolvimento normal (Uziel e Piron 1991). Molini et al (1991), detectaram a presença de EOAT em todas as 18 orelhas normais das crianças avaliadas.

Erwing et al (1991) estudando a ocorrência das EOAT em 266 orelhas de 148 crianças entre 3 meses e 11 anos de idade, verificaram que irregularidades leves da orelha média, como por exemplo, pressão negativa entre -50 e $-100 d a P a$, podem reduzir a taxa de registro das EOAT de 95\% (70/74) no grupo normal, para 78\% (34/47). Quando crianças mostraram um timpanograma com ausência de pico, o registro 
das EOAT foi de apenas $12 \%(n=34)$ dos casos. Tais resultados estão relacionados às efusões serosas e mucosas, provavelmente evitando a transmissão da EOAT da cóclea para o meato acústico externo. Analisando a relação entre perdas condutivas na audiometria tonal liminar e nos registros das EOAT, foi demonstrado que nenhuma EOAT poderia ser registrada com perda condutiva acima de 20dBNA. Referiram ainda que, quando a perda condutiva é menor que 20dBNA, não é possivel predizer se uma EOAT pode ser registrada ou não. Seu estudo enfatiza a necessidade de reexaminar crianças com alterações da orelha média que não apresentam EOAT positivas.

Satoh (1992) relatou que PAETE e EOAT foram realizadas em 166 orelhas de 85 crianças de 5 dias a 5 anos, com suspeita de perda auditiva. Encontrou, neste estudo, 95 orelhas com perda auditiva acima de 35dBNPS no PAETE e ausência de EOAT; 59 orelhas com audição normal pelo PAETE em 30dBNPS, apresentaram boas respostas nas EOAT, porém 12 orelhas julgadas como audição normal não apresentaram respostas nas emissões; destas, 6 tinham suspeita de otite média em exames seguintes.

Fuse et al (1993), estudando 109 orelhas das 67 crianças com otite média com efusão, avaliadas pela audiometria, timpanometria e EOAT, encontraram em 45 casos limiares melhores quando estes apresentaram EOAT. Relataram que pressão intratimpânica baixa, na timpanometria, foi registrada quando ocorria ausência das EOAT. 
Proschel e Eysholdt (1993) estudando a influência de mudanças na impedância da orelha média com e sem otite média serosa, declararam que crianças com otite média serosa nunca apresentaram boas EOAT, em 108 crianças entre 3 e 12 anos de idade. Verificaram que aquelas que somente tinham mudanças na impedância da orelha média sem o fluído seroso, apresentavam amplitude das EOAT diminuídas, relacionadas mais ao grau da perda condutiva do que com a mudança na impedância em si. Seus resultados são comparados com os do projeto com screening do recém-nascido, nos quais, alguns dos 532 recém-nascidos sadios, mostraram EOAT pobres no primeiro dia de vida. Concluíram que parece razoável assumir que isto seja devido a pneumatização incompleta da orelha média dessas crianças, especialmente quando em seus audiogramas posteriores, mostraram limiares auditivos normais.

White et al (1994) num estudo utilizando EOAT em recémnascidos, reconheceram a importância de se identificar todas as crianças com perda auditiva significante antes dos 12 meses de idade. Referiram que perda auditiva moderada, uni ou bilateral, pode afetar negativamente o desenvolvimento cognitivo, da fala e das habilidades sociais. Sugeriram o uso das EOAT, juntamente com o PAETE como instrumento de screening e de técnicas audiológicas comportamentais para a avaliação diagnóstica.

Amedee (1995) verificou em seu estudo com crianças com história de otite média crônica, com achados sugestivos de efusão na orelha 
média, que o tipo de efusão afeta a presença ou ausência das EOAT, sendo a efusão mucóide, resultante, em menor chance de se detectar as emissões otoacústicas. Relatou ainda que esses resultados tendem a contradizer noções prévias de que as EOAT não são mensuráveis se o timpanograma é anormal ou se o fluído está presente na orelha média.

Rogowski (1995) estudou diferentes graus de alterações da orelha média em 41 crianças entre 3 e 7 anos de idade. Realizou timpanomometria, otoscopia e audiometria de tom puro e as relacionou com os resultados do registro de EOAT. Observou que as EOAT não foram registradas em orelhas com perda auditiva condutiva maiores do que 20dBNA e, nas crianças com timpanograma sem pico de máxima complacência o registro das EOAT foi possivel em 10,5\% dos casos.

Doyle et al (1997) verificaram em 200 recém-nascidos de 5 a 48 horas de vida a relação entre fatores na orelha externa e média interferindo nos resultados do screening audiológico por meio da otoscopia, do PAETE e das EOAT. A otoscopia mostrou que $28 \%$ das orelhas apresentaram vérnix, dificultando a visão da membrana timpânica, sendo que $91 \%$ passaram no PAETE e 58,5\% passaram na EOAT. Após a eliminação do vérnix o resultado passou para $96 \%$ no PAETE e 69\% nas EOAT. Verificaram diminuição na mobilidade da membrana timpânica em $22,7 \%$ dos casos, o que interferiu no resultado da EOAT, pois apenas $33,4 \%$ dos casos passaram no screening, enquanto 95\% passaram no PAETE. 
Beppu et al (1997) compararam os resultados de EOAT com audiometria com brinquedos em crianças de 3 anos de idade e concluíram que as EOAT podem produzir resultados qualitativos para determinar a presença ou ausência de problemas auditivos.

Mir Plana et al (1997) realizaram otoscopia, EOAT e timpanometria em 616 crianças com idade média de 6,2 anos e verificaram que patologias de orelha média, principalmente otite média secretora, podem resultar em falhas da EOAT.

Costa e Costa Filho (1998) analisaram o registro de EOAT de 36 recém-nascidos pré-termo (ate`37 semanas de idade gestacional, que apresentavam no momento da avaliação idade pós-concepcional variando entre 37 e 44 semanas) e verificaram que as respostas por freqüência têm seus maiores valores entre $3000 \mathrm{~Hz}$ e $5000 \mathrm{~Hz}$. Quanto à média dos valores de reprodutibilidade geral e amplitude por banda de freqüência, não foi observada diferença estatisticamente significante entre o lado direito e esquerdo, nem entre os gêneros.

Soares et al (1998) compararam triagens auditivas por EOAT, observação comportamental e medidas de imitância acústica de 52 recém-nascidos, com e sem risco auditivo. Os resultados mostraram compatibilidade de $100 \%$ entre as três triagens, após uma segunda avaliação. No grupo sem risco auditivo todas as crianças passaram, e no grupo com risco auditivo, 2 crianças falharam nas três triagens, por apresentarem deficiência auditiva moderada, confirmada pelo PAETE. 
Anteunis et al (1998) realizaram EOAT em crianças com fissura labiopalatina, sendo 9 com fissura de lábio, 11 com fissura de palato e 1 com fissura de palato submucosa, com idade média de 3 semanas. Naquelas que falharam no primeiro teste novamente foi realizado EOAT, otoscopia, imitânciometria e PAETE. Os resultados mostraram presença de EOAT em todas as crianças com fissura de lábio e fissura de palato submucosa. Naquelas com fissura de palato observaram a presença de EOAT em 4 de 22 orelhas, 6 apresentaram falhas no registro devido ao ruído e 12 não apresentaram EOAT. Quanto aos demais exames, encontraram 4 orelhas com PAETE sugerindo perda auditiva neurossensorial e imitanciometria de 3 orelhas com resultado de otite média com efusão. Os autores defenderam o uso da EOAT em recémnascidos com fissura isolada de lábio. Em bebês com fissura de palato sugeriram que o uso do PAETE poderia ser mais apropriado.

Piazentin-Penna e Feniman (1999) realizaram EOAT, audiometria de observação comportamental e medidas de imitância acústica em 15 crianças entre 3 e 12 meses de idade, com fissura pré-forame incisivo e verificaram presença de EOAT em $87 \%$ das orelhas testadas. Alteração da orelha média, comprovada pela timpanometria, ocorreu em $13 \%$ das orelhas. Os dados sugeriram que alterações auditivas em crianças com fissura isolada de lábio são menos freqüentes quando comparadas com aquelas que apresentam fissura de palato, como demonstrado por Fernandes et al (1999). 
Koivunen et al (2000) verificaram resultados de EOAT e de timpanometria em 102 crianças de 0,7 a 11,4 anos de idade, com otite média secretora, submetidas a miringotomia. Concluíram que $72 \%$ dos ouvidos que continham efusão mostraram EOAT reduzidas e a sensitividade da timpanometria em identificar os ouvidos com ausência de EOAT foi de $73 \%$ e a especificidade foi de $81 \%$. Observaram, ainda, que a presença ea quantidade de efusão do tipo mucoso reduz mais as EOAT do que a do tipo não mucoso. Os autores concluíram que a transmissão da energia acústica para a orelha média está alterada em crianças que experienciam qualquer tipo de otite média com efusão.

Carvallo et al (2000) investigaram a presença e ausência de EOAT e emissão otoacústica produto de distorção (EOAPD) em adultos jovens e idosos com diferentes padrões timpanométricos em $226 \mathrm{~Hz}, 678 \mathrm{~Hz}$, $1000 \mathrm{~Hz}$, com limiares audiométricos dentro dos padrões de normalidade. Observaram que a freqüência de $1000 \mathrm{~Hz}$ evidenciou maior concordância entre os achados de normalidade e alteração timpanométrica em relação à captação de EOAT e EOAPD. Em condições de normalidade de orelha média, a proporção de captação de e EOAPD foi maior que de EOAT tanto em jovens como em idosos. A captação de EOAT foi maior em jovens e a captação de EOAPD foi semelhante entre jovens e idosos. 


\section{OBJETIVOS.}

- Verificar a ocorrência de Emissões Otoacústicas Evocada por Estímulo Transiente em crianças com fissura labiopalatina não operada,

- Associar os resultados das Emissões Otoacústicas Evocada por Estímulo Transiente, com os resultados da Entrevista Audiológica, da Audiometria de Observação Comportamental, da Audiometria de Reforço Visual e das Medidas de Imitância Acústica realizadas. 


\section{MATERIAL E MÉTODO.}

\section{1- Constituição da amostra.}

Foram observadas, para a realização deste trabalho, 82 crianças, de ambos os gêneros, regularmente matriculadas no Hospital de Reabilitação de Anomalias Craniofaciais (HRAC) da USP-Campus Bauru, com fissura labiopalatina. A amostra foi dividida em 3 grupos, segundo o tipo de fissura labiopalatina, de acordo com a classificação de Spina et al (1972).

\section{Grupo 1:}

Composto por 48 crianças, 16 do gênero feminino e 32 do gênero masculino, na faixa etária compreendida entre 3 a 12 meses e 20 dias, com fissura labiopalatina não operada, sendo 8 com fissura transforame incisivo bilateral (TIB), 11 com fissura transforame incisivo unilateral direita (TIUD), 20 com fissura transforame incisivo unilateral esquerda (TIUE), 2 com fissura pós-forame incisivo completa (PÓSCOM), 7 com fissura pós-forame incisivo incompleta (PÓS-IN).

A fissura transforame incisivo é uma fenda congênita, uni ou bilateral, que inclui lábio, arcada dentária, palato duro e palato mole, até a úvula, colocando em comunicação total as cavidades nasal e oral (Figuras 1 e 2). 


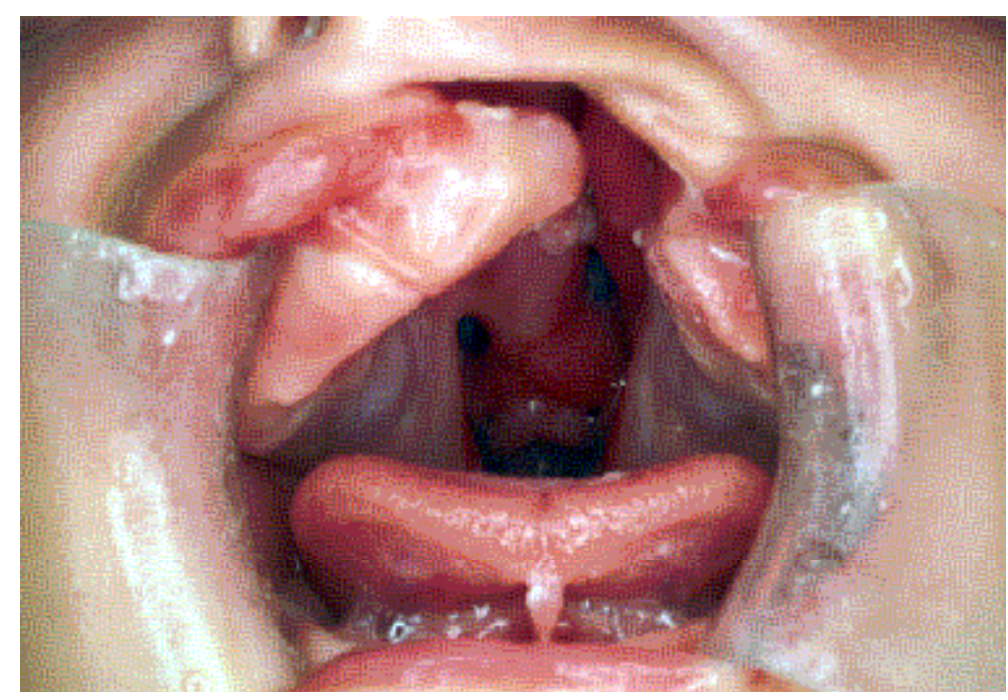

Figura 1- Fissura transforame incisivo unilateral

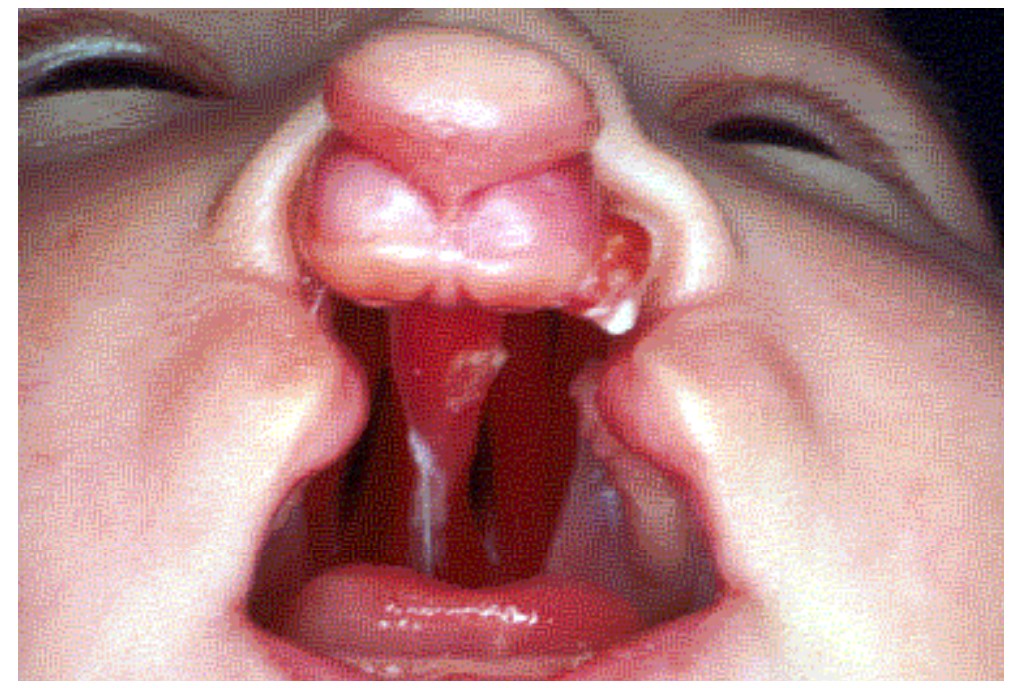

Figura 2 - Fissura transforame incisivo bilateral 
A fissura pós-forame incisivo está localizada posteriormente ao forame palatino anterior. É sempre mediana e seu grau pode variar quanto à largura e extensão, podendo ser representada desde as formas mais simples em que somente a úvula é fendida, outras em que há somente comprometimento do palato mole (pós-forame incompleta), até os casos em que a fissura atinge o forame palatino anterior, com comprometimento do palato duro (pós-forame completa). Neste tipo de fissura, há a comunicação da cavidade nasal posterior com a cavidade oral em maior ou menor grau (Figuras 3 e 4).

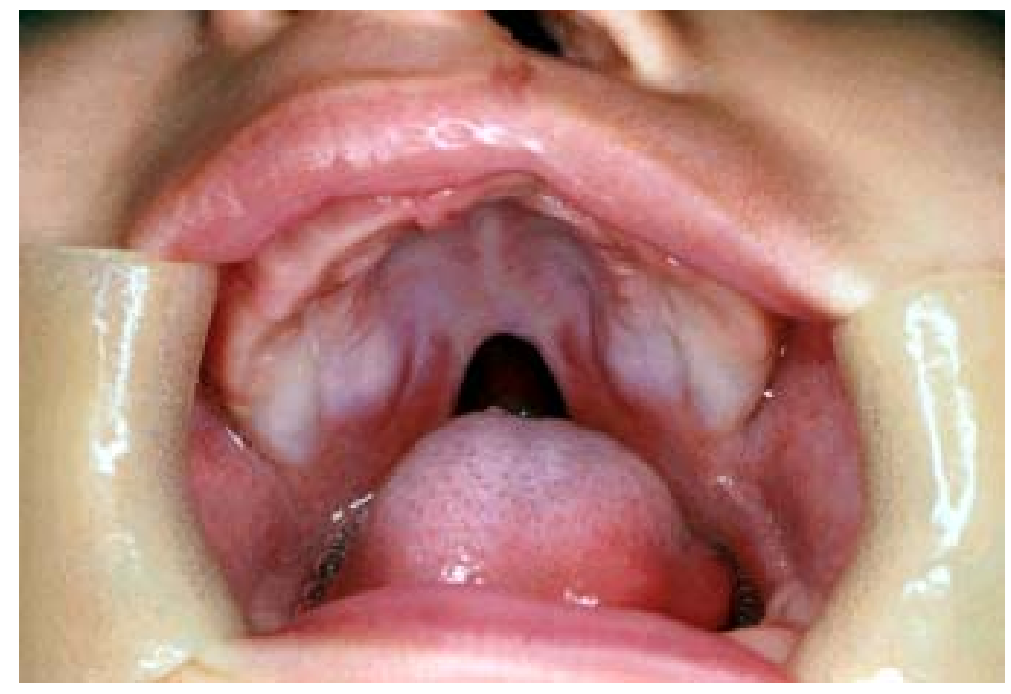

Figura 3 - Fissura pós-forame incisivo incompleta 


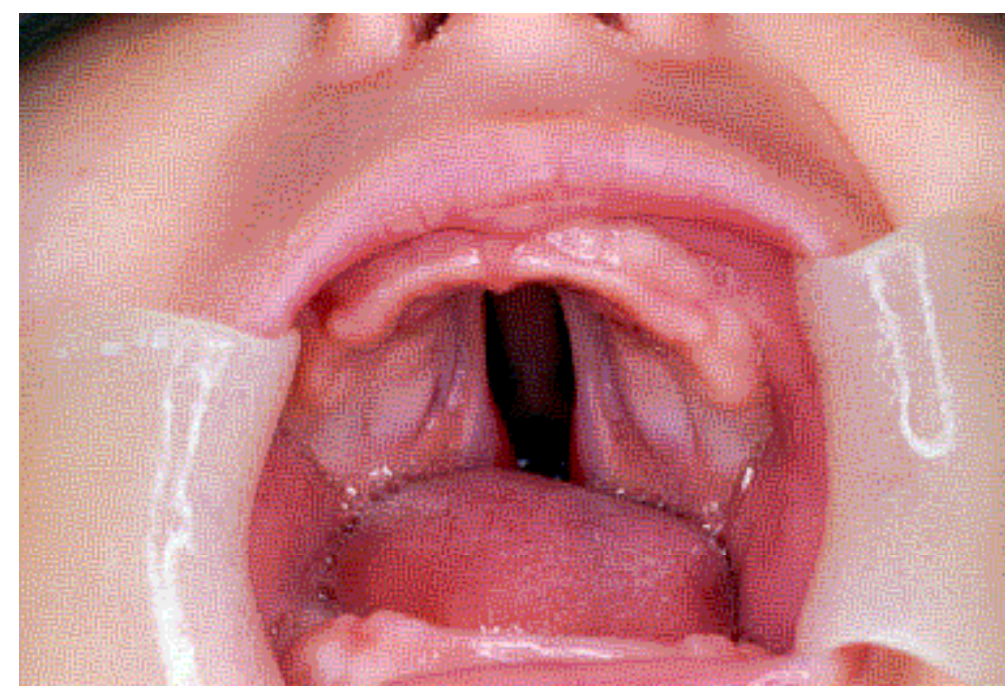

Figura 4 - Fissura pós-forame incisivo completa

Grupo 2

Composto por 29 crianças (11 do gênero feminino e 18 do gênero masculino), na faixa etária de 3 a 9 meses e 25 dias, com fissura labial, sendo 3 com fissura pré-forame incisivo bilateral (PRÉ BI), 9 com fissura pré-forame incisivo unilateral direita (PRÉ DIR), 17 com fissura pré-forame incisivo unilateral esquerda (PRÉ ESQ).

A fissura pré-forame pode ser uni ou bilateral, completa ou incompleta. Nas formas completas a fenda começa no forame palatino anterior, atinge a porção anterior do palato, arcada alveolar no nível do incisivo lateral e canino, assoalho nasal e lábio superior. Nas formas incompletas, pode ocorrer desde um simples entalhe no vermelhão do lábio, ou o comprometimento somente do lábio, ou o lábio e assoalho 
nasal, com ou sem arcada alveolar fendida, numa grande variedade de formas (Figuras 5 e 6).

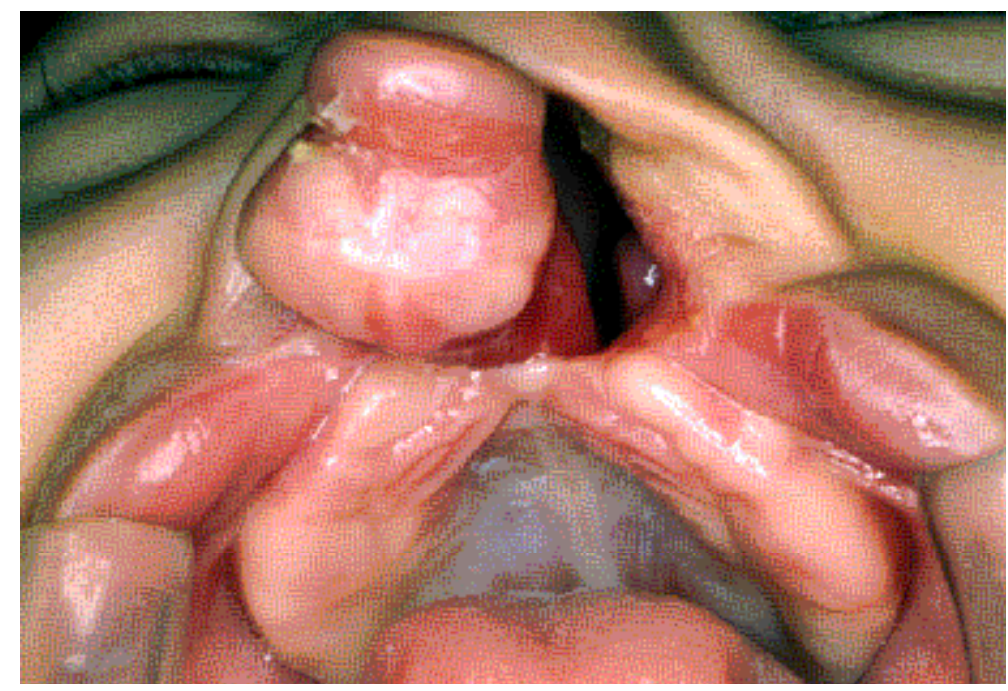

Figura 5 - Fissura pré-forame incisivo completa bilateral

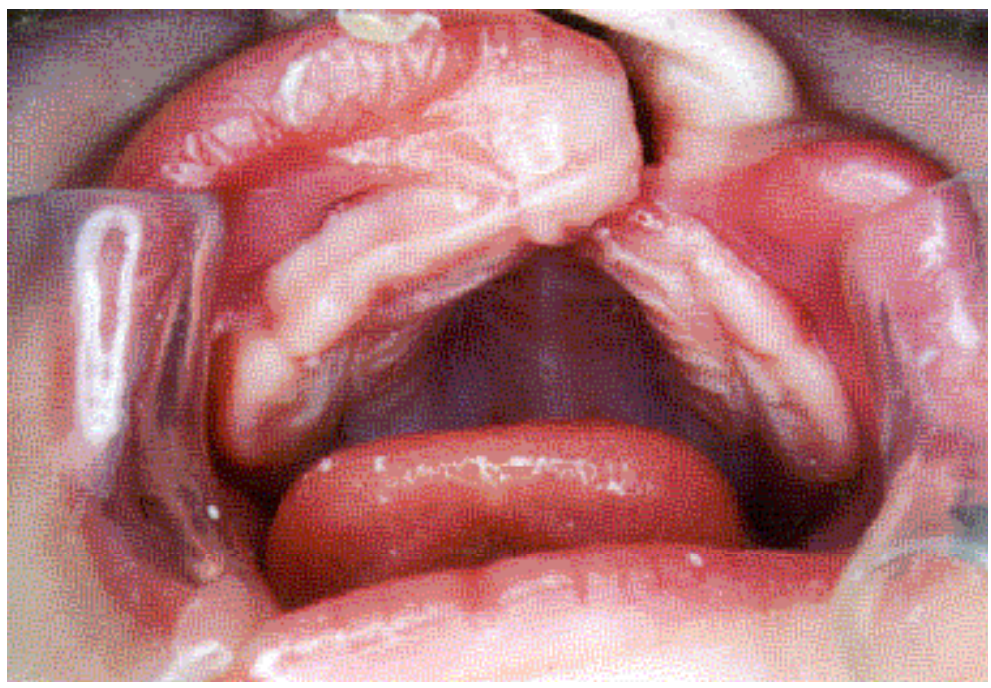

Figura 6 - Fissura pré-forame incisivo incompleta unilateral 


\section{Grupo 3}

Composto por 5 crianças (3 do gênero feminino e 2 do gênero masculino), na faixa etária de 3 a 6 meses e 10 dias, com fissura de palato submucosa (FPSM), não operada.

A fissura de palato submucosa é uma variante da fissura pósforame incisivo, em que os planos mucosos oral e nasal estão íntegros; porém não há continuidade da musculatura de ambos os lados da linha média (Figura 7).

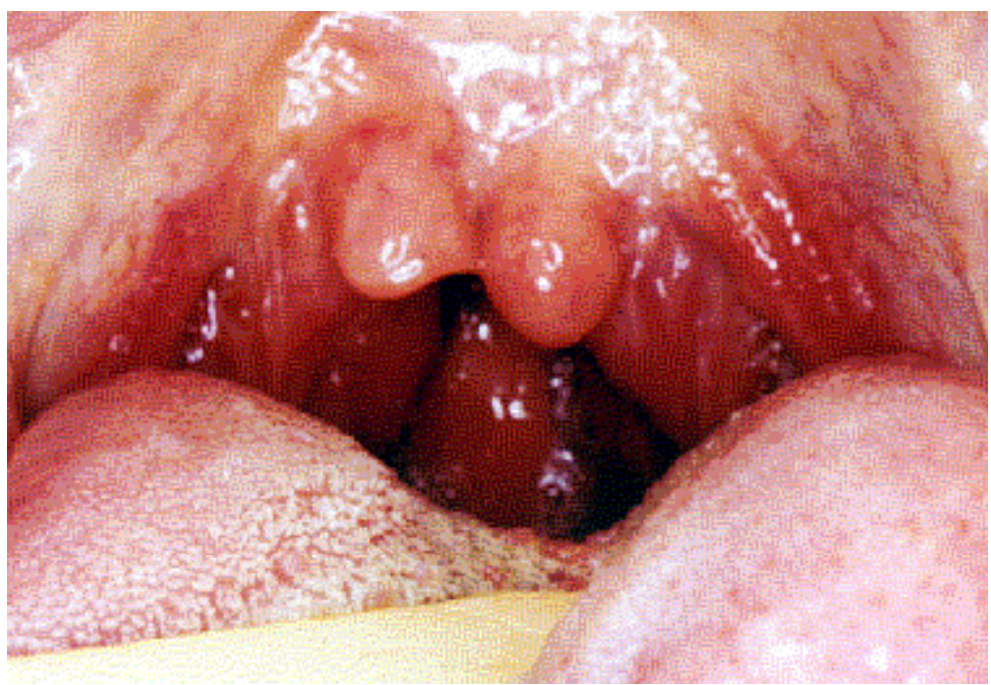

Figura 7 - Fissura de palato submucosa 
As tabelas 1, 2 e 3 apresentam a distribuição das crianças amostradas nos 3 grupos, quanto ao gênero, à faixa etária e ao tipo de fissura, respectivamente.

Tabela 1 - Distribuição de pacientes do grupo 1, do grupo 2 e do grupo 3, quanto ao gênero

\begin{tabular}{ccc}
\hline N & MASC & FEM \\
\hline Grupo 1 (48) & 32 & 16 \\
Grupo 2 (29) & 18 & 11 \\
Grupo 3 ( 5) & 2 & 3 \\
\hline
\end{tabular}

MASC - masculino

FEM - feminino 
Tabela 2 - Distribuição de pacientes do grupo 1, do grupo 2 e do grupo 3, quanto à faixa etária

\begin{tabular}{cccc}
\hline $\mathbf{N}$ & $\mathbf{3 m} \mathbf{~ a ~ 6 m}$ & $\mathbf{6 m ~ a ~ 9 m}$ & $\mathbf{9 m}$ a 12m \\
\hline Grupo $1(48)$ & 28 & 10 & 10 \\
Grupo 2 (29) & 21 & 8 & 0 \\
Grupo 3 ( 5) & 5 & 0 & 0 \\
\hline
\end{tabular}

m- meses 
Tabela 3 - Distribuição de pacientes do grupo 1, do grupo 2 e do grupo 3, quanto ao tipo de fissura

\begin{tabular}{|c|c|c|c|c|c|c|c|c|c|}
\hline $\mathbf{N}$ & $\begin{array}{c}\text { PRÉ } \\
\text { BI }\end{array}$ & $\begin{array}{l}\text { PRÉ } \\
\text { DIR }\end{array}$ & $\begin{array}{l}\text { PRÉ } \\
\text { ESQ }\end{array}$ & TIB & TIUD & TIUE & $\begin{array}{l}\text { Pós } \\
\text { COM }\end{array}$ & $\begin{array}{l}\text { PÓS } \\
\text { INC }\end{array}$ & FPSM \\
\hline $\begin{array}{c}\text { Grupo } 1 \\
(48)\end{array}$ & 0 & 0 & 0 & 8 & 11 & 20 & 2 & 7 & 0 \\
\hline $\begin{array}{c}\text { Grupo } 2 \\
(29)\end{array}$ & 3 & 9 & 17 & 0 & 0 & 0 & 0 & 0 & 0 \\
\hline $\begin{array}{c}\text { Grupo } 3 \\
(5)\end{array}$ & 0 & 0 & 0 & 0 & 0 & 0 & 0 & 0 & 5 \\
\hline
\end{tabular}

DIR - direita; ESQ - esquerda; PRÉ - fissura pré-forame incisivo; BI - bilateral; DIR direita; ESQ - esquerda; TIB - fissura transforame incisivo bilateral; TIUD - fissura transforame incisivo unilateral direita; TIUE - fissura transforame incisivo unilateral esquerda; PÓS - fissura pós-forame incisivo; FPSM - fissura de palato submucosa; COM - completa; INC - incompleta 


\section{2- Procedimentos.}

Inicialmente, o projeto com a proposta do estudo em questão foi encaminhada ao Comitê de Ética em Pesquisa do HRAC, para apreciação, tendo sido aprovado em 30 de setembro de 1998 (anexo 1).

O trabalho foi desenvolvido nos setores de Fonoaudiologia e Genética Clínica do HRAC-USP, sendo constituído pelas seguintes avaliações: entrevista audiológica com os pais ou responsáveis, meatoscopia, medidas de imitância acústica, audiometria de observação comportamental, audiometria de reforço visual e emissão otoacústica evocada por estímulo transiente (EOAT).

\section{Entrevista Audiológica}

A entrevista foi realizada com os pais ou responsável sob forma de perguntas dirigidas, em linguagem acessivel, dependendo do nivel de entendimento de cada um, com o objetivo de obter informações sobre a audição da criança (anexo 2). Foi baseada no Joint Committee on Infant Hearing (1994), Azevedo et al (1995) e questões indicativas de risco para a otite média.

\section{$\underline{\text { Meatoscopia }}$}

A meatoscopia foi realizada com o otoscópio da marca HEINE, tipo STANDART N 2.5, de fibras ópticas, para verificar a presença de cerume no meato acústico externo (MAE), ou algum outro impedimento para a realização dos exames. $\mathrm{Na}$ ocorrência destes, as crianças eram encaminhadas ao médico otorrinolaringologista para as providências necessárias. 


\section{$\underline{\text { Medidas de Imitância Acústica }}$}

Nas medidas de imitância acústica, foram executadas a timpanometria, e a medida da compliância, utilizando os equipamentos GRASON-STADLER INC, GSI33 versão 2, MIDDLE-EAR ANALYZER, e SIEMENS SD30, com o objetivo de se verificar as condições funcionais da orelha média $(\mathrm{OM})$.

\section{Audiometria de Observação Comportamental}

A audiometria de observação comportamental a estímulos sonoros instrumentais foi realizada em cabina acústica, com a criança acordada, sentada no colo dos pais ou do responsável, de acordo com o procedimento descrito por Northern e Downs em 1991 e Azevedo et al em 1995. Os estímulos sonoros utilizados foram produzidos em intensidade média pelo guizo (76dBNPS), sino (87dBNPS), black-black (92dBNPS) e agogô - campânula grande - (102dBNPS). A medida do nível de pressão sonora dos instrumentos foi realizada com o auxílio do medidor do nível de pressão sonora ENTELBRA ETB-142-A.

Os estimulos sonoros foram apresentados em ordem crescente de intensidade, ou seja, do mais fraco para o mais forte, a distância aproximada de $20 \mathrm{~cm}$ do pavilhão auricular, com 2 segundos de duração, mantendo-se um intervalo de, aproximadamente, 30 segundos entre as apresentações. 
As respostas obtidas foram registradas na ficha de resposta (anexo 3), de acordo com a classificação proposta por Azevedo et al (1995).

\section{$\underline{\text { Audiometria de Reforço Visual }}$}

A audiometria de reforço visual foi realizada em cabina acústica, em campo livre, com a criança acordada, sentada no colo dos pais ou do responsável, com o audiômetro modelo AD27, da Interacoustic, que produziu tons puros modulados (Warble), nas freqüências de $500 \mathrm{~Hz}, 1000 \mathrm{~Hz}, 2000 \mathrm{~Hz}$ e $4000 \mathrm{~Hz}$, através de condicionamento estímulo-resposta-reforço visual, conforme proposto por Suzuki e Ogiba (1961), Lidén e Kankkunen (1969) e Azevedo et al (1995). Os tons puros modulados foram apresentados do som para o silêncio, a $50 \mathrm{~cm}$ do pavilhão auricular, à direita e à esquerda. A resposta da criança era reforçada acionando-se o estímulo luminoso. A intensidade mínima em que a resposta ocorreu para cada freqüência foi registrada na ficha de resposta (anexo 3).

\section{$\underline{\text { Emissão Otoacústica Evocada por Estímulo Transiente }}$}

Para o registro e análise da EOAT, utilizou-se o equipamento ILO 88 versão 4.2 OTODYMANIC ANALISER hardware e software, acoplado a um microcomputador.

O hardware compreende duas placas: uma com o objetivo de fornecer o estímulo click; e uma segunda para o processamento da 
resposta acústica na orelha em que foi dado o estímulo. Foi programado para ser controlado por mínimas instruções do software. O software permite executar as medidas da EOAT, as quais consistem do ajuste da sonda, coleta e análise dos dados e um detalhado registro da medida. O programa apresenta uma série de opções no menu, mostradas no painel do monitor do vídeo, que são invocadas para a execução das medidas, fazendo uso do teclado do computador e seguindo instruções do programa.

Com a função de liberação do click, recepção da pressão sonora e medição da resposta no MAE, uma sonda acústica ILO OTODYNAMIC tipo E faz parte do equipamento. Tal sonda é constituída de transdutores miniaturas (estimulador e microfone altamente sensivel e ruído intrínseco fraco) da KNOWLES LTDA., envolvidos em um espéculo plástico. Seu cabo é bastante flexivel, para reduzir a transmissão do ruído à sonda.

O exame foi realizado em uma sala com tratamento acústico, com a criança dormindo, ou tranqüila, sentada no colo dos pais ou do responsável. Inseriu-se no MAE a sonda ILO E contendo um molde de borracha na extremidade. Os registros dos exames foram anotados na ficha de respostas e impressos em uma impressora para análise dos dados (anexo 3).

Com o intuito de receber as instruções e informações adequadas pertinentes à execução do teste, ou ainda, de verificar a estabilidade do ajuste da sonda, a qualidade dos dados coletados, bem 
como os dados processados, um monitor de vídeo foi acoplado ao equipamento.

Utilizamos o modo quickscreen que registrou medidas de 800 a $4000 \mathrm{~Hz}$ com intervalos de oitavas, com a finalidade de encurtar o tempo do teste e reduzir o ruído adicionado às baixas freqüências e o sistema de ajuste de ganho do estímulo, que de forma automática ajusta o nível do estímulo em maior ou menor intensidade (dB) em função das características do MAE e a colocação da sonda, para obtermos um nível de estímulo ótimo.

4.3- Análise dos resultados.

\section{Entrevista Audiológica}

$\mathrm{Na}$ entrevista audiológica os dados obtidos foram classificados em:

- Ausência de indicadores de risco para a audição, além da fissura labiopalatina: quando não foi referido algum dado que pudesse levar a problema auditivo, ou seja, entrevista negativa.

- Presença de indicadores de risco para a audição, além da fissura labiopalatina: quando foi referido um ou mais tipos de informações que pudessem ser considerados como risco para a audição, ou seja, entrevista positiva, de acordo com o Joint Committee on Infant Hearing Screening (1994) e Azevedo et al (1995) (anexo 2). 


\section{$\underline{\text { Meatoscopia }}$}

Pela meatoscopia, o MAE foi classificado em:

- Sem impedimento: quando não foi observado cerume no MAE, ou algum processo infeccioso em atividade.

- Com impedimento: quando foi observado cerume no MAE, ou algum processo infeccioso em atividade.

\section{$\underline{\text { Medidas de Imitância Acústica }}$}

As medidas de imitância acústica foram baseadas na classificação de Jerger (1970), sendo consideradas normais quando os valores da compliância estavam entre 0,3 à $1,3 \mathrm{ml}$ e a pressão da OM entre -100 daPa e +70 daPa (curva tipo A). Quando alteradas, foram divididas em curva tipo B (ausência de pico de máxima compliância), curva tipo C (compliância estática entre 0,3 a $1,3 \mathrm{ml}$ e a pressão da $\mathrm{OM}$ negativa - à esquerda de -100 daPa), curva tipo As (compliância estática menor que 0,3ml) e curva tipo Ad (compliância estática maior que $1,3 \mathrm{ml}$ e pressão da OM entre -100 daPa e +70 daPa).

\section{$\underline{\text { Audiometria de Observação Comportamental }}$}

$\mathrm{Na}$ audiometria de observação comportamental, foram consideradas como resposta a estímulos instrumentais, as modificações de comportamento eliciadas até 2 segundos após a apresentação do estímulo. 
Para facilitar a análise das respostas, de acordo com a sua ocorrência, baseou-se na classificação de Azevedo et al (1995):

1. Respostas Reflexas e/ou Automatismos Inatos:

a) Reflexo cocleopalpebral (RCP) - contração do músculo orbicular do olho que pode ser observada através da movimentação palpebral;

b) Reação de sobressalto (Startle) - reação corporal global que pode aparecer como Reação de Moro (completo ou incompleto) ou como um estremecimento corporal com movimentação súbita de membros;

2. Atenção ao som (A) - respostas indicativas de atenção ao som, tais como parada de atividade ou de sucção, ou abrir a rima palpebral, ou movimentos faciais como franzir da testa ou elevar as sobrancelhas;

3. Procura da fonte $(\mathrm{PF})$ - considerada quando a criança busca a direção da fonte sonora, olhando ao redor, sem entretanto localizá-la corretamente;

4. Localização lateral (LL) - quando a criança volta a cabeça ou o olhar imediatamente em direção a fonte sonora.

As respostas foram consideradas sempre que ocorreram as mudanças comportamentais acima descritas. Os resultados foram analisados de acordo com a faixa etária, ou seja, para as crianças de 3 meses a 6 meses e 15 dias de idade foram consideradas como esperadas para a idade, as reações de sobressalto, atenção ao som, procura da fonte sonora, RCP para o agogô e localização da fonte sonora para as crianças com 6 meses de idade. Entre 6 meses e 16 dias a 12 meses e 
20 dias de idade foi considerada a reação de localização da fonte sonora e RCP para o agogô. Considerou-se alterado quando a criança deixou de apresentar uma ou mais reações citadas acima, ou quando não apresentou o RCP para o agogô.

\section{$\underline{\text { Audiometria de Reforço Visual }}$}

$\mathrm{Na}$ audiometria de reforço visual, considerou-se resposta a menor intensidade em que ocorreu a localização de tons puros - Warblepara cada freqüência sonora testada, sendo os valores estabelecidos, baseados em Northern e Downs (1991). Para a faixa etária de 3 meses a 6 meses e 15 dias, considerou-se normal quando as respostas nas freqüências de $500 \mathrm{~Hz}, 1000 \mathrm{~Hz}, 2000 \mathrm{~Hz}$ e $4000 \mathrm{~Hz}$, estavam entre $40 \mathrm{e}$ 60 dBNPS. Para a faixa etária de 6 meses e 16 dias a 9 meses e 15 dias, considerou-se normal quando as respostas nas freqüências de $500 \mathrm{~Hz}$, $1000 \mathrm{~Hz}, 2000 \mathrm{~Hz}$ e $4000 \mathrm{~Hz}$ estavam entre e 30 e 40 dBNPS e para a faixa etária de 9 meses e 15 dias a 12 meses e 20 dias, considerou-se normal quando as respostas nas freqüências de $500 \mathrm{~Hz}, 1000 \mathrm{~Hz}$, $2000 \mathrm{~Hz}$ e $4000 \mathrm{~Hz}$ estavam entre 25 e 35 dBNPS (Northern e Downs 1991).

\section{Emissão Otoacústica Evocada por Estímulo Transiente}

Os parâmetros estabelecidos na interpretação do registro das EOAT basearam-se naqueles citados por Gattaz e Cerruti, (1994) e Chapchap e Segre (2000). 
Inicialmente, o registro das respostas ocorreu em uma janela de 20ms (janela original) porém, à medida que fomos realizando o exame tivemos dificuldade em realizá-lo na janela original, devido à constante movimentação das crianças, à presença de movimentação da língua na região da fissura não operada, sucção e respiração ruidosa. Desse modo, passamos a realizar os registros das EOAT no modo quickscreen, com o intuito de encurtar o tempo do teste e reduzir o ruído adicionado às baixas freqüências.

A interpretação do exame das EOAT foi realizada separadamente para as orelhas direita e esquerda, considerando a análise conjunta dos dados oferecidos pelo próprio registro das EOAT (figura 8), tais como:

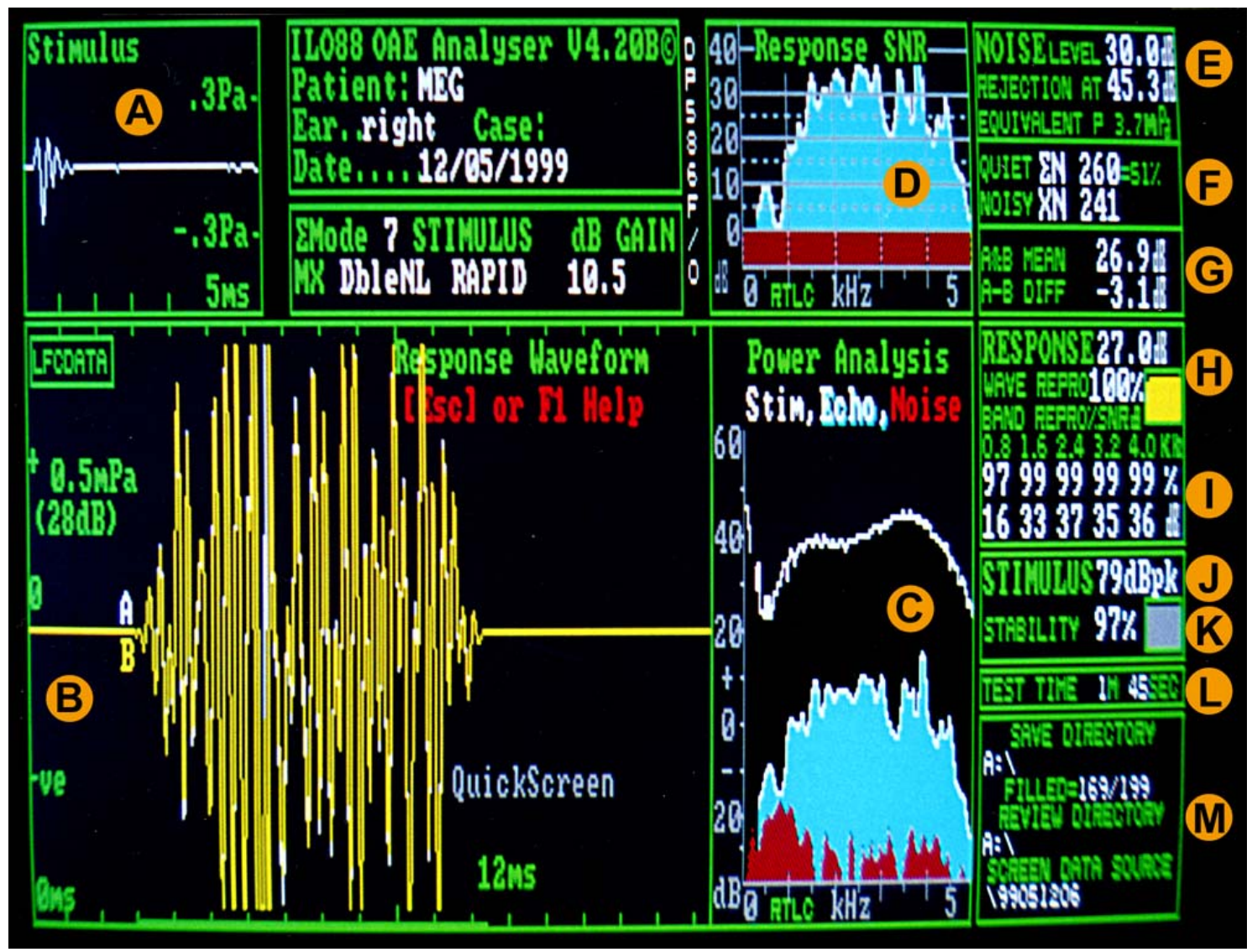

Figura 8 - Registro das EOAT de uma criança 
A - Estímulo

O estímulo utilizado foi o click não linear. A característica do estímulo no meato acústico externo foi observada por exercer influência na obtenção das EOAT. Foi considerada como característica do estímulo uma deflexão positiva e negativa, seguida de poucas oscilações.

B - Reprodutibilidade das ondas A e B

C - Espectro do estímulo no meato acústico externo

D - Espectro da amplitude das EOAT em comparação ao espectro do ruído

E - Nível de ruído no meato acústico externo durante o registro das EOAT e limite de rejeição de ruído, expressos em dB

F - Número e porcentagem total de estímulos aceitos e estímulos rejeitados

G - Média da amplitude dos sinais iguais e sinais diferentes, sendo que a somatória da ondas A e B teria que ser no mínimo o dobro da diferença A-B para se caracterizar presença de resposta

$\mathrm{H}$ - Amplitude geral em dBNPS e porcentagem referente à reprodutibilidade geral dos sinais registrados

I - Porcentagem referente à reprodutibilidade e relação sinal/ruído em dBNPS para cada uma das bandas de oitava analisadas

Considerou-se presença de EOAT quando a relação sinal/ruído foi maior ou igual a 3dB para a bandas de freqüências de 0,8 e 1,6 kHz e, maior ou igual a $6 \mathrm{~dB}$ para as demais bandas de freqüências $(2,4$. 
3,2 e 4,0 kHz). Reprodutibilidade geral maior ou igual a 50\% e presença de EOAT em pelo menos 3 bandas de freqüência

$\mathrm{J}$ - Pico do estímulo

Foi considerada a intensidade de 78 a 85 dBNPS.

$\mathrm{K}$ - Estabilidade da onda

Quando não ocorreu uma boa estabilidade, a sonda foi removida e um novo ajuste, realizado. Posteriormente, o teste foi repetido. Considerou-se uma boa estabilidade da sonda quando os indivíduos apresentaram valores maiores que $70 \%$.

L - Tempo de execução do exame

M - Dados do diretório

4.4- Método estatístico.

Utilizamos métodos estatísticos descritivos absolutos e relativos. Para verificar a associação entre as variáveis estudadas o teste de Fisher e o Qui-quadrado foram aplicados. Foi adotado nível de significância de 5\%. 


\section{RESULTADOS.}

Para facilitar a análise dos dados e o entendimento do texto, os resultados quanto à entrevista audiológica, medidas de imitância acústica, audiometria de observação comportamental, audiometria de reforço visual e emissão otoacústica evocada por estímulo transiente, foram descritos por grupo e por faixa etária ( 3 a 6 meses e 20 dias; 6 meses e 16 dias a 9 meses e 15 dias e 9 meses e 16 dias a 12 meses e 20 dias).

\section{1- Grupo 1}

5.1.1- Entrevista Audiológica com pais e/ou responsável 5.1.1.1- Crianças de 3 a 6 meses

Das 28 crianças avaliadas 19(68\%) apresentaram presença de indicadores de risco para a audição, além da fissura labiopalatina e $9(32 \%)$ ausência de indicadores de risco para a audição, além da fissura labiopalatina.

Os indicadores de risco referidos estão descritos na tabela 4.

Quanto ao item aleitamento materno, vale ressaltar que das 15 crianças que receberam o leite materno, através de ordenha, 1 criança foi amamentada por 7 dias; 2 por 10 dias; 1 por 12 dias; 5 por 15 dias; 1 por 18 dias; 1 por 20 dias; 2 por 30 dias e 2 por 45 dias. 


\subsubsection{2- Crianças de 6 a 9 meses}

Das 10 crianças avaliadas 9(90\%) apresentaram presença de indicadores de risco para a audição, além da fissura labiopalatina e 1 criança (10\%) era adotiva, não tendo dados sobre antecedentes familiares, gestacionais e condições de nascimento. Quanto aos demais itens, o indicador de risco referido pela família adotiva, foi que a criança não recebeu aleitamento materno.

Os indicadores de risco referidos estão descritos na tabela 4.

Quanto ao item aleitamento materno, vale ressaltar que uma criança recebeu o leite materno, através de ordenha, por 27 dias.

\subsubsection{3- Crianças de 9 a 12 meses}

Das 10 crianças avaliadas 9(90\%) apresentaram presença de indicadores de risco para a audição, além da fissura labiopalatina e $1(10 \%)$ ausência de indicadores de risco para a audição, além da fissura.

Os indicadores de risco referidos estão descritos na tabela 4.

$$
\text { Quanto ao item aleitamento materno, vale }
$$
ressaltar que uma criança recebeu o leite materno, através de ordenha, por 2 meses. 
Tabela 4 - Distribuição dos indicadores de risco, além da fissura labiopalatina, referidos pelos pais e/ou responsáveis das crianças do grupo 1

\begin{tabular}{|c|c|c|c|c|}
\hline IDADE & 3 a $6 \mathrm{~m}$ & 6 a $9 \mathrm{~m}$ & 9 a $12 \mathrm{~m}$ & TOTAL \\
\hline $\begin{array}{l}\text { Não aleitamento } \\
\text { materno }\end{array}$ & 13 & 9 & 9 & 31 \\
\hline Pais tabagistas & 7 & 0 & 3 & 10 \\
\hline Incubadora & 2 & 1 & 0 & 3 \\
\hline Consangüinidade & 2 & 0 & 0 & 2 \\
\hline Cianose & 1 & 0 & 1 & 2 \\
\hline Otalgia & 1 & 0 & 1 & 2 \\
\hline OMS & 1 & 2 & 3 & 6 \\
\hline Creche & 1 & 0 & 0 & 1 \\
\hline $\begin{array}{l}\text { Antecedente } \\
\text { familiar de DA }\end{array}$ & 1 & 1 & 0 & 2 \\
\hline IVAS & 0 & 3 & 2 & 5 \\
\hline
\end{tabular}

\footnotetext{
$\mathrm{m}$ - meses

IR - indicadores de risco

OMS - otite média secretora

DA - deficiência auditiva

IVAS - infecções de vias aéreas superiores
}

\subsection{2- Meatoscopia}

Em nenhuma criança do grupo1 foi observado cerume no MAE ou algum outro impedimento para a realização dos exames.

\subsection{3- Medidas de Imitância Acústica}

\subsubsection{1- Crianças de 3 a 6 meses}

Das 28 crianças avaliadas verificamos $6(21 \%)$ com curva timpanométrica normal (tipo A) bilateral e 22(79\%) com 
curva alterada, sendo 7, alteradas unilateral e 15, alteradas bilateralmente. Para a OD obtivemos $10(36 \%)$ com timpanometria tipo A; $1(3 \%)$ com timpanometria tipo $\mathrm{C} ; 7(25 \%)$ com timpanometria tipo As e $10(36 \%)$ com curva tipo B. Para a OE verificamos $9(32 \%)$ com timpanometria tipo A; $1(3 \%)$ com curva tipo $\mathrm{C} ; 3(11 \%)$ com timpanometria tipo As e 15 (54\%) com curva tipo B (Figura 9).

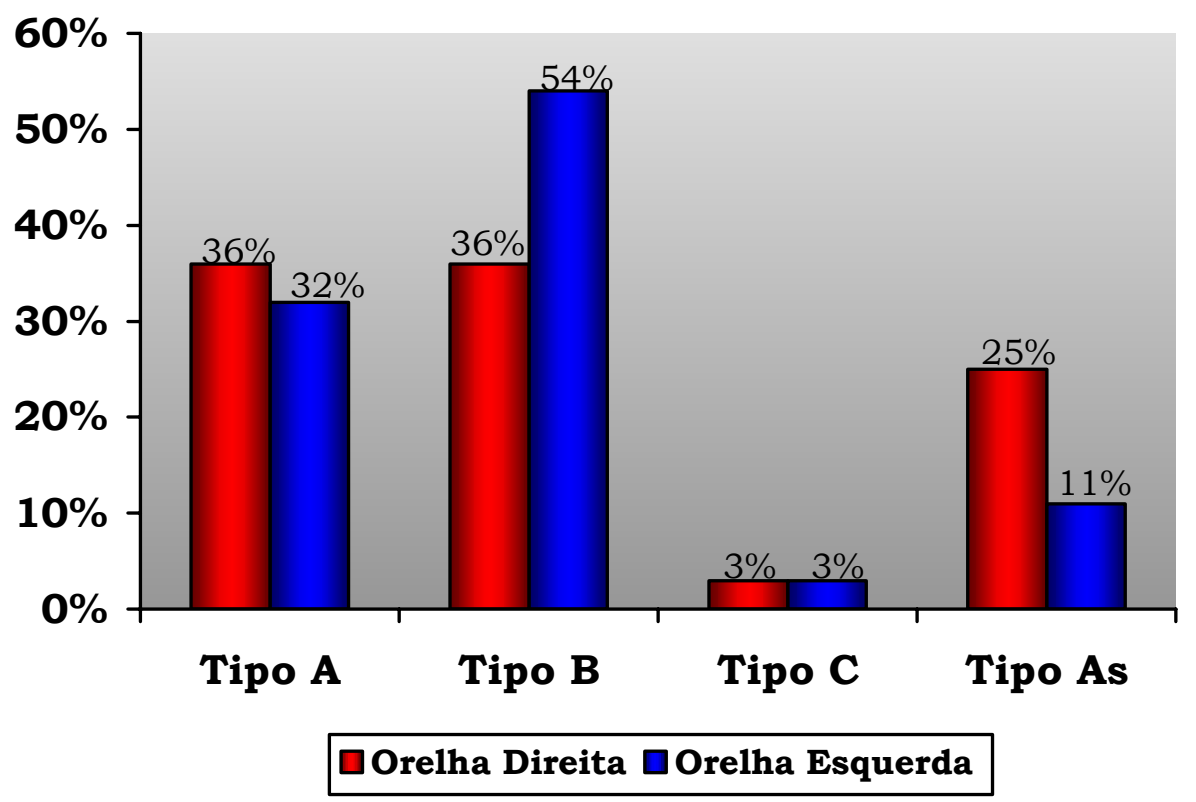

Figura 9- Distribuição da porcentagem de orelhas segundo o critério tipo de curva timpanométrica de crianças de 3 a 6 meses do grupo 1 


\subsubsection{2- Crianças de 6 a 9 meses}

Das 10 crianças avaliadas todas(100\%) apresentaram medidas de imitância acústica alteradas bilateralmente, sendo, para a OD, 3(30\%) com timpanometria tipo As; $1(10 \%)$ com curva tipo C e 6(60\%) com curva tipo B. Para a OE verificamos $1(10 \%)$ com curva tipo As; $1(10 \%)$ com timpanometria tipo C e $8(80 \%)$ com curva tipo B (Figura 10).

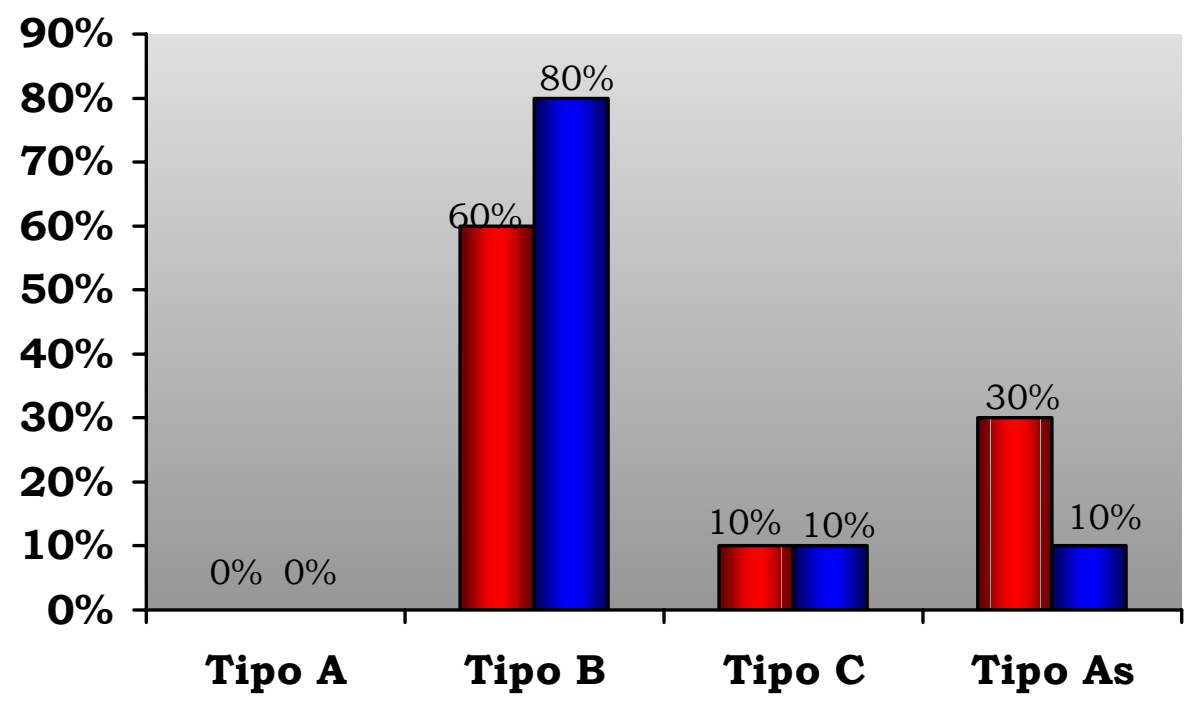

DOrelha Direita DOrelha Esquerda

Figura 10- Distribuição da porcentagem de orelhas segundo o critério tipo de curva timpanométrica de crianças de 6 a 9 meses do grupo 1 


\subsubsection{3- Crianças de 9 a 12 meses}

Dos 10 casos avaliados nesta faixa etária encontramos, para as medidas de imitância acústica, 100\% de alteração, sendo 9 casos com alteração bilateral e 1 com alteração unilateral. Em relação a OD, verificou-se 1(10\%) curva tipo A; 3(30\%) curva tipo As e 6(60\%) curva tipo B. Em relação a OE, 1 apresentou curva tipo $\mathrm{C}(10 \%), 3(30 \%)$ apresentaram curva tipo As e 6(60\%) curva tipo B (Figura 11).

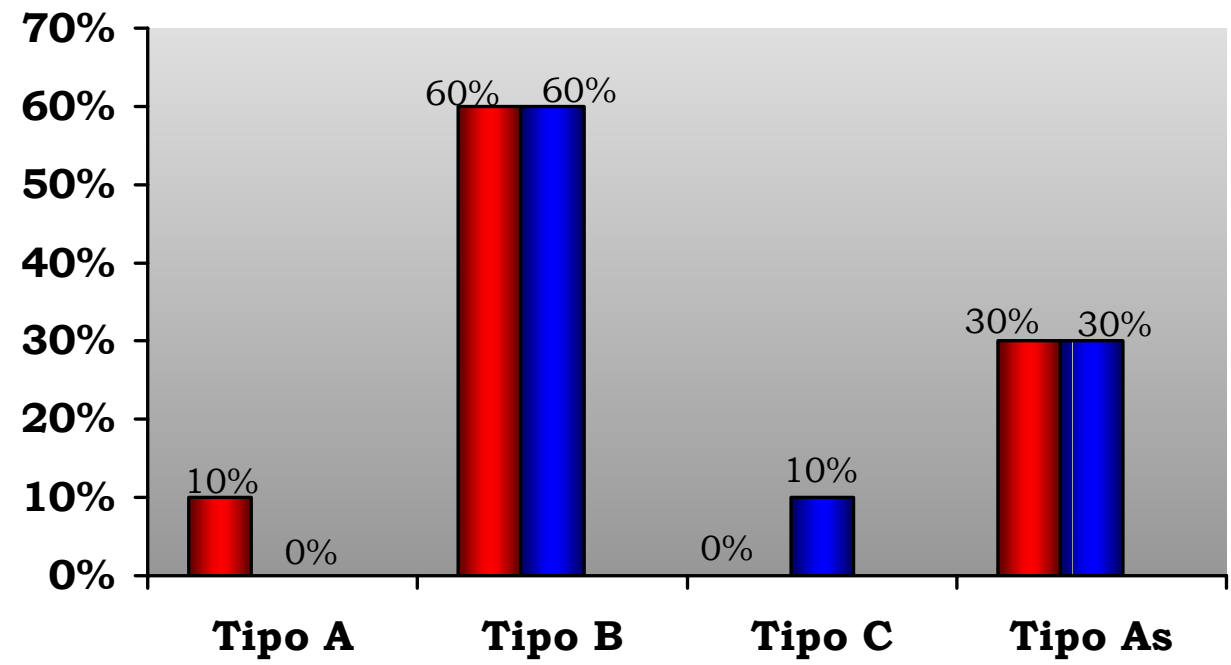

Orelha Direita DOrelha Esquerda

Figura 11- Distribuição da porcentagem de orelhas segundo o critério tipo de curva timpanométrica de crianças de 9 a 12 meses do grupo 1 


\subsection{4- Audiometria de Observação Comportamental}

\subsubsection{1- Crianças de 3 a 6 meses}

Das 28 crianças avaliadas, 14(50\%) apresentaram os resultados dentro dos padrões considerados de normalidade para a faixa etária e $14(50 \%)$ com resultados alterados pois, apesar de apresentar reação de Atenção, Procura da Fonte e Localização Lateral da fonte sonora não, apresentaram o Reflexo Cocleopalpebral (RCP) para o agogô.

A ocorrência das diferentes respostas (RCP, Reação de Sobressalto, Atenção, Procura da Fonte, Localização) para cada um dos estímulos instrumentais utilizados (Guizo, Sino, Blackblack, Agogô), está demonstrada na tabela 5.

Tabela 5 - Distribuição da freqüência da ocorrência das respostas a sons instrumentais, nas crianças de 3 a 6 meses do grupo 1

\begin{tabular}{|c|c|c|c|c|c|c|}
\hline & $\begin{array}{l}\mathrm{RRCP} \\
\mathbf{( N )}\end{array}$ & $\begin{array}{c}\mathrm{RCP}+\mathrm{S} \\
\mathbf{( N )}\end{array}$ & $\begin{array}{l}\text { ATENÇÃO } \\
\mathbf{( N )} \\
\end{array}$ & $\begin{array}{l}\text { PROCURA } \\
\mathbf{( N )} \\
\end{array}$ & $\begin{array}{l}\text { LOCALIZAÇÃO } \\
(\mathbf{N})\end{array}$ & $\begin{array}{l}\text { TOTAL } \\
\mathbf{( N )}\end{array}$ \\
\hline $\mathbf{A}$ & - & - & $15(54 \%)$ & $7(25 \%)$ & $6(21 \%)$ & $28(100 \%)$ \\
\hline $\boldsymbol{B}$ & - & - & $16(57 \%)$ & $6(21,5 \%)$ & $6(21,5 \%)$ & $28(100 \%)$ \\
\hline C & - & - & $14(50 \%)$ & $8(29 \%)$ & $6(21 \%)$ & $28(100 \%)$ \\
\hline D & $15(54 \%)$ & - & $8(29 \%)$ & $4(14 \%)$ & $1(3 \%)$ & $28(100 \%)$ \\
\hline
\end{tabular}

RCP- reflexo cocleopalpebral $\mathrm{RCP}+\mathrm{S}-$ reflexo cocleopalpebral + reação de sobressalto PROCURA- procura da fonte LOCALIZAÇÃO- localização lateral
A- guizo

B- sino

C- black-black

D- agogô 
5.1.4.2- Crianças de 6 a 9 meses

Das 10 crianças avaliadas, $4(40 \%)$ apresentaram as reações dentro dos padrões considerados de normalidade. Em 6(60\%) os resultados apresentaram-se alterados pois, apesar de apresentar reação de Localização Lateral da fonte sonora, não apresentaram o RCP para o agogô.

A ocorrência das diferentes respostas (RCP, Reação de Sobressalto, Atenção, Procura da Fonte, Localização) para cada um dos estímulos instrumentais utilizados (Guizo, Sino, Blackblack, Agogô), está demonstrada na tabela 6.

Tabela 6 - Distribuição da freqüência de ocorrência das respostas a sons instrumentais, nas crianças de 6 a 9 meses do grupo 1

\section{RCP RCP+S ATENÇÃO PROCURA LOCALIZAÇÃO TOTAL}

(N)

(N)

(N)

(N)

(N)

(N)

\begin{tabular}{|c|c|c|c|c|c|c|}
\hline $\mathbf{A}$ & - & - & - & - & $10(100 \%)$ & $10(100 \%)$ \\
\hline B & - & - & - & - & $10(100 \%)$ & $10(100 \%)$ \\
\hline C & - & - & - & - & $10(100 \%)$ & $10(100 \%)$ \\
\hline D & $4(40 \%)$ & - & - & - & $6(60 \%)$ & $10(100 \%)$ \\
\hline
\end{tabular}

RCP- reflexo cocleopalpebral $\mathrm{RCP}+\mathrm{S}-$ reflexo cocleopalpebral + reação de sobressalto

A- guizo PROCURA- procura da fonte

B- sino LOCALIZAÇÃO- localização lateral

C- black-black

D- agogô 
5.1.4.3- Crianças de 9 a 12 meses

Das 10 crianças avaliadas, 6(60\%) apresentaram as reações dentro dos padrões considerados de normalidade e $4(40 \%)$ resultados alterados pois, apesar de apresentar reação de Localização Lateral da fonte sonora, não apresentaram o RCP para o agogô.

A ocorrência das diferentes respostas (RCP, Reação de Sobressalto, Atenção, Procura da Fonte, Localização) para cada um dos estímulos instrumentais utilizados (Guizo, Sino, Blackblack, Agogô), está demonstrada na tabela 7 .

Tabela 7 - Distribuição da freqüência de ocorrência das respostas a sons instrumentais, nas crianças de 9 a 12 meses do grupo 1

\begin{tabular}{ccccccc}
\hline & $\begin{array}{c}\text { RCP } \\
\text { (N) }\end{array}$ & $\begin{array}{c}\text { RCP+S } \\
(\mathbf{N})\end{array}$ & $\begin{array}{c}\text { ATENÇÃO } \\
\text { (N) }\end{array}$ & $\begin{array}{c}\text { PROCURA } \\
\text { (N) }\end{array}$ & $\begin{array}{c}\text { LOCALIZAÇÃO } \\
\text { (N) }\end{array}$ & TOTAL \\
\hline & - & - & - & - & $10(100 \%)$ & $10(100 \%)$ \\
B & - & - & - & - & $10(100 \%)$ & $10(100 \%)$ \\
C & - & - & - & - & $10(100 \%)$ & $10(100 \%)$ \\
D & $6(60 \%)$ & - & - & - & $4(40 \%)$ & $10(100 \%)$ \\
\hline
\end{tabular}

RCP- reflexo cocleopalpebral

A- guizo

$\mathrm{RCP}+\mathrm{S}$ - reflexo cocleopalpebral + reação de sobressalto PROCURA- procura da fonte LOCALIZAÇÃO- localização lateral
B- sino

C- black-black

D- agogô 


\subsection{5- Audiometria de Reforço Visual}

\subsubsection{1- Crianças de 3 a 6 meses}

Das 28 crianças avaliadas, encontramos tanto para a OD como para a OE, $23(82 \%)$ com niveis de respostas dentro dos padrões considerados de normalidade para a faixa etária e $5(18 \%)$ com desvio destes padrões.

As ocorrências dos niveis de respostas para tons puros obtidos para as freqüências de $500 \mathrm{~Hz}, 1000 \mathrm{~Hz}, 2000 \mathrm{~Hz}$ e $4000 \mathrm{~Hz}$ para o lado direito e esquerdo estão descritas na tabela 8 .

Tabela 8 - Distribuição da ocorrência dos níveis de respostas para tons puros obtidos para as freqüências de $500 \mathrm{~Hz}, 1000 \mathrm{~Hz}, 2000 \mathrm{~Hz}$ e $4000 \mathrm{~Hz}$ para o lado direito e esquerdo das crianças de 3 a 6 meses do grupo 1

\begin{tabular}{ccccccc}
\hline \multicolumn{7}{c}{ dBNPS } \\
Hz & & $\mathbf{4 0}$ & $\mathbf{5 0}$ & $\mathbf{5 5}$ & $\mathbf{6 0}$ & $\mathbf{7 0}$ \\
\hline \multirow{2}{*}{$\mathbf{5 0 0}$} & OD & 2 & 9 & 1 & 11 & 5 \\
& OE & 3 & 8 & 1 & 11 & 5 \\
\hline \multirow{2}{*}{$\mathbf{1 0 0 0}$} & OD & 3 & 8 & 1 & 11 & 5 \\
& OE & 3 & 7 & 1 & 12 & 5 \\
\hline \multirow{2}{*}{$\mathbf{2 0 0 0}$} & OD & 3 & 8 & 0 & 12 & 5 \\
& OE & 3 & 7 & 1 & 12 & 5 \\
\hline \multirow{2}{*}{$\mathbf{4 0 0 0}$} & OD & 3 & 8 & 0 & 12 & 5 \\
& OE & 3 & 7 & 1 & 12 & 5 \\
\hline
\end{tabular}

dBNPS- decibel nivel de pressão sonora; OD- orelha direita $\mathrm{OE}$ - orelha esquerda; Hz- Hertz 


\subsubsection{2- Crianças de 6 a 9 meses}

Das 10 crianças avaliadas, encontramos tanto para o lado direito como para o lado esquerdo, $8(80 \%)$ com níveis de respostas dentro dos padrões de normalidade para a faixa etária e $2(20 \%)$ com desvio destes padrões.

As ocorrências dos niveis de respostas para tons puros obtidos para as freqüências de $500 \mathrm{~Hz}, 1000 \mathrm{~Hz}, 2000 \mathrm{~Hz} \mathrm{e}$ $4000 \mathrm{~Hz}$ para o lado direito e esquerdo estão descritas na tabela 9.

Tabela 9 - Distribuição da ocorrência dos niveis de respostas para tons puros obtidos para as freqüências de $500 \mathrm{~Hz}, 1000 \mathrm{~Hz}, 2000 \mathrm{~Hz}$ e $4000 \mathrm{~Hz}$ para o lado direito e esquerdo das crianças de 6 a 9 meses do grupo 1

\section{dBNPS}

\begin{tabular}{ccccccc}
\hline Hz & & $\mathbf{3 0}$ & $\mathbf{3 5}$ & $\mathbf{4 0}$ & $\mathbf{4 5}$ & $\mathbf{5 0}$ \\
\hline \multirow{2}{*}{$\mathbf{5 0 0}$} & OD & 7 & 0 & 1 & 1 & 1 \\
& OE & 6 & 1 & 1 & 1 & 1 \\
\hline \multirow{2}{*}{$\mathbf{1 0 0 0}$} & OD & 7 & 0 & 1 & 1 & 1 \\
& OE & 6 & 1 & 1 & 1 & 1 \\
\hline \multirow{2}{*}{$\mathbf{2 0 0 0}$} & OD & 7 & 0 & 1 & 1 & 1 \\
& OE & 6 & 1 & 1 & 1 & 1 \\
\hline \multirow{2}{*}{$\mathbf{4 0 0 0}$} & OD & 6 & 0 & 2 & 1 & 1 \\
& OE & 5 & 1 & 2 & 1 & 1 \\
\hline
\end{tabular}

dBNPS- decibel nivel de pressão sonora; OD- orelha direita $\mathrm{OE}$ - orelha esquerda; Hz- Hertz 
5.1.5.3- Crianças de 9 a 12 meses

Das 10 crianças pertencentes a essa faixa etária, encontramos, para ao lado direito e para o lado esquerdo, 9(90\%) com níveis de respostas dentro dos padrões considerados de normalidade para a faixa etária e $1(10 \%)$ com desvio destes padrões.

As ocorrências dos níveis de respostas para tons puros obtidos para as freqüências de $500 \mathrm{~Hz}, 1000 \mathrm{~Hz}, 2000 \mathrm{~Hz}$ e $4000 \mathrm{~Hz}$ para o lado direito e esquerdo estão descritas na tabela 10.

Tabela 10 - Distribuição da ocorrência dos níveis de respostas para tons puros obtidos para as freqüências de $500 \mathrm{~Hz}, 1000 \mathrm{~Hz}, 2000 \mathrm{~Hz}$ e $4000 \mathrm{~Hz}$ para o lado direito e esquerdo das crianças de 9 a 12 meses do grupo 1

\begin{tabular}{|c|c|c|c|c|c|}
\hline \multicolumn{6}{|c|}{ dBNPS } \\
\hline $\mathbf{H z}$ & & 25 & 30 & 35 & 70 \\
\hline \multirow{2}{*}{500} & OD & 4 & 2 & 3 & 1 \\
\hline & $\mathbf{O E}$ & 2 & 3 & 4 & 1 \\
\hline \multirow{2}{*}{1000} & OD & 3 & 3 & 3 & 1 \\
\hline & OE & 2 & 3 & 4 & 1 \\
\hline \multirow{2}{*}{2000} & OD & 3 & 2 & 4 & 1 \\
\hline & $\mathbf{O E}$ & 2 & 3 & 4 & 1 \\
\hline \multirow{2}{*}{4000} & $\mathrm{OD}$ & 3 & 2 & 4 & 1 \\
\hline & OE & 2 & 3 & 4 & 1 \\
\hline
\end{tabular}

dBNPS- decibel nivel de pressão sonora $\mathrm{Hz}$ - Hertz

OD- orelha direita

OE- orelha esquerda 
5.1.6- Emissão otoacústica evocada por estímulo transiente

5.1.6.1- Crianças de 3 a 6 meses

Nos resultados quanto à presença ou ausência de EOAT, das 28 crianças avaliadas nesta faixa etária encontramos: $17(61 \%)$ em que o exame foi realizado bilateralmente; $4(14 \%)$ em que o exame foi realizado unilateralmente e $7(25 \%)$ em que o exame não foi realizado*. Para a OD verificamos ausência de EOAT em 18(64\%); e exame não realizado* em 10(36\%). Para a OE, EOAT ausente em $20(71 \%)$ e em $8(29 \%)$ o exame não foi realizado* (Figura 12$).$

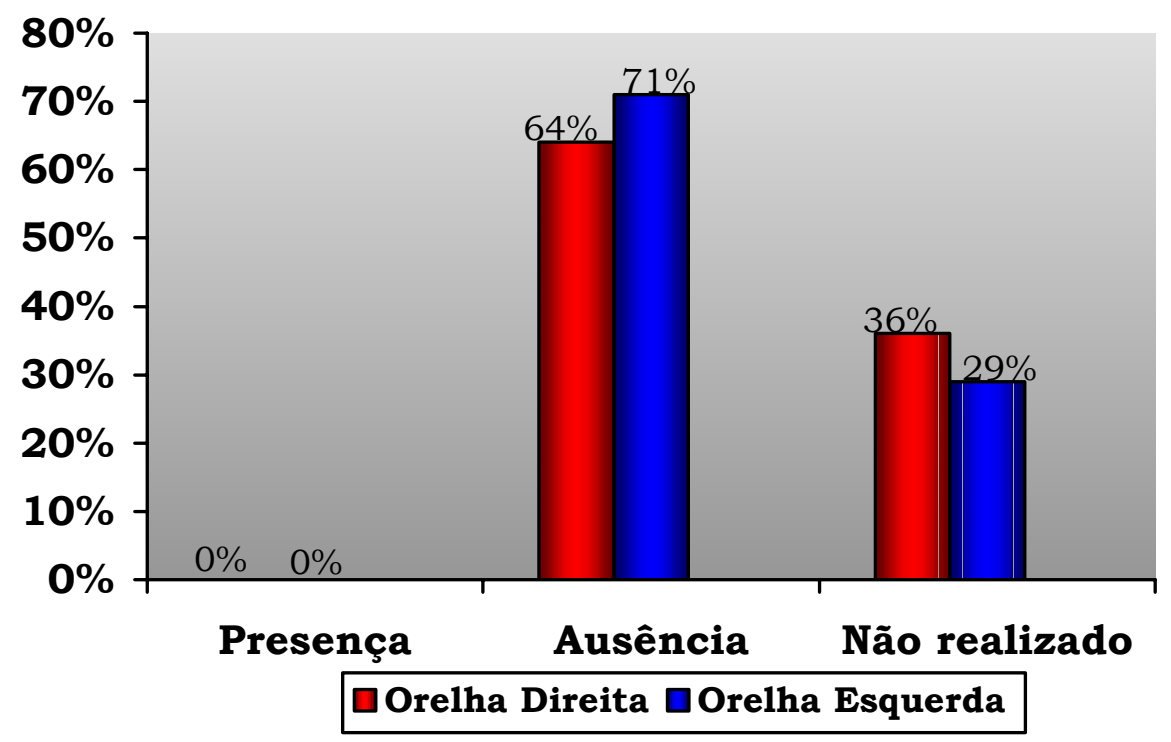

Figura 12- Distribuição da porcentagem de orelhas das crianças de 3 a 6 meses do grupo 1, quanto ao critério presença ou ausência de EOAT

* exame não realizado devido a respiração muito ruidosa, choro. 


\subsubsection{2- Crianças de 6 a 9 meses}

Nos resultados com relação à presença ou ausência de EOAT, das 10 crianças avaliadas nesta faixa etária encontramos: $7(70 \%)$ em que o exame foi realizado bilateralmente e em $3(30 \%)$ em que o exame não foi realizado*. Para a OD verificamos ausência de EOAT em 7(70\%); e exame não realizado* em 3(30\%). Para a OE, EOAT ausente em $7(70 \%)$ e em $3(30 \%)$ em que não se realizou o exame* (Figura 13).

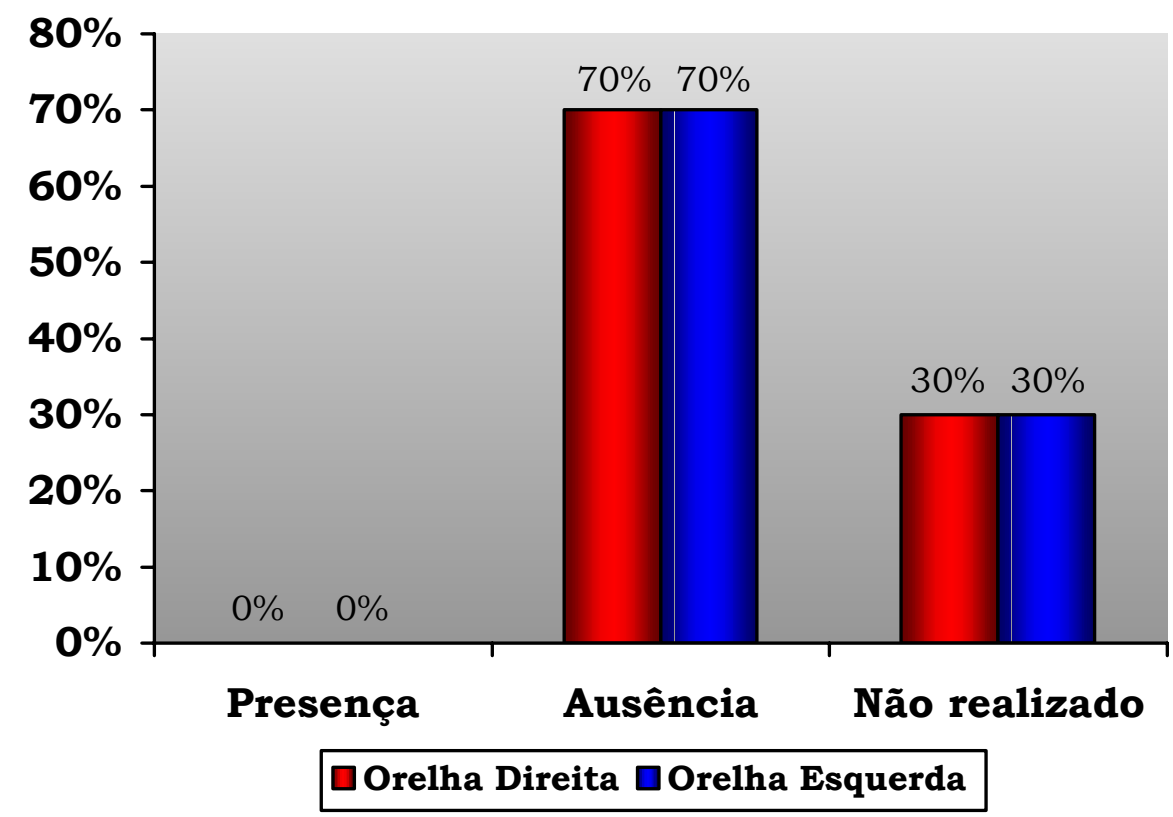

Figura 13- Distribuição da porcentagem de orelhas das crianças de 6 a 9 meses do grupo 1, quanto ao critério presença ou ausência de EOAT

* exame não realizado devido a respiração muito ruidosa, choro. 


\subsubsection{3- Crianças de 9 a 12 meses}

Com relação à presença ou ausência de EOAT, das 10 crianças avaliadas nesta faixa etária encontramos: $7(70 \%) \mathrm{em}$ que o exame foi realizado bilateralmente; $1(10 \%)$ em que o exame foi realizado unilateralmente e $2(20 \%)$ em que o exame não foi realizado*. Para a OD verificamos ausência de EOAT em $7(70 \%) ; 1(10 \%)$ presença de EOAT e exame não realizado* em 2(20\%). Para a OE, EOAT ausente em $7(70 \%)$ e em $3(30 \%)$ em que não se realizou o exame* (Figura 14).

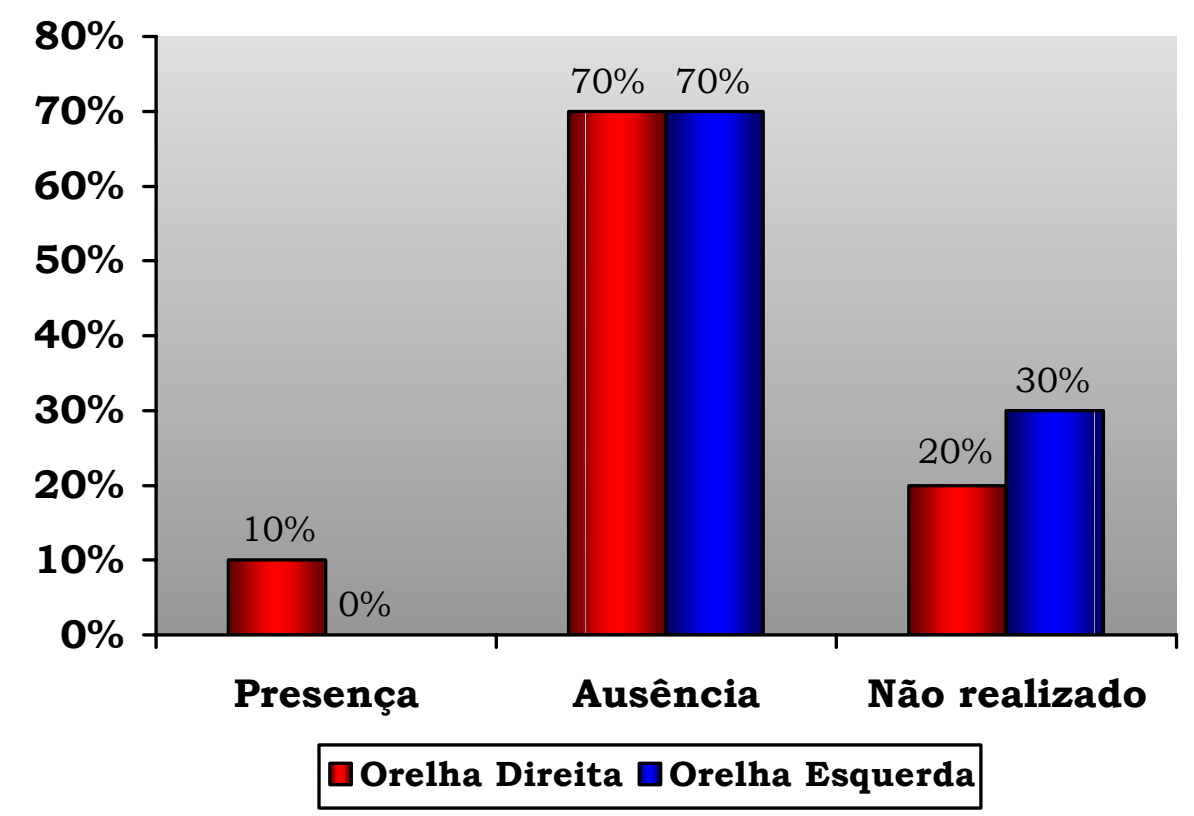

Figura 14- Distribuição da porcentagem de orelhas das crianças de 9 a 12 meses do grupo 1, quanto ao critério presença ou ausência de EOAT

\footnotetext{
* exame não realizado devido a respiração muito ruidosa, choro, sucção.
} 
Após a análise dos resultados, fizemos a associação dos mesmos entre os dados da EOAT com os dados de cada um dos outros procedimentos (entrevista audiológica, medidas de imitância acústica, audiometria de observação comportamental e audiometria de reforço visual), por orelha testada, nas 30 crianças que realizaram todos os exames bilateralmente, ou seja, 17 crianças (34 orelhas) na faixa etária de 3 a 6 meses, 7 crianças (14 orelhas) na faixa etária de 6 a 9 meses e 7 crianças (14 orelhas) na faixa etária de 9 a 12 meses (Tabelas 11,12 , $13,14,15,16,17,18,19,20,21$ e 22).

De acordo com o estudo estatístico realizado não vimos diferença estatisticamente significante entre a associação dos dados da EOAT com os dados de cada um dos outros procedimentos utilizados nas crianças do grupo 1 que realizaram os exames bilateralmente, independente da faixa etária (Tabelas $11,12,13,14,15,16,17,18,19$, 20, 21 e 22). 
Tabela 11 - Associação dos dados da EOAT com os dados da entrevista audiológica, das 17 crianças de 3 a 6 meses do grupo 1 que realizaram os procedimentos bilateralmente

\begin{tabular}{lccc}
\hline EOAT & & & \\
\hline POSITIVA & 0 & $11(65 \%)$ & $11(65 \%)$ \\
NEGATIVA & 0 & $6(35 \%)$ & $6(35 \%)$ \\
TOTAL & 0 & $17(100 \%)$ & $17(100 \%)$ \\
\hline
\end{tabular}

EOAT - Emissão otoacústica evocada por estímulo transiente E.A. - Entrevista Audiológica

Tabela 12 - Associação dos dados da EOAT com os dados da entrevista audiológica, das 7 crianças de 6 a 9 meses do grupo 1 que realizaram os procedimentos bilateralmente

\begin{tabular}{lccc}
\hline EOAT & PRESENTE & AUSENTE & TOTAL \\
POSITIVA & 0 & $7(100 \%)$ & $7(100 \%)$ \\
NEGATIVA & 0 & 0 & 0 \\
TOTAL & 0 & $7(100 \%)$ & $7(100 \%)$ \\
\hline
\end{tabular}

EOAT - Emissão otoacústica evocada por estímulo transiente E.A. - Entrevista Audiológica 
Tabela 13 - Associação dos dados da EOAT com os dados da entrevista audiológica, das 7 crianças de 9 a 12 meses do grupo 1 que realizaram os procedimentos bilateralmente

\begin{tabular}{lccc}
\hline POA & & & \\
POSITIVA & $1(14 \%)$ & $6(86 \%)$ & $7(100 \%)$ \\
NEGATIVA & 0 & 0 & 0 \\
TOTAL & $1(14 \%)$ & $6(86 \%)$ & $7(100 \%)$ \\
\hline
\end{tabular}

EOAT - Emissão otoacústica evocada por estímulo transiente

E.A. - Entrevista Audiológica

Tabela 14 - Associação dos dados da EOAT com os dados das medidas de imitância acústica, por orelha testada, das 17 crianças (34 orelhas) de 3 a 6 meses do grupo 1 que realizaram os exames bilateralmente

\begin{tabular}{lccc}
\hline EOAT & PRESENTE & AUSENTE & TOTAL \\
NORMAL & 0 & $9(26,5 \%)$ & $9(26,5 \%)$ \\
ALTERADA & 0 & $25(73,5 \%)$ & $25(73,5 \%)$ \\
TOTAL & 0 & $34(100 \%)$ & $34(100 \%)$ \\
\hline
\end{tabular}

EOAT - Emissão otoacústica evocada por estímulo transiente IMIT - Medidas de Imitância Acústica 
Tabela 15 - Associação dos dados da EOAT com os dados das medidas de imitância acústica, das 7 crianças (14 orelhas) de 6 a 9 meses do grupo 1 que realizaram os procedimentos bilateralmente

\begin{tabular}{lccc}
\hline IMIT & & & \\
\hline NORMAL & 0 & 0 & 0 \\
ALTERADA & 0 & $14(100 \%)$ & $14(100 \%)$ \\
TOTAL & 0 & $14(100 \%)$ & $14(100 \%)$ \\
\hline
\end{tabular}

EOAT - Emissão otoacústica evocada por estímulo transiente IMIT - Medidas de Imitância Acústica

Tabela 16 - Associação dos dados da EOAT com os dados das medidas de imitância acústica, das 7 crianças (14 orelhas) de 9 a 12 meses do grupo 1 que realizaram os procedimentos bilateralmente

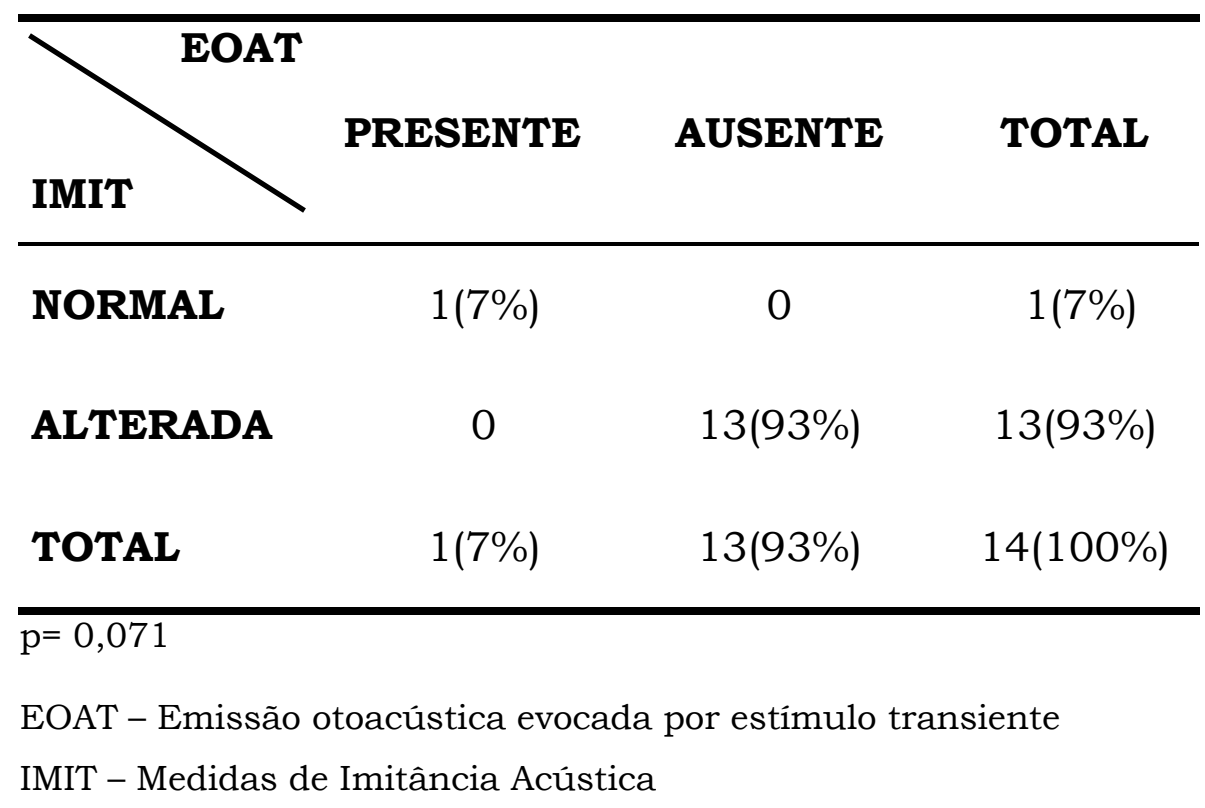


Tabela 17 - Associação dos dados da EOAT com os dados da audiometria de reforço visual, por orelha testada, das 17 crianças (34 orelhas) de 3 a 6 meses do grupo 1 que realizaram os exames bilateralmente

\begin{tabular}{lccc}
\hline PRA & & & \\
\hline NORMAL & 0 & $28(82 \%)$ & $28(82 \%)$ \\
ALTERADA & 0 & $6(18 \%)$ & $6(18 \%)$ \\
TOTAL & 0 & $34(100 \%)$ & $34(100 \%)$ \\
\hline
\end{tabular}

EOAT- Emissão otoacústica evocada por estímulo transiente VRA- Audiometria de Reforço Visual

Tabela 18 - Associação dos dados da EOAT com os dados da audiometria de reforço visual, por orelha testada, das 7 crianças (14 orelhas) de 6 a 9 meses do grupo 1 que realizaram os exames bilateralmente

\begin{tabular}{llll}
\hline ERA & & & \\
\hline NORMAL & 0 & $10(71 \%)$ & $10(71 \%)$ \\
ALTERADA & 0 & $4(29 \%)$ & $4(29 \%)$ \\
TOTAL & 0 & $14(100 \%)$ & $14(100 \%)$ \\
\hline
\end{tabular}

EOAT- Emissão otoacústica evocada por estímulo transiente VRA- Audiometria de Reforço Visual 
Tabela 19 - Associação dos dados da EOAT com os dados da audiometria de reforço visual, por orelha testada, das 7 crianças (14 orelhas) de 9 a 12 meses do grupo 1 que realizaram os exames bilateralmente

\begin{tabular}{lccc}
\hline NRA & & & \\
\hline NORMAL & $1(7 \%)$ & $11(79 \%)$ & $12(86 \%)$ \\
ALTERADA & 0 & $2(14 \%)$ & $2(14 \%)$ \\
TOTAL & $1(7 \%)$ & $13(93 \%)$ & $14(100 \%)$ \\
\hline$p=0,364$ & & &
\end{tabular}

EOAT- Emissão otoacústica evocada por estímulo transiente VRA- Audiometria de Reforço Visual

Tabela 20 - Associação dos dados da EOAT com os dados da audiometria de observação comportamental, das 17 crianças de 3 a 6 meses do grupo 1 que realizaram os exames bilateralmente

\begin{tabular}{lccc}
\hline EOC & & & \\
\hline NORMAL & 0 & $9(53 \%)$ & $9(53 \%)$ \\
ALTERADA & 0 & $8(47 \%)$ & $8(47 \%)$ \\
TOTAL & 0 & $17(100 \%)$ & $17(100 \%)$ \\
\hline
\end{tabular}

EOAT- Emissão otoacústica evocada por estímulo transiente AOC- Audiometria de Observação Comportamental 
Tabela 21 - Associação dos dados da EOAT com os dados da audiometria de observação comportamental, das 7 crianças de 6 a 9 meses do grupo 1 que realizaram os exames bilateralmente

\begin{tabular}{lccc}
\hline POC & & & \\
\hline NORMAL & 0 & $3(43 \%)$ & $3(43 \%)$ \\
ALTERADA & 0 & $4(57 \%)$ & $4(57 \%)$ \\
TOTAL & 0 & $7(100 \%)$ & $7(100 \%)$ \\
\hline
\end{tabular}

EOAT- Emissão otoacústica evocada por estímulo transiente AOC- Audiometria de Observação Comportamental

Tabela 22 - Associação dos dados da EOAT com os dados da audiometria de observação comportamental, das 7 crianças de 9 a 12 meses do grupo 1 que realizaram os exames bilateralmente

\begin{tabular}{lccc}
\hline EOC & & & \\
NORMAL & $1(14 \%)$ & $3(43 \%)$ & $4(57 \%)$ \\
ALTERADA & 0 & $3(43 \%)$ & $3(43 \%)$ \\
TOTAL & $1(14 \%)$ & $6(86 \%)$ & $7(100 \%)$ \\
\hline
\end{tabular}

EOAT- Emissão otoacústica evocada por estímulo transiente AOC- Audiometria de Observação Comportamental 


\section{2- Grupo 2}

5.2.1- Entrevista Audiológica com pais e/ou responsável

5.2.1.1- Crianças de 3 a 6 meses de idade

Das 21 crianças avaliadas 10(48\%)

apresentaram presença de indicadores de risco para a audição, além da fissura labiopalatina, $11(52 \%)$ ausência de indicadores de risco para a audição, além da fissura.

Os indicadores de risco referidos estão descritos na tabela 23.

Quanto ao item aleitamento materno, salientamos que das 20 crianças que o receberam tivemos 10 crianças com 3 meses de idade que estavam sendo amamentadas; 4 com 4 meses sendo amamentadas; 2 com 5 meses sendo amamentadas; 1 criança com 6 meses sendo amamentada; 1 foi amamentada por 1 mês; 1 por 2 meses e 1 por 4 meses.

\subsubsection{2- Crianças de 6 a 9 meses de idade}

Das 8 crianças avaliadas $4(50 \%)$ apresentaram presença de indicadores de risco para a audição, além da fissura labiopalatina, 3(37,5\%) ausência de indicadores de risco para a audição, além da fissura e 1 criança $(12,5 \%)$ era adotiva, não tendo dados sobre antecedentes familiares, gestacionais e condições de nascimento. Quanto aos demais itens os pais adotivos não referiram nenhuma queixa. 
Os indicadores de risco referidos estão descritos

na tabela 23.

$$
\text { Quanto ao item aleitamento materno, vale }
$$

ressaltar que das 6 crianças que o receberam, tivemos 2 com 6 meses de idade que estavam sendo amamentadas; 2 crianças com 9 meses sendo amamentadas; 1, que foi amamentada por 1 mês; e 1 por 2 meses.

Tabela 23 - Distribuição dos indicadores de risco, além da fissura labiopalatina, referidos pelos pais e/ou responsáveis das crianças do grupo 2

\begin{tabular}{|c|c|c|c|}
\hline${ }^{I D A D E}$ & 3 a $6 \mathrm{~m}$ & 6 a $9 \mathrm{~m}$ & TOTAL \\
\hline $\begin{array}{l}\text { Não aleitamento } \\
\text { materno }\end{array}$ & 1 & 2 & 3 \\
\hline Pais tabagistas & 6 & 1 & 7 \\
\hline Cianose & 1 & 0 & 1 \\
\hline Otalgia & 5 & 0 & 5 \\
\hline OMS & 3 & 2 & 5 \\
\hline
\end{tabular}

m - meses

IR - indicadores de risco

OMS - otite média secretora

\subsection{2- Meatoscopia}

Em nenhuma criança desse grupo foi observado cerume no MAE ou algum outro impedimento para a realização dos exames. 


\subsection{3- Medidas de Imitância Acústica}

\subsubsection{1- Crianças de 3 a 6 meses de idade}

Das 21 crianças avaliadas observamos 13(62\%) com curva timpanométrica normal (tipo A) bilateral, e 8(48\%) com curva alterada, sendo 1, alterada unilateral e 7 bilateral. Para a OD 13(62\%) com timpanometria tipo A; 3(14\%) com timpanometria tipo As; $2(10 \%)$ com timpanometria tipo C; 3(14\%) com curva tipo B. Para a OE verificamos $14(67 \%)$ com timpanometria tipo A; 2(9,5\%) com timpanometria tipo As; $3(14 \%)$ com curva tipo C e 2(9,5\%) com curva tipo B (Figura 15).

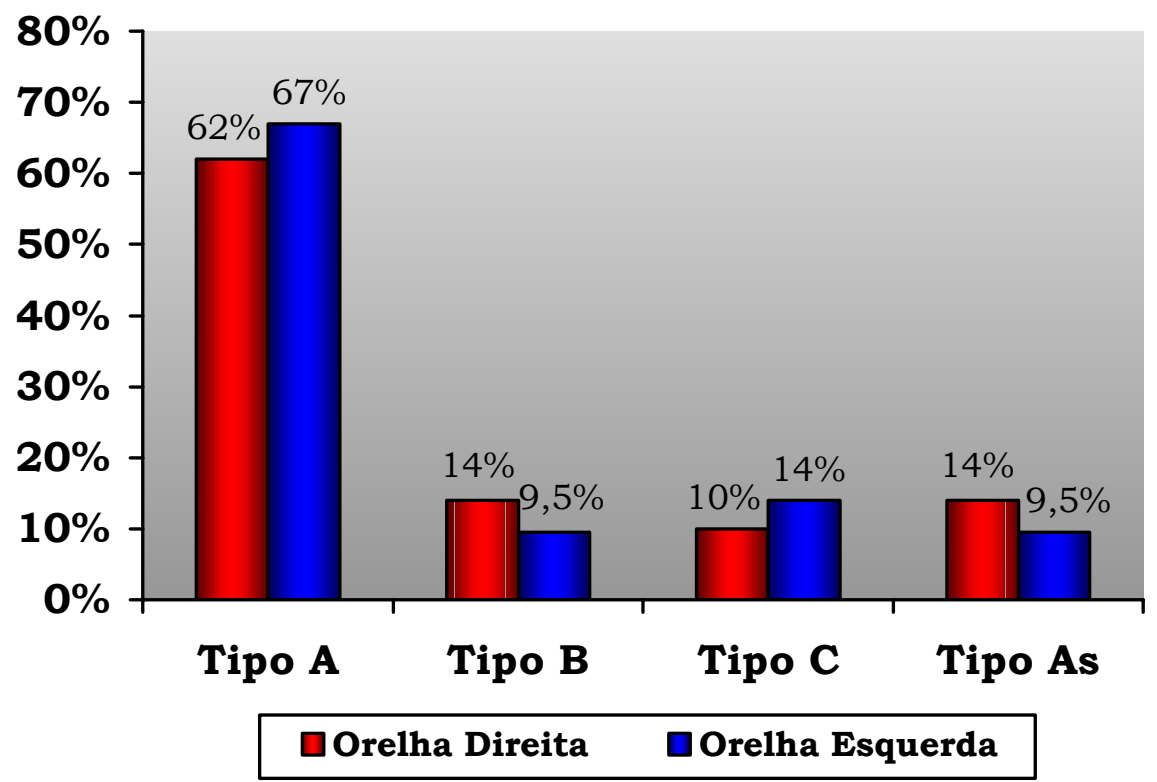

Figura 15- Distribuição da porcentagem de orelhas segundo o critério tipo de curva timpanométrica das crianças de 3 a 6 meses do grupo 2 
5.2.3.2- Crianças de 6 a 9 meses de idade

$$
\text { Das } 8 \text { crianças avaliadas, 2(25\%) }
$$

apresentaram curvas normais bilateral e 6(75\%) curvas alteradas, sendo 2 alteradas unilateral e 4 alteradas bilateralmente; Para a OD $3(37,5 \%)$ com timpanometria tipo $A ; 1(12,5 \%)$ com curva tipo As; $1(12,5 \%)$ com curva tipo $\mathrm{C}$ e $3(37,5 \%)$ com curva tipo B. Para a OE verificamos $3(37,5 \%)$ com curva tipo A; 2(25\%) com curva tipo As; $1(12,5 \%)$ com timpanometria tipo $\mathrm{C}$ e $2(25 \%)$ com curva tipo B (Figura 16).

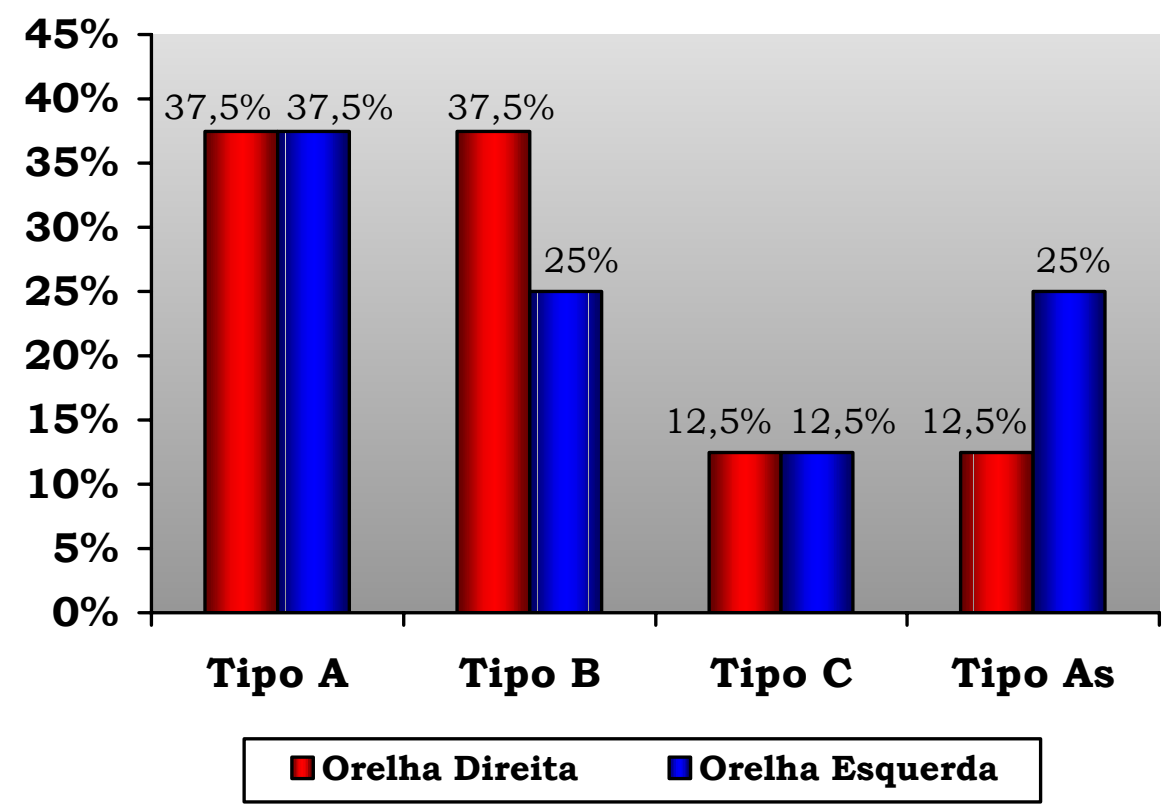

Figura 16- Distribuição da porcentagem de orelhas segundo o critério tipo de curva timpanométrica das crianças de 6 a 9 meses do grupo 2 


\subsection{4- Audiometria de Observação Comportamental}

5.2.4.1- Crianças de 3 a 6 meses de idade

Das 21 crianças avaliadas, 18(86\%) apresentaram os resultados dentro dos padrões considerados de normalidade para a faixa etária e $3(14 \%)$ com desvio destes padrões, pois, apesar de apresentar reação de Atenção, Procura da Fonte e Localização Lateral da fonte sonora não apresentaram o reflexo cocleopalpebral (RCP) para o agogô.

A ocorrência das diferentes respostas $(\mathrm{RCP}$, Reação de Sobressalto, Atenção, Procura da Fonte, Localização) para cada um dos estímulos instrumentais utilizados (Guizo, Sino, Blackblack, Agogô), está registrada na tabela 24. 
Tabela 24 - Distribuição da freqüência de ocorrência das respostas a sons instrumentais, nas crianças de 3 a 6 meses do grupo 2

\begin{tabular}{|c|c|c|c|c|c|c|}
\hline & $\begin{array}{l}\text { RCP } \\
(\mathbf{N})\end{array}$ & $\begin{array}{c}\mathbf{R C P}+\mathbf{S} \\
\text { (N) }\end{array}$ & $\begin{array}{c}\text { ATENÇÃO } \\
\text { (N) }\end{array}$ & $\begin{array}{l}\text { PROCURA } \\
\text { (N) }\end{array}$ & $\begin{array}{c}\text { LOCALIZAÇÃO } \\
\text { (N) }\end{array}$ & $\begin{array}{l}\text { TOTAL } \\
\text { (N) }\end{array}$ \\
\hline A & - & - & $9(43 \%)$ & $9(43 \%)$ & $3(14 \%)$ & $21(100 \%)$ \\
\hline B & - & - & $12(57 \%)$ & $6(29 \%)$ & $3(14 \%)$ & $21(100 \%)$ \\
\hline \multirow[t]{2}{*}{$\mathrm{C}$} & - & - & $10(48 \%)$ & $7(33 \%)$ & $4(19 \%)$ & $21(100 \%)$ \\
\hline & $16(76 \%)$ & $2(9,5 \%)$ & $1(5 \%)$ & $2(9,5 \%)$ & - & $21(100 \%)$ \\
\hline
\end{tabular}

RCP- reflexo cocleopalpebral

RCP+S- reflexo cocleopalpebral + reação de sobressalto

PROCURA- procura da fonte

LOCALIZAÇÃO- localização lateral
A- guizo
B- sino
C- black-black
D- agogô 


\subsubsection{2- Crianças de 6 a 9 meses}

Das 8 crianças avaliadas, $3(37,5 \%)$ apresentaram as reações consideradas como esperadas para a idade. Em 5(62,5\%) os resultados mostraram-se alterados pois, apesar de apresentar reação de Localização Lateral da fonte sonora, não apresentaram o reflexo cocleopalpebral (RCP) para o agogô.

A ocorrência das diferentes respostas $(\mathrm{RCP}$, Reação de Sobressalto, Atenção, Procura da Fonte, Localização), para cada um dos estímulos instrumentais utilizados (Guizo, Sino, Blackblack, Agogô), está demonstrada na tabela 25.

Tabela 25 - Distribuição da freqüência de ocorrência de respostas a sons instrumentais, nas crianças de 6 a 9 meses de idade do grupo 2

\begin{tabular}{|c|c|c|c|c|c|c|}
\hline & $\begin{array}{l}\mathbf{C P} \\
\text { (N) }\end{array}$ & $\begin{array}{c}\mathbf{R C P}+\mathbf{S} \\
\text { (N) }\end{array}$ & $\begin{array}{c}\text { ATENÇÃO } \\
\text { (N) }\end{array}$ & $\begin{array}{c}\text { PROCURA } \\
\text { (N) }\end{array}$ & $\begin{array}{c}\text { LOCALIZAÇÃO } \\
\text { (N) }\end{array}$ & $\begin{array}{c}\text { TOTAL } \\
\text { (N) }\end{array}$ \\
\hline A & - & - & - & - & $8(100 \%)$ & $8(100 \%)$ \\
\hline B & - & - & - & - & $8(100 \%)$ & $8(100 \%)$ \\
\hline $\mathrm{C}$ & - & - & - & - & $8(100 \%)$ & $8(100 \%)$ \\
\hline $\mathrm{D}$ & $3(37,5 \%)$ & - & - & - & $5(62,5 \%)$ & $8(100 \%)$ \\
\hline
\end{tabular}

$\mathrm{RCP}$ - reflexo cocleopalpebral $\mathrm{RCP}+\mathrm{S}$ - reflexo cocleopalpebral + reação de sobressalto PROCURA- procura da fonte LOCALIZAÇÃO- localização lateral
A- guizo
B- sino
C- black-black
D- agogô 


\subsection{5- Audiometria de Reforço Visual}

\subsubsection{1- Crianças de 3 a 6 meses}

Das 21 crianças avaliadas, encontramos tanto para a OD, como para a OE $100 \%$ dos casos com niveis de respostas dentro dos padrões considerados de normalidade para a faixa etária.

As ocorrências dos niveis de respostas para tons puros obtidos para as freqüências de $500 \mathrm{~Hz}, 1000 \mathrm{~Hz}, 2000 \mathrm{~Hz}$ e $4000 \mathrm{~Hz}$ para o lado direito e esquerdo estão descritas na tabela 26.

Tabela 26 - Distribuição da ocorrência dos níveis de respostas para tons puros obtidos para as freqüências de $500 \mathrm{~Hz}, 1000 \mathrm{~Hz}, 2000 \mathrm{~Hz}$ e $4000 \mathrm{~Hz}$ para o lado direito e esquerdo das crianças de 3 a 6 meses do grupo 2

\begin{tabular}{ccccccc}
\hline \multicolumn{7}{c}{ dBNPS } \\
\hline $\mathbf{H z}$ & & $\mathbf{4 0}$ & $\mathbf{4 5}$ & $\mathbf{5 0}$ & $\mathbf{5 5}$ & $\mathbf{6 0}$ \\
\hline \multirow{2}{*}{$\mathbf{5 0 0}$} & OD & 5 & 0 & 11 & 1 & 4 \\
& OE & 4 & 0 & 11 & 2 & 4 \\
\hline \multirow{2}{*}{$\mathbf{1 0 0 0}$} & OD & 3 & 1 & 11 & 1 & 5 \\
& OE & 3 & 1 & 12 & 1 & 4 \\
\hline \multirow{2}{*}{$\mathbf{2 0 0 0}$} & OD & 3 & 2 & 8 & 3 & 5 \\
& OE & 3 & 1 & 11 & 2 & 4 \\
\hline \multirow{2}{*}{$\mathbf{4 0 0 0}$} & OD & 4 & 1 & 8 & 4 & 4 \\
& OE & 3 & 1 & 11 & 0 & 6 \\
\hline
\end{tabular}

dBNPS - decibel nivel de pressão sonora

$\mathrm{Hz}-$ Hertz

OD - orelha direita

OE - orelha esquerda 
5.2.5.2- Crianças de 6 a 9 meses de idade

Das 8 crianças avaliadas, encontramos tanto para a OD como para a OE, 6 casos (75\%) com niveis de respostas dentro dos padrões considerados de normalidade para a faixa etária e 2 casos $(25 \%)$ com desvio destes padrões.

As ocorrências dos niveis de respostas para tons puros obtidos para as freqüências de $500 \mathrm{~Hz}, 1000 \mathrm{~Hz}, 2000 \mathrm{~Hz}$ e $4000 \mathrm{~Hz}$ para o lado direito e esquerdo estão descritas na tabela 27.

Tabela 27 - Distribuição da ocorrência dos niveis de respostas para tons puros obtidos para as freqüências de $500 \mathrm{~Hz}, 1000 \mathrm{~Hz}, 2000 \mathrm{~Hz}$ e $4000 \mathrm{~Hz}$ para o lado direito e esquerdo das crianças de 6 a 9 meses do grupo 2

\begin{tabular}{ccccccc}
\hline \multicolumn{7}{c}{ dBNPS } \\
\hline \multirow{2}{*}{ Hz } & & $\mathbf{3 0}$ & $\mathbf{3 5}$ & $\mathbf{4 0}$ & $\mathbf{4 5}$ & $\mathbf{6 0}$ \\
\hline \multirow{2}{*}{$\mathbf{5 0 0}$} & OD & 4 & 0 & 2 & 1 & 1 \\
& OE & 3 & 1 & 2 & 1 & 1 \\
\hline \multirow{2}{*}{$\mathbf{1 0 0 0}$} & OD & 4 & 0 & 3 & 0 & 1 \\
& OE & 3 & 1 & 2 & 1 & 1 \\
\hline \multirow{2}{*}{$\mathbf{4 0 0 0}$} & OD & 4 & 0 & 2 & 1 & 1 \\
& OE & 3 & 1 & 2 & 1 & 1 \\
\hline
\end{tabular}

dBNPS - decibel nivel de pressão sonora

$\mathrm{Hz}$ - Hertz

OD - orelha direita

$\mathrm{OE}$ - orelha esquerda 
5.2.6- Emissão otoacústica evocada por estímulo transiente 5.2.6.1- Crianças de 3 a 6 meses

Nos resultados quanto à presença ou ausência de EOAT, das 21 crianças avaliadas nessa faixa etária encontramos: $16(76 \%)$ em que o exame foi realizado bilateralmente; $1(5 \%)$ em que o exame foi realizado unilateralmente e $4(19 \%)$ em que o exame não foi realizado*. Para a OD verificamos ausência de EOAT em 3(14\%); presença em $13(62 \%)$ e exame não realizado* em 5(24\%). Para a OE, EOAT ausente em 3(14\%); presença em $14(67 \%)$ e em 4(19\%) cujo exame não foi realizado* (Figura 17).

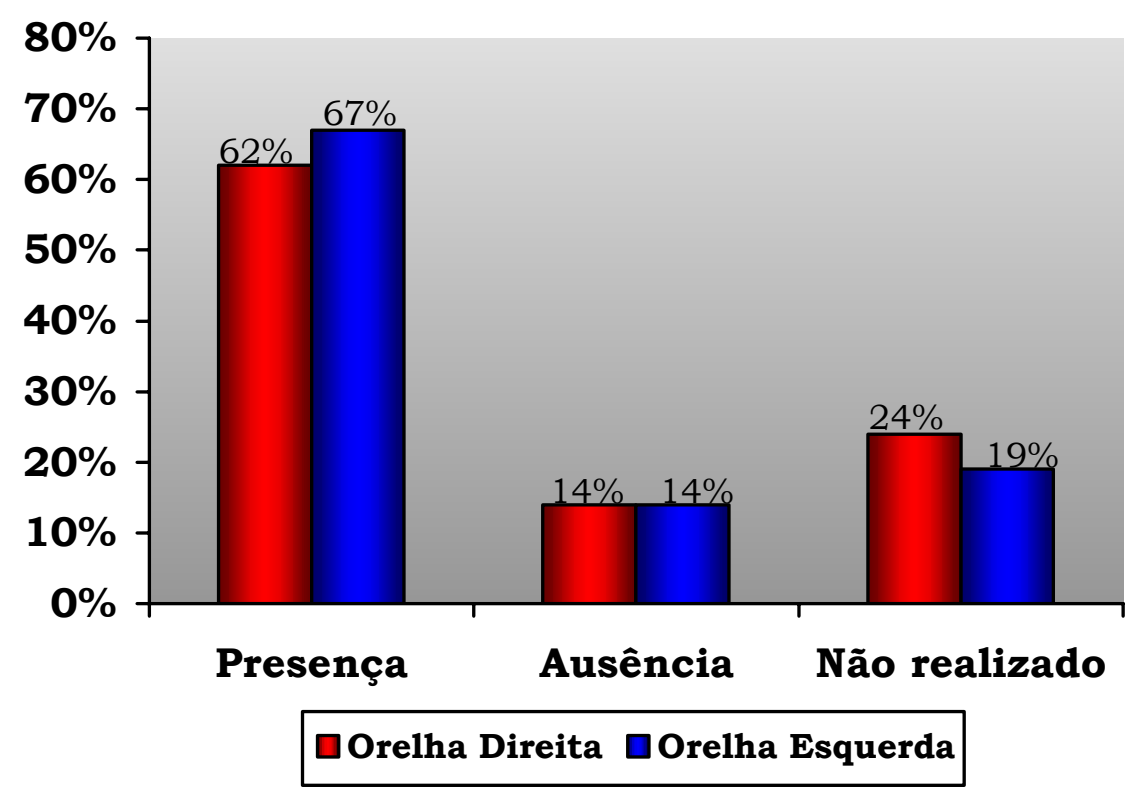

Figura 17- Distribuição da porcentagem de orelhas das crianças de 3 a 6 meses do grupo 2, quanto ao critério presença ou ausência de EOAT

* exame não realizado devido a respiração muito ruidosa, choro. 


\subsubsection{2- Crianças de 6 a 9 meses}

Nos resultados quanto à presença ou ausência de EOAT, das 8 crianças avaliadas nessa faixa etária encontramos: 4(50\%) em que o exame foi realizado bilateralmente; $2(25 \%)$ em que o exame foi realizado unilateralmente e $2(25 \%)$ em que o exame não foi realizado*. Para a OD verificamos ausência de EOAT em 2(25\%); presença em $3(37,5 \%)$ e exame não realizado* em $3(37,5 \%)$. Para a OE, EOAT ausente em $3(37,5 \%)$; presença em $2(25 \%)$ e em $3(37,5 \%)$ em que o exame não foi realizado* (Figura 18).

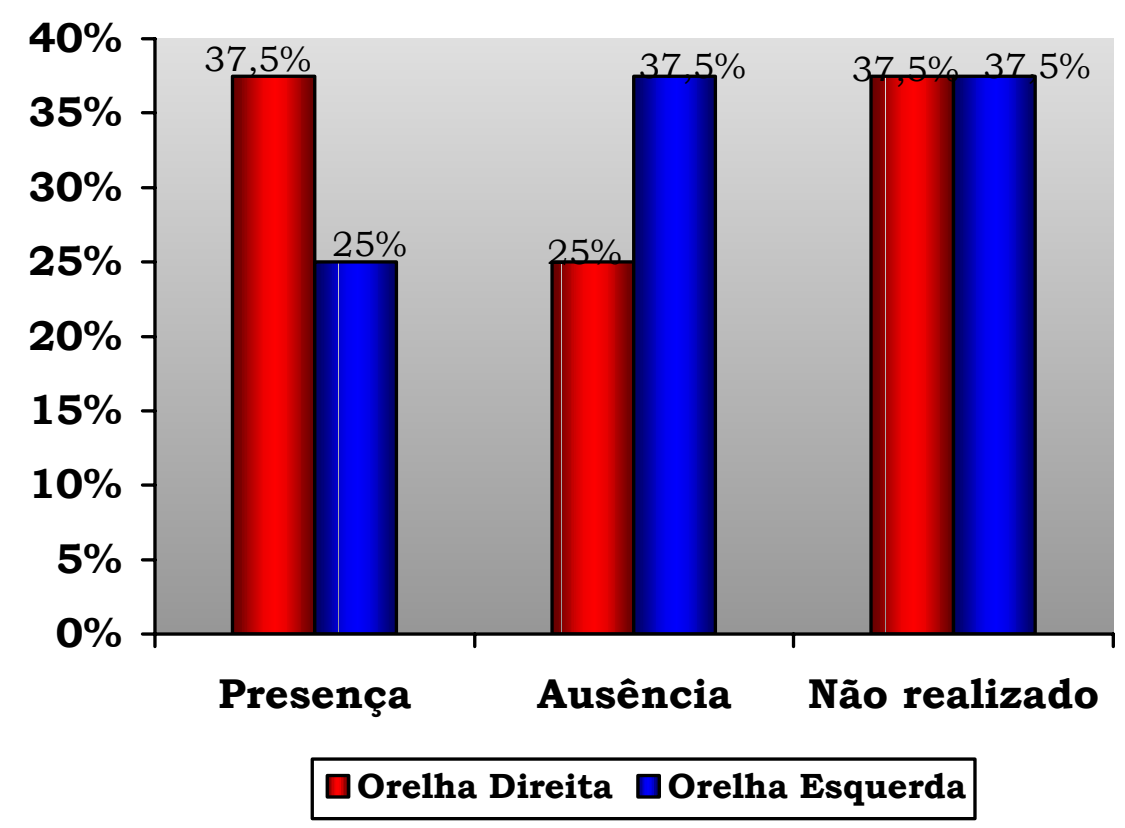

Figura 18- Distribuição da porcentagem de orelhas das crianças de 6 a 9 meses do grupo 2, quanto ao critério presença ou ausência de EOAT

* exame não realizado devido a respiração muito ruidosa, choro. 
Após a análise dos resultados, fizemos a associação dos mesmos entre a EOAT com cada teste separadamente (entrevista audiológica, medidas de imitância acústica, audiometria de reforço visual e audiometria de observação comportamental), por orelha testada, nas 20 crianças que realizaram todos os exames bilateralmente, ou seja, 16 crianças (32 orelhas) na faixa etária de 3 a 6 meses e 4 crianças (8 orelhas) na faixa etária de 6 a 9 meses de idade (Tabelas 28, 29, 30, 31, 32, 33, 34 e 35).

De acordo com o estudo estatístico realizado verificamos diferença estatisticamente significante $(p=0,003)$ quanto à associação entre os dados da EOAT e os dados das medidas de imitância acústica, por orelha testada, das 16 crianças (32 orelhas ) de 3 a 6 meses de idade do grupo 2 que realizaram os exames bilateralmente (Tabela 30). Nas associações realizadas entre os demais procedimentos não foram encontradas diferenças estatisticamente significantes (Tabelas 28, 29, $31,32,33,34$ e 35). 
Tabela 28- Associação dos dados da EOAT com os dados da entrevista audiológica, das 16 crianças de 3 a 6 meses do grupo 2 que realizaram os exames bilateralmente

\begin{tabular}{lccc} 
POSITIVA & PRESENTE & AUSENTE & TOTAL \\
NEGATIVA & $5(31 \%)$ & $1(6 \%)$ & $6(37 \%)$ \\
TOTAL & $7(44 \%)$ & $3(19 \%)$ & $10(63 \%)$ \\
& & & \\
\hline p=1,000 & & & \\
EOAT - Emissão otoacústica evocada por estímulo transiente \\
E.A. - Entrevista Audiológica
\end{tabular}

Tabela 29 - Associação dos dados da EOAT com os dados da entrevista audiológica, das 4 crianças de 6 a 9 meses do grupo 2 que realizaram os exames bilateralmente

\begin{tabular}{|c|c|c|c|}
\hline EOAT & PRESENTE & AUSENTE & TOTAL \\
\hline POSITIVA & 0 & $2(50 \%)$ & $2(50 \%)$ \\
\hline NEGATIVA & $1(25 \%)$ & $1(25 \%)$ & $2(50 \%)$ \\
\hline TOTAL & $1(25 \%)$ & $3(75 \%)$ & $4(100 \%)$ \\
\hline
\end{tabular}


Tabela 30 - Associação dos dados da EOAT com os dados das medidas de imitância acústica, por orelha testada, das 16 crianças (32 orelhas) de 3 a 6 meses do grupo 2 que realizaram os exames bilateralmente

\begin{tabular}{lccc}
\hline & & & \\
\hline NORMAL & $22(69 \%)$ & $1(3 \%)$ & $23(72 \%)$ \\
ALTERADA & $4(12 \%)$ & $5(16 \%)$ & $9(28 \%)$ \\
TOTAL & $26(81 \%)$ & $6(19 \%)$ & $32(100 \%)$ \\
\hline $\begin{array}{l}\text { p=0,003* } \\
\text { EOAT- Emissão Otoacústica Evocada por Transiente } \\
\text { IMIT- Medidas de Imitância Acústica }\end{array}$
\end{tabular}

Tabela 31 - Associação dos dados da EOAT com os dados das medidas de imitância acústica, por orelha testada, das 4 crianças ( 8 orelhas) de 6 a 9 meses do grupo 2 que realizaram os exames bilateralmente

\begin{tabular}{|c|c|c|c|}
\hline EOAT & PRESENTE & AUSENTE & TOTAL \\
\hline NORMAL & $3(37,5 \%)$ & 0 & $3(37,5 \%)$ \\
\hline ALTERADA & $1(12,5 \%)$ & $4(50 \%)$ & $5(62,5 \%)$ \\
\hline TOTAL & $4(50 \%)$ & $4(50 \%)$ & $8(100 \%)$ \\
\hline
\end{tabular}


Tabela 32 - Associação dos dados da EOAT com os dados da audiometria de reforço visual, por orelha testada, das 16 crianças (32 orelhas) de 3 a 6 meses do grupo 2 que realizaram os exames bilateralmente

\begin{tabular}{lccc}
\hline ERA & PRESENTE & AUSENTE & TOTAL \\
NORMAL & $26(81 \%)$ & $6(19 \%)$ & $32(100 \%)$ \\
ALTERADA & 0 & 0 & 0 \\
TOTAL & $26(81 \%)$ & $6(19 \%)$ & $32(100 \%)$ \\
\hline
\end{tabular}

EOAT - Emissão Otoacústica Evocada por Transiente VRA - Audiometria de Reforço Visual

Tabela 33 - Associação dos dados da EOAT com os dados da audiometria de reforço visual, por orelha testada, dos 4 crianças (8 orelhas) de 6 a 9 meses do grupo 2 que realizaram os exames bilateralmente

\begin{tabular}{lccc}
\hline EOAT & PRESENTE & AUSENTE & TOTAL \\
\hline NORMAL & $4(50 \%)$ & $2(25 \%)$ & $6(75 \%)$ \\
ALTERADA & 0 & $2(25 \%)$ & $2(25 \%)$ \\
TOTAL & $4(50 \%)$ & $4(50 \%)$ & $8(100 \%)$ \\
\hline $\mathrm{p}=0,429$ & & &
\end{tabular}

EOAT- Emissão otoacústica evocada por estímulo transiente VRA- Audiometria de Reforço Visual 
Tabela 34 - Associação dos dados da EOAT com os dados da audiometria de observação comportamental das 16 crianças de 3 a 6 meses do grupo 2 que realizaram os exames bilateralmente

\begin{tabular}{lccc} 
EOAT & PRESENTE & AUSENTE & TOTAL \\
NORMAL & $11(69 \%)$ & $4(25 \%)$ & $15(94 \%)$ \\
ALTERADA & $1(6 \%)$ & 0 & $1(6 \%)$ \\
TOTAL & $12(75 \%)$ & $4(25 \%)$ & $16(100 \%)$ \\
\hline $\begin{array}{l}\text { p= } 1,000 \\
\text { EOAT - Emissão otoacústica evocada por estímulo transiente } \\
\text { AOC - Audiometria de Observação Comportamental }\end{array}$
\end{tabular}

Tabela 35 - Associação dos dados da EOAT com os dados da audiometria de observação comportamental das 4 crianças de 6 a 9 meses do grupo 2 que realizaram os exames bilateralmente

\begin{tabular}{lccc}
\hline & & & \\
NORMAL & 0 & $2(50 \%)$ & $2(50 \%)$ \\
ALTERADA & $1(25 \%)$ & $1(25 \%)$ & $2(50 \%)$ \\
TOTAL & $1(25 \%)$ & $3(75 \%)$ & $4(100 \%)$ \\
\hline $\begin{array}{l}\text { p=0,500 } \\
\text { EOAT - Emissão otoacústica evocada por estimulo transiente } \\
\text { AOC - Audiometria de Observação Comportamental }\end{array}$
\end{tabular}




\section{3- Grupo 3}

5.3.1- Entrevista Audiológica com pais e/ou responsável

\subsubsection{1- Crianças de 3 a 6 meses de idade}

Das 5 crianças avaliadas 3(60\%) apresentaram ausência de indicadores de risco para a audição, além da fissura labiopalatina, 2(40\%) apresentaram presença de indicadores de risco para a audição, além da fissura, pois os pais eram tabagistas.

Quanto ao item aleitamento materno, todas as crianças receberam o leite materno por algum tempo, sendo 2 crianças com 3 meses de idade que estavam sendo amamentadas; 1 criança com 7 meses sendo amamentada; 1 foi amamentada por 15 dias e 1 por 3 meses.

\subsection{2- Meatoscopia}

Em nenhuma criança foi observado cerume no MAE ou algum outro impedimento para a realização dos exames.

\subsection{3- Medidas de Imitância Acústica}

5.3.3.1- Crianças de 3 a 6 meses de idade

Das 5 crianças avaliadas observamos 3(60\%) com curva timpanométrica normal (tipo A) bilateral e 2(40\%) com curva alterada, sendo 1 criança com curva alterada unilateral e 1 com curva alterada bilateralmente. Para a OD $4(80 \%)$ com timpanometria tipo A e $1(20 \%)$ com curva tipo B. Para a OE verificamos $3(60 \%)$ com timpanometria tipo A e 2(40\%) com curva tipo B (Figura 19). 


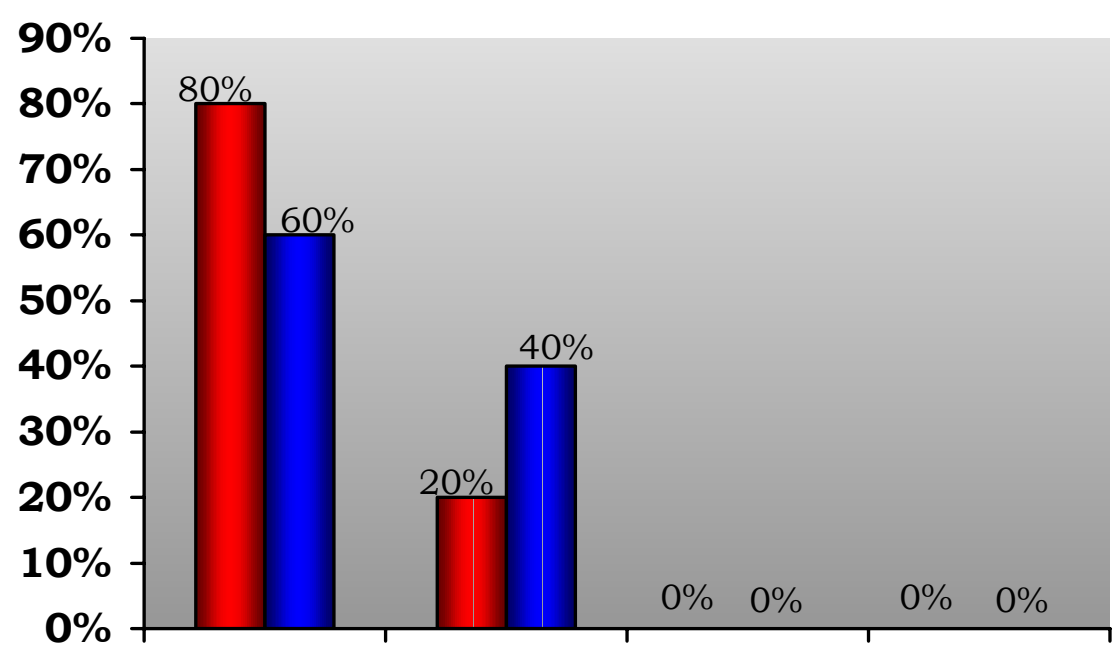

Tipo A Tipo B Tipo C Tipo As

DOrelha Direita DOrelha Esquerda

Figura 19- Distribuição da porcentagem de orelhas segundo o critério tipo de curva timpanométrica do grupo 3

\subsection{4- Audiometria de Observação comportamental}

5.3.4.1- Crianças de 3 a 6 meses de idade

Das 5 crianças avaliadas, todas (100\%) apresentaram os resultados dentro dos padrões considerados de normalidade para a faixa etária.

A ocorrência das diferentes respostas (RCP, Reação de Sobressalto, Atenção, Procura da Fonte, Localização) para cada um dos estímulos instrumentais utilizados (Guizo, Sino, Blackblack, Agogô), está relacionada na tabela 36. 
Tabela 36 - Distribuição da freqüência de ocorrência de respostas a sons instrumentais, nas crianças do grupo 3

\begin{tabular}{cccccc}
\hline $\begin{array}{r}\text { RCP } \\
(\mathbf{N})\end{array}$ & $\begin{array}{r}\text { RCP+S } \\
(\mathbf{N})\end{array}$ & $\begin{array}{r}\text { ATENÇÃO } \\
(\mathbf{N})\end{array}$ & $\begin{array}{c}\text { PROCURA } \\
(\mathbf{N})\end{array}$ & $\begin{array}{c}\text { LOCALIZAÇÃO } \\
(\mathbf{N})\end{array}$ & $\begin{array}{c}\text { TOTAL } \\
(\mathbf{N})\end{array}$ \\
\hline- & - & $2(40 \%)$ & $1(20 \%)$ & $2(40 \%)$ & $5(100 \%)$ \\
- & - & $2(40 \%)$ & $1(20 \%)$ & $2(40 \%)$ & $5(100 \%)$ \\
- & - & $3(60 \%)$ & - & $2(40 \%)$ & $5(100 \%)$ \\
$5(100 \%)$ & - & - & - & & $5(100 \%)$ \\
\hline
\end{tabular}

RCP- reflexo cocleopalpebral

A- guizo

$\mathrm{RCP}+\mathrm{S}-$ reflexo cocleopalpebral + reação de sobressalto

B- sino

PROCURA- procura da fonte

C- black-black

LOCALIZAÇÃO- localização lateral

D- agogô

\subsection{5- Audiometria de Reforço Visual}

\subsubsection{1- Crianças de 3 a 6 meses de idade}

Das 5 crianças avaliadas, encontramos tanto para a OD como para a OE 100\% dos casos com níveis de respostas dentro dos padrões considerados de normalidade para a faixa etária. 
As ocorrências dos níveis de respostas para tons puros obtidos para as freqüências de $500 \mathrm{~Hz}, 1000 \mathrm{~Hz}, 2000 \mathrm{~Hz}$ e $4000 \mathrm{~Hz}$ para o lado direito e esquerdo estão descritas na tabela 37.

Tabela 37 - Distribuição da ocorrência dos níveis de respostas para tons puros obtidos para as freqüências de $500 \mathrm{~Hz}, 1000 \mathrm{~Hz}, 2000 \mathrm{~Hz}$ e $4000 \mathrm{~Hz}$ para o lado direito e esquerdo das criança do grupo 3

\section{dBNPS}

\begin{tabular}{cccccccc}
\hline $\mathbf{H z}$ & & $\mathbf{3 0}$ & $\mathbf{3 5}$ & $\mathbf{4 5}$ & $\mathbf{5 0}$ & $\mathbf{5 5}$ & $\mathbf{6 0}$ \\
\hline \multirow{2}{*}{$\mathbf{5 0 0}$} & OD & 1 & 0 & 1 & 1 & 1 & 1 \\
& OE & 0 & 1 & 0 & 2 & 2 & 0 \\
\hline \multirow{2}{*}{$\mathbf{1 0 0 0}$} & OD & 1 & 0 & 1 & 2 & 1 & 0 \\
& OE & 0 & 1 & 0 & 2 & 2 & 0 \\
\hline \multirow{2}{*}{$\mathbf{2 0 0 0}$} & OD & 1 & 0 & 0 & 2 & 1 & 1 \\
& OE & 1 & 0 & 1 & 0 & 0 & 3 \\
\hline \multirow{2}{*}{$\mathbf{4 0 0 0}$} & OD & 0 & 1 & 0 & 1 & 2 & 1 \\
& OE & 1 & 0 & 1 & 0 & 2 & 1 \\
\hline
\end{tabular}

dBNPS - decibel nível de pressão sonora

$\mathrm{Hz}-$ Hertz

OD - orelha direita

OE - orelha esquerda 
5.3.6- Emissão otoacústica evocada por estímulo transiente

5.3.6.1- Crianças de 3 a 6 meses de idade

Nos resultados quanto à presença ou ausência

de EOAT, das 5 crianças avaliadas nessa faixa etária o exame foi

realizado bilateralmente em todos os casos(100\%). Para a OD

verificamos ausência de EOAT em 1(20\%) e presença em 4(80\%). Para a OE, ausência de EOAT em 2(40\%); presença em 3(60\%) (Figura 20).

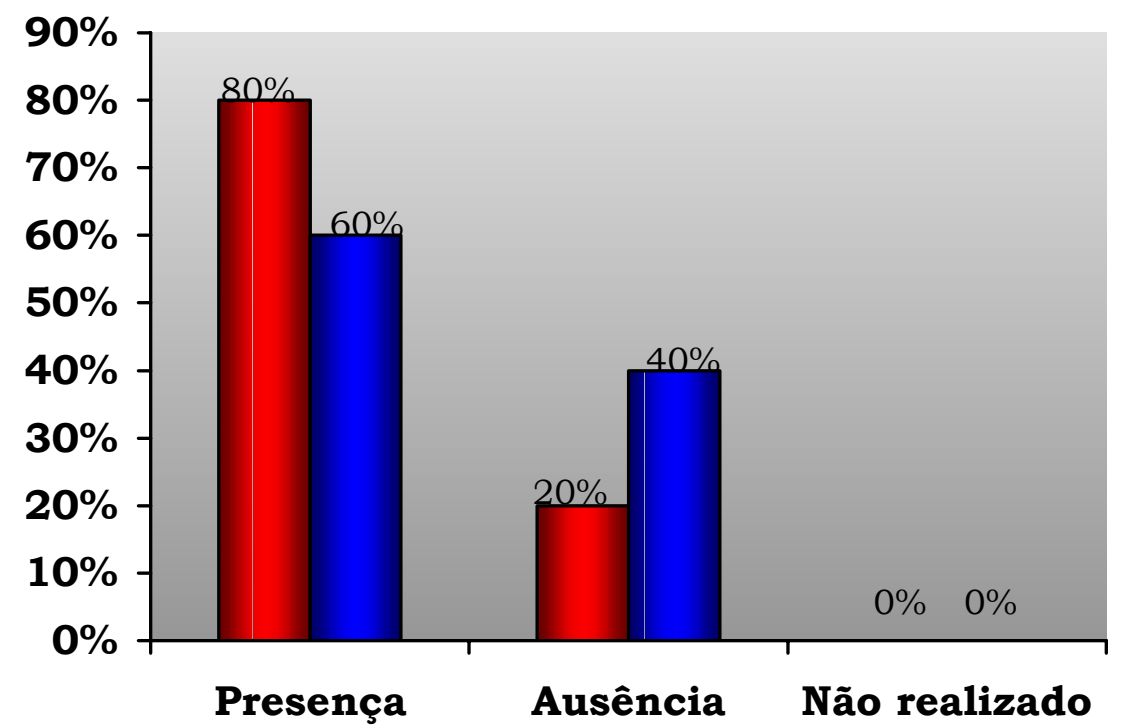

口Orelha Direita DOrelha Esquerda

Figura 20- Distribuição da porcentagem de orelhas das crianças do grupo 3, quanto ao critério presença ou ausência de EOAT 
Após a análise dos resultados, realizamos a associação dos mesmos entre a EOAT com cada teste separadamente (entrevista audiológica, medidas de imitância acústica, audiometria de reforço visual e audiometria de observação comportamental), por orelha testada, nas 5 crianças que realizaram todos os exames bilateralmente (Tabelas 38, 39, 40 e 41).

De acordo com o estudo estatístico realizado verificamos diferença estatisticamente significante $(\mathrm{p}=0,008)$ quanto à associação entre os dados da EOAT com os dados das medidas de imitância acústica, por orelha testada, das 5 crianças (10 orelhas ) do grupo 3 que realizaram os exames bilateralmente (Tabela 39). Nas associações realizadas entre as EOAT e os demais procedimentos não foram encontradas diferenças estatisticamente significantes (Tabelas 38, 40 e 41). 
Tabela 38 - Associação dos dados da EOAT com os dados da, entrevista audiológica, das 5 crianças de 3 a 6 meses do grupo 3 que realizaram os exames bilateralmente

\begin{tabular}{lccc}
\hline & EOAT & & \\
POSITIVA & $1(20 \%)$ & $1(20 \%)$ & $2(40 \%)$ \\
NEGATIVA & $2(40 \%)$ & $1(20 \%)$ & $3(60 \%)$ \\
TOTAL & $2(40 \%)$ & $5(100 \%)$ \\
\hline $\begin{array}{l}\text { p=0,700 } \\
\text { EOAT }- \text { Emissão otoacústica evocada por estímulo transiente } \\
\text { E.A. }- \text { Entrevista Audiológica }\end{array}$
\end{tabular}

Tabela 39 - Associação dos dados da EOAT com os dados das medidas de imitância acústica, por orelha testada, das 5 crianças (10 orelhas) do grupo 3 que realizaram os exames bilateralmente

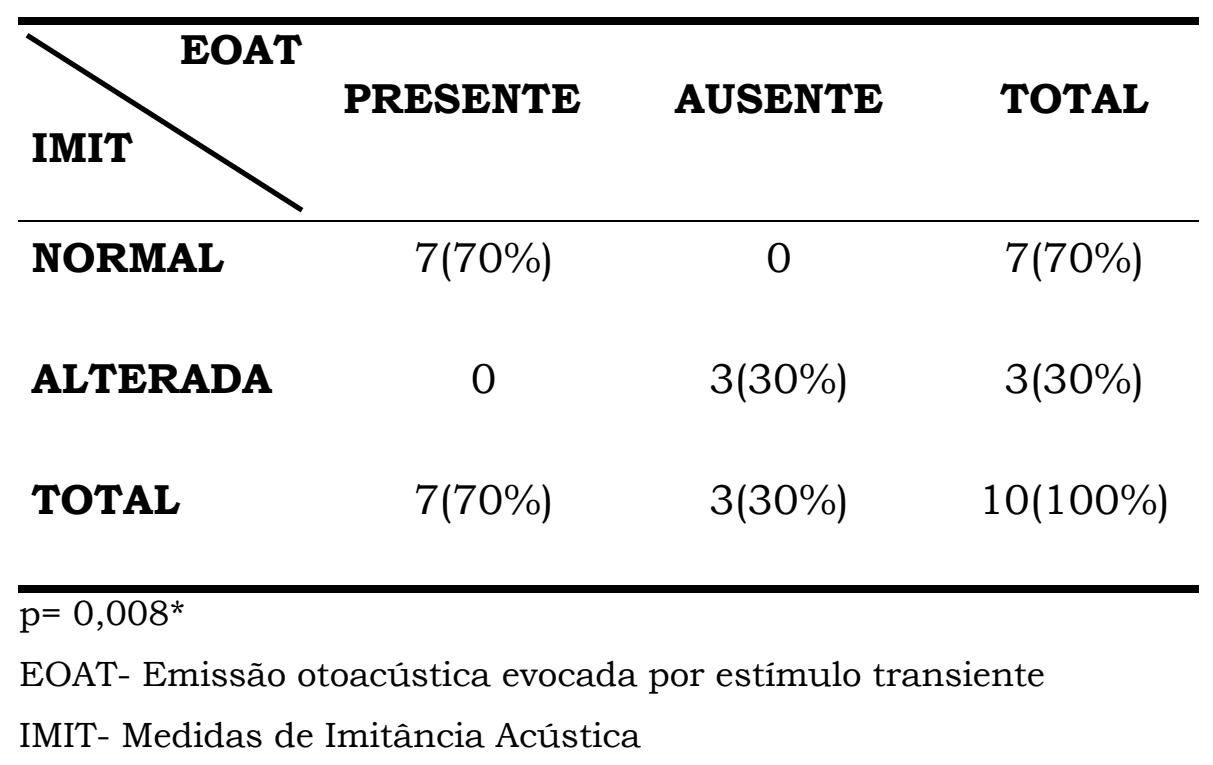


Tabela 40 - Associação dos dados da EOAT com os dados da audiometria de reforço visual, por orelha testada, das 5 crianças (10 orelhas) do grupo 3 que realizaram os exames bilateralmente

\begin{tabular}{lccc}
\hline EOAT & PRESENTE & AUSENTE & TOTAL \\
NORMAL & $7(70 \%)$ & $3(30 \%)$ & $10(100 \%)$ \\
ALTERADA & 0 & 0 & 0 \\
TOTAL & $7(70 \%)$ & $3(30 \%)$ & $10(100 \%)$ \\
\hline
\end{tabular}

EOAT - Emissão otoacústica evocada por estímulo transiente VRA - Audiometria de Reforço Visual

Tabela 41 - Associação dos dados da EOAT com os dados da audiometria de observação comportamental das 5 crianças do grupo 3 que realizaram os exames bilateralmente

\begin{tabular}{lccc}
\hline EOAT & PRESENTE & AUSENTE & TOTAL \\
NORMAL & $3(60 \%)$ & $2(40 \%)$ & $5(100 \%)$ \\
ALTERADA & 0 & 0 & 0 \\
TOTAL & $3(60 \%)$ & $2(40 \%)$ & $5(100 \%)$ \\
\end{tabular}

EOAT - Emissão otoacústica evocada por estímulo transiente AOC - Audiometria de Observação Comportamental 
Seguindo a proposição do trabalho, nas tabelas 42, 43, 44, 45, 46, $47,48,49,50$, e 51 realizamos a associação entre cada procedimento realizado (EOAT, Entrevista Audiológica, Medidas de Imitância Acústica, Audiometria de Observação Comportamental e Audiometria de Reforço Visual) e os 3 grupos participantes do estudo, nas diferentes faixas etárias.

No estudo estatístico obtido verificamos haver diferença estatisticamente significante $(\mathrm{p}<0,001)$ quanto aos dados da EOAT, nas crianças de 3 a 6 meses de idade do grupo 1 , do grupo 2 e do grupo 3 que realizaram os exames bilateralmente. Entre as crianças de 6 a 9 meses de idade dos grupos 1 e 2 também houve diferença estatisticamente significante $(p=0,014)$. A porcentagem de ocorrência de EOAT foi maior nas crianças dos grupos 3 e 2, seguida pelo grupo 1 (Tabela 42).

Quanto à associação dos dados da entrevista audiológica das crianças de 6 a 9 meses de idade do grupo 1 e do grupo 2 a análise revelou diferença estatisticamente significante $(p<0,023)$, sendo que, no grupo 1, 100\% dos casos apresentaram presença de indicadores de risco para a audição e no grupo 2, 50\% dos casos apresentaram presença de indicadores de risco para a audição (Tabela 44). Na faixa etária de 3 a 6 meses de idade a presença de indicadores de risco para a audição foi maior no grupo 1, seguida dos grupos 3 e 2, não sendo, estatisticamente, significante (Tabela 43). 
Tabela 42 - Associação dos dados da EOAT de orelhas de crianças de 3 a 6 meses do grupo 1, grupo 2 e grupo 3 que realizaram os exames bilateralmente, em relação ao total de orelhas testadas

\begin{tabular}{lccc}
\hline POPULAÇÃO & $\begin{array}{c}\text { GRUPO } 1 \\
\text { (N=34) }\end{array}$ & $\begin{array}{c}\text { GRUPO } 2 \\
\text { (N=32) }\end{array}$ & $\begin{array}{c}\text { GRUPO 3 } \\
\text { (N=10) }\end{array}$ \\
\hline PRESENTE & 0 & $26(81 \%)$ & $7(70 \%)$ \\
AUSENTE & $34(100 \%)$ & $6(19 \%)$ & $3(30 \%)$ \\
TOTAL & $34(100 \%)$ & $32(100 \%)$ & $10(100 \%)$ \\
\hline $\begin{array}{l}\mathrm{X}^{2}=47,61 \\
\text { p }<0,001^{*}\end{array}$ & & \\
EOAT - Emissão otoacústica evocada por estímulo transiente
\end{tabular}

Tabela 43 - Associação dos dados da EOAT de orelhas de crianças de 6 a 9 meses do grupo 1 e do grupo 2 que realizaram os exames bilateralmente, em relação ao total de orelhas testadas

\begin{tabular}{|c|c|c|}
\hline EOAT & $\begin{array}{l}\text { GRUPO } 1 \\
(\mathbf{N}=12)\end{array}$ & $\begin{array}{c}\text { GRUPO } 2 \\
(\mathbf{N}=\mathbf{8})\end{array}$ \\
\hline PRESENTE & 0 & $4(50 \%)$ \\
\hline AUSENTE & $12(100 \%)$ & $4(50 \%)$ \\
\hline TOTAL & $12(100 \%)$ & $8(100 \%)$ \\
\hline
\end{tabular}

EOAT - Emissão otoacústica evocada por estímulo transiente 
Tabela 44 - Associação dos dados da entrevista audiológica de crianças de 3 a 6 meses do grupo 1, do grupo 2 e do grupo 3

\begin{tabular}{lccc}
\hline POPULAÇÃO & $\begin{array}{c}\text { GRUPO 1 } \\
\text { (N=28) }\end{array}$ & $\begin{array}{c}\text { GRUPO 2 } \\
\text { (N=2 1) }\end{array}$ & $\begin{array}{c}\text { GRUPO 3 } \\
\text { (N=5) }\end{array}$ \\
\hline POSITIVA & $19(68 \%)$ & $10(48 \%)$ & $2(40 \%)$ \\
NEGATIVA & $9(32 \%)$ & $11(52 \%)$ & $3(60 \%)$ \\
TOTAL & $28(100 \%)$ & $21(100 \%)$ & $5(100 \%)$ \\
\hline
\end{tabular}

$\mathrm{X}^{2}=2,69$

$\mathrm{p}=0,260$

E.A. - Entrevista Audiológica

Tabela 45 - Associação dos dados da entrevista audiológica de crianças de 6 a 9 meses do grupo 1 e do grupo 2

\begin{tabular}{lcc}
\hline E.A. & $\begin{array}{c}\text { GRUPO } 1 \\
(\mathbf{N}=\mathbf{1 0})\end{array}$ & $\begin{array}{c}\text { GRUPO } 2 \\
(\mathbf{N}=\mathbf{8})\end{array}$ \\
\hline POSITIVA & $10(100 \%)$ & $4(50 \%)$ \\
NEGATIVA & 0 & $4(50 \%)$ \\
TOTAL & $10(100 \%)$ & $8(100 \%)$ \\
\hline p= 0,023* & \\
E.A. - Entrevista Audiológica
\end{tabular}


Tabela 46 - Associação dos dados das medidas de imitância acústica de crianças de 3 a 6 meses do grupo 1, do grupo 2 e do grupo 3 que realizaram os exames bilateralmente, de acordo com a orelha testada

\begin{tabular}{lccc}
\hline IMIT & $\begin{array}{c}\text { GOPULAÇÃO } \\
\text { (N=56) }\end{array}$ & $\begin{array}{c}\text { GRUPO } 2 \\
(\mathbf{N}=\mathbf{4 2})\end{array}$ & $\begin{array}{c}\text { GRUPO 3 } \\
(\mathbf{N}=\mathbf{1 0})\end{array}$ \\
\hline NORMAL & $19(34 \%)$ & $27(64 \%)$ & $7(70 \%)$ \\
ALTERADA & $37(66 \%)$ & $15(36 \%)$ & $3(30 \%)$ \\
\hline TOTAL & $56(100 \%)$ & $42(100 \%)$ & $10(100 \%)$ \\
\hline $\begin{array}{l}\mathrm{X}^{2}=10,78 \\
\text { p=0,005* }\end{array}$ & & \\
IMIT - Medidas de Imitância Acústica &
\end{tabular}

Tabela 47- Associação dos dados das medidas de imitância acústica de crianças de 6 a 9 meses do grupo 1 e do grupo 2 que realizaram os exames bilateralmente, de acordo com a orelha testada

\begin{tabular}{lcc}
\hline IMIT & $\begin{array}{c}\text { POPULAÇÃO } \\
(\mathbf{N}=\mathbf{2 0})\end{array}$ & $\begin{array}{c}\text { GRUPO } 1 \\
\text { (N=16) }\end{array}$ \\
\hline NORMAL & $0)$ & $6(37,5 \%)$ \\
ALTERADA & $20(100 \%)$ & $10(62,5 \%)$ \\
TOTAL & $20(100 \%)$ & $16(100 \%)$ \\
\hline p=0,004* & \\
IMIT - Medidas de Imitância Acústica
\end{tabular}


Tabela 48 - Associação dos dados da audiometria de observação comportamental de crianças de 3 a 6 meses do grupo 1, do grupo 2 e do grupo 3

\begin{tabular}{|c|c|c|c|}
\hline AOC & $\begin{array}{l}\text { GRUPO } 1 \\
(\mathbf{N}=\mathbf{2 8})\end{array}$ & $\begin{array}{l}\text { GRUPO } 2 \\
(\mathbf{N}=\mathbf{2 1})\end{array}$ & $\begin{array}{l}\text { GRUPO } 3 \\
\qquad(\mathbf{N}=5)\end{array}$ \\
\hline NORMAL & $14(50 \%)$ & $18(86 \%)$ & $5(100 \%)$ \\
\hline ALTERADA & $14(50 \%)$ & $3(14 \%)$ & 0 \\
\hline TOTAL & $14(100 \%)$ & $21(100 \%)$ & $5(100 \%)$ \\
\hline $\begin{array}{l}X^{2}=9,63 \\
p=0,008^{*}\end{array}$ & & & \\
\hline
\end{tabular}

Tabela 49 - Associação dos dados da audiometria de observação comportamental de crianças de 6 a 9 meses do grupo 1 e do grupo 2

\begin{tabular}{lcc}
\hline & $\begin{array}{c}\text { GRUPO } 1 \\
(\mathbf{N}=\mathbf{1 0})\end{array}$ & $\begin{array}{c}\text { GRUPO 2 } \\
\mathbf{( N = 8 )}\end{array}$ \\
\hline NORMAL & $4(40 \%)$ & $3(37,5 \%)$ \\
ALTERADA & $6(60 \%)$ & $5(62,5 \%)$ \\
TOTALÃO & $10(100 \%)$ & $8(100 \%)$ \\
\hline p= 0,648 & \\
AOC - Audiometria de Observação Comportamental
\end{tabular}


Tabela 50 - Associação dos dados da audiometria de reforço visual de crianças de 3 a 6 meses do grupo 1, do grupo 2 e do grupo 3 que realizaram os exames bilateralmente, de acordo com a orelha testada

\begin{tabular}{lccc}
\hline VRA & $\begin{array}{c}\text { GRULAÇÃO } \\
\text { (N=56) }\end{array}$ & $\begin{array}{c}\text { GRUPO } 2 \\
(\mathbf{N}=\mathbf{4 2})\end{array}$ & $\begin{array}{c}\text { GRUPO } 3 \\
(\mathbf{N}=\mathbf{1 0})\end{array}$ \\
\hline NORMAL & $46(82 \%)$ & $42(100 \%)$ & $10(100 \%)$ \\
ALTERADA & $10(18 \%)$ & 0 & 0 \\
TOTAL & $56(100 \%)$ & $42(100 \%)$ & $10(100 \%)$ \\
\hline $\begin{array}{l}\mathrm{X}^{2}=10,23 \\
\text { p=0,006* }\end{array}$ & & \\
VRA - Audiometria de Reforço Visual &
\end{tabular}

Tabela 51- Associação dos dados da audiometria de reforço visual de crianças de 6 a 9 meses do grupo 1 e do grupo 2 que realizaram os exames bilateralmente, de acordo com a orelha testada

\begin{tabular}{lcc}
\hline PRA & $\begin{array}{c}\text { GRUPO } 1 \\
\text { (N=20) }\end{array}$ & $\begin{array}{c}\text { GRUPO 2 } \\
\text { (N=16) }\end{array}$ \\
\hline NORMAL & $18(90 \%)$ & $12(75 \%)$ \\
ALTERADA & $2(10 \%)$ & $4(25 \%)$ \\
TOTAL & $20(100 \%)$ & $16(100 \%)$ \\
\hline p= 0,374 & & \\
VRA - Audiometria de Reforço Visual
\end{tabular}


No que diz respeito à associação entre os dados das medidas de imitância acústica, o estudo mostrou diferença estatisticamente significante tanto nas crianças de 3 a 6 meses de idade do grupo 1, do grupo 2 e do grupo 3 (p=0,005), como nas crianças de 6 a 9 meses de idade do grupo 1 e do grupo 2 ( $p=0,004)$ (Tabelas 45 e 46). Observamos, nas crianças de 3 a 6 meses de idade, o teste alterado em $66 \%$ das crianças do grupo 1, 36\% nas crianças do grupo 2 e $30 \%$ naquelas do grupo 3. Para as crianças de 6 a 9 meses de idade verificamos resultados alterados das medidas de imitância acústica em $100 \%$ dos casos do grupo 1 e $62,5 \%$ dos casos do grupo 2 .

No estudo realizado entre a associação dos dados da audiometria de observação comportamental de crianças de 3 a 6 meses de idade do grupo 1, do grupo 2 e do grupo 3 , houve diferença estatisticamente significante $(p=0,008)$, enquanto, nas crianças de 6 a 9 meses de idade do grupo 1 e do grupo 2, essa associação não foi estatisticamente significante (Tabelas 48 e 49). Os resultados mostraram que, nas crianças de 3 a 6 meses de idade no grupo 1, 50\% dos casos apresentaram-se alterados, $14 \%$ de casos alterados no grupo 2 e no grupo 3, 100\% dos casos com resultados normais. Para as crianças de 6 a 9 meses de idade verificamos $60 \%$ dos casos alterados no grupo 1 e $62,5 \%$ no grupo 2 .

A análise da associação dos dados da audiometria de reforço visual mostrou diferença estatisticamente significante $(p=0,006)$, apenas crianças de 3 a 6 meses do grupos 1, 2 e 3 (Tabela 50). Nas crianças de 
6 a 9 meses dos grupos 1 e 2 não houve diferença estatisticamente significante (Tabela 51). Para a faixa etária de 3 a 6 meses de idade, observamos resultados alterados em 18\% dos casos do grupo 1 e nos grupos 2 e 3 todas as crianças mostraram resultados normais. Para faixa etária de 6 a 9 meses, $10 \%$ dos casos estavam alterados no grupo 1 e $25 \%$ dos casos do grupo 2 . 


\section{DISCUSSÃO.}

Neste capítulo apresentamos uma análise crítica dos resultados obtidos no presente estudo, no que se refere à ocorrência de EOAT em 82 crianças com fissura labiopalatina não operada, de ambos os gêneros e, na faixa etária de 3 a 12 meses e 20 dias de idade, associando com os resultados da audiometria de observação comportamental (AOC), audiometria de reforço visual (VRA) e medidas de imitância acústica (IMIT), comparando-os com os resultados verificados na literatura especializada consultada.

De acordo com o Joint Committee on Infant Hearing (1994) são 10 os indicadores de risco para a identificação da deficiência auditiva e, dentre esses, destacam-se as anomalias craniofaciais. Sendo assim, todas as crianças envolvidas no presente estudo são consideradas de risco sob o aspecto auditivo, devido à presença da fissura labiopalatina, devendo ser avaliadas e acompanhadas audiológica e otorrinolaringologicamente o mais cedo possivel.

Deste modo, realizamos, como primeira etapa da avaliação audiológica, a entrevista com os pais ou responsáveis, elaborada com base no Joint Committee on Infant Hearing (1994) e em Azevedo et al (1995), cujos resultados dividiram-se entre aqueles que, além da fissura labiopalatina referiram ou não, indicadores de risco para a audição.

Nos 3 grupos avaliados, independente da faixa etária, verificamos que a maioria dos pais ou responsáveis que referiram presença de 
indicadores de risco, além da fissura labiopalatina, eram do grupo 1 (79\%). No grupo $2,48 \%$ dos pais ou responsáveis referiram indicadores de risco para a audição. No grupo 3, 40\%, indicadores de risco para a audição.

Realizando a associação dos dados da entrevista audiológica entre os 3 grupos envolvidos no estudo, observamos diferença estatisticamente significante apenas entre os grupos 1 e 2, nas crianças de 6 a 9 meses de idade, pois no grupo 1 todos apresentaram a presença de um ou mais indicadores de risco e, no grupo 2, 50\% referiram indicadores de risco. Entre as crianças de 3 a 6 meses de idade não se observou diferença estatisticamente significante entre os 3 grupos, porém a presença de indicadores de risco foi maior no grupo 1, seguida pelos grupo 2 e 3.

Entre os indicadores de risco para a deficiência auditiva referidos, comentaremos os três de maior ocorrência em nosso estudo; ou seja, o não aleitamento materno, o tabagismo e a presença de otite média secretora.

Quanto ao aleitamento materno, das 82 crianças avaliadas, 34 não o receberam, nem mesmo através da ordenha. Paradise e Elbster (1994) verificaram que o aleitamento materno é um fator importante na prevenção da otite média. Hubig e Costa (1997) referiram que, através do aleitamento materno, ocorre transferência de anticorpos da mãe para o bebê cujo sistema imunológico não está suficientemente desenvolvido para defendê-lo dos agentes patogênicos encontrados no meio ambiente. 
Essa proteção oferecida ao bebê pela imunoglobulina é considerada na prevenção da otite média aguda.

Observamos que no grupo 1 , das 48 crianças, apenas 17 receberam o aleitamento materno, através da ordenha, durante o periodo de 7 dias a 2 meses. No grupo 2, das 29 crianças, 26 foram amamentadas por um período de 1 a 9 meses. No grupo 3, todas as crianças (5) foram amamentadas por um periodo de 15 dias a 7 meses. Esses resultados parecem mostrar que as crianças com fissura de palato (transforame e pós-forame incisivo), não corrigida cirurgicamente, apresentam maior dificuldade para o aleitamento materno do que as com fissura pré-forame incisivo e fissura de palato submucosa.

Thomé (1990) verificou que a mal formaçãolabiopalatina parece interferir no aleitamento materno acelerando o processo do desmame; quanto mais complexo é o tipo de fissura, mais cedo é o desmame.

Paradise e Elster (1994) defenderam o leite de peito como variável proteção contra o desenvolvimento de otite média com efusão em crianças com fissura labiopalatina porém, normalmente, essas crianças, principalmente as que apresentam fissura de palato, apresentam dificuldade em sugar o peito, não recebendo o leite materno. De acordo com Miguel et al (1998) e Trindade et al (1999), as crianças com fissura de lábio e/ou de palato têm dificuldade em impor pressão negativa na cavidade oral durante a sucção, um pré-requisito para a alimentação ao peito e em mamadeira. 
Como demonstrado, as crianças com fissura labiopalatina podem apresentar dificuldade em se alimentar, principalmente em receber o aleitamento materno. No presente estudo, observamos que mesmo as crianças que receberam o leite materno por meio de ordenha, foi por pouco tempo, não atingindo 4 meses na grande maioria das crianças avaliadas, e a literatura mostra que, para a proteção contra a otite média, são necessários pelo o menos 4 meses de alimentação exclusiva com leite materno (Duncan 1993).

Aniansson et al (2002) e Hanson et al (2002) também relataram a alimentação por meio do leite materno reduzindo a ocorrência de otite média, dentre outras patologias.

Sendo assim, nos indivíduos estudados, além da presença da fissura labiopalatina, a baixa ocorrência ou o curto período de tempo em que as crianças receberam o aleitamento materno, poderiam, também, contribuir para o desenvolvimento da otite média nesta população.

Programas de treinamento e encorajamento às mães de crianças com fissuras labiopalatinas deveriam ser realizados na tentativa de que a alimentação dessas crianças fosse por meio do leite materno e em um maior período de tempo possível, visto sua grande importância, não somente na proteção contra a ocorrência da otite média, mas no desenvolvimento global da criança.

Um outro indicador de risco, também relatado na entrevista audiológica, foi a presença de pais tabagistas. Vários autores 
encontraram uma associação significativa entre crianças com otite média e pais fumantes dentro de casa. Sih (1999) referiu que o fumo passivo provoca a hiperplasia das células caliciformes, com hipersecreção mucosa e a diminuição do transporte mucociliar, alterando o mecanismo de defesa inespecífica, podendo produzir estado de hipersenssibilidade (Kós e Soares 1999).

Observamos a ocorrência de 18 pais tabagistas, sendo dez no grupo 1, seis no grupo 2 e dois no grupo 3. Etzel et al (1992), Lubianca Neto et al (1996), Hubig e Costa (1997) e Ilicali et al (1999) referiram que o fumo passivo é um dos fatores para o desenvolvimento da otite média. A exposição à fumaça do tabaco pode levar a um maior risco de doenças respiratórias nos primeiros anos de vida, e, ainda a otite média com efusão.

Em relação à otite média secretora, encontramos um total de 11 pais que referiram a sua ocorrência em algum período da vida de seus filhos (6 no grupo 1 e 5 no grupo 2).

Sabemos que é alta a ocorrência de alterações auditivas e otológicas na população com fissura labiopalatina e, dentre elas, destaca-se a otite média secretora. Vários autores atribuem o fato a uma inadequação da musculatura do véu palatino, especialmente do músculo tensor, com conseqüente interferência no mecanismo de abertura da tuba auditiva (Cantekin et al 1980, Doyle 1980, Cantekin et al 1983 e Matsune et al 1991), enquanto outros citam a atuação do 
músculo levantador do véu palatino neste mecanismo (Shprintzen e Croft 1981).

Costa Filho e Piazentin (1997) referiram que nas fissuras palatinas o músculo tensor do véu palatino, responsável pela abertura da tuba auditiva, não encontra força suficiente para a manutenção da sua função, causando a disfunção tubária, pois não ocorrem aberturas intermitentes da tuba auditiva com conseqüente prejuízo de suas outras funções. Para Strupler (1980), isto ocasionará ausência ou redução da aeração da cavidade da orelha média, levando a problemas auditivos e otológicos.

Além da inadequação da musculatura do véu palatino, também podem ser encontradas alterações morfológicas da tuba auditiva, como a hipoplasia do torus tubário e anormalidades na cartilagen tubária (Shprintzen e Croft 1981). Como relatado por vários autores, dentre eles Katz (1989) e Castro (1999), a tuba auditiva tem três funções importantes: equipressiva, de drenagem e de proteção. O conjunto destas funções deve funcionar harmonicamente, pois a alteração de uma delas leva ao comprometimento das outras. Na criança, a tuba auditiva encontra-se mais curta e horizontalizada em relação à nasofaringe e à orelha média. Sendo assim, ocorre uma facilitação para a entrada de substâncias estranhas, como a secreção, tornando-se mais suscetiveis às infecções da orelha média, contribuindo dessa forma para a instalação de uma perda auditiva. Com o crescimento, a tuba auditiva 
torna-se mais longa e verticalizada, protegendo melhor a orelha média de infecções.

Desta forma fica evidente a relação entre a fissura labiopalatina e o funcionamento da tuba auditiva, pois grande parte da literatura afirma que os problemas auditivos na fissura labiopalatina advêm de alterações da orelha média, e teriam como causa principal a disfunção tubária, com conseqüente otite média secretora.

Além da inadequação da musculatura do véu palatino, do fumo passivo, e do não aleitamento materno, outros fatores podem contribuir para o desenvolvimento da otite média secretora, como: antecedentes familiares, processos alérgicos, infecções das vias aéreas superiores, variações sazonais, baixo nível sócio-econômico, dentre outros. Entretanto, nem todos esses fatores foram aqui estudados.

Para tanto, faz-se necessária a realização de estudos futuros para levantamento dos indicadores de risco para a audição, na população com fissura labiopalatina, a fim de se prevenir e/ou minimizar a ocorrência de alterações otológicas e/ou audiológicas encontradas nessa população, visto a escassez desses trabalhos na literatura.

No que diz respeito à avaliação por meio das medidas de imitância acústica, verificamos diferença estatisticamente significante entre as crianças dos grupos 1, 2 e 3, tanto para a faixa etária de 3 a 6 meses, como para a de 6 a 9 meses. Nas crianças de 3 a 6 meses de idade a maior ocorrência de alteração foi no grupo 1 (66\%), seguida pelo grupo 
$2(36 \%)$ e pelo grupo $3(30 \%)$. Na faixa etária de 6 a 9 meses verificamos $100 \%$ de alteração no grupo 1 e $62,5 \%$ no grupo 2. Nas crianças de 9 a 12 meses de idade do grupo 1 verificamos 100\% de alteração. Esses resultados nos mostram maior ocorrência de alterações nas crianças com fissura transforame e pós-forame incisivo e a partir dos 6 meses de idade.

Dessa forma, em concordância com a literatura estudada, podemos dizer que as fissuras apenas de lábio, apresentam menor ocorrência de alterações timpanométricas quando comparadas com as que acometem completamente o palato. Antecedentes familiares, presença de tonsilas palatinas e faríngea, fatores alérgicos, dentre outros, poderiam explicar a ocorrência de otite média observada nos indivíduos com fissura préforame incisivo (Feniman 1998).

Quanto à fissura submucosa (grupo 3), também observamos menor ocorrência de alterações timpanométricas comparando-se com o grupo 1. Existem controvérsias na literatura quanto à ocorrência de perdas auditivas condutivas nos indivíduos com fissura submucosa. Filkenstein et al (1990) relatam que a fissura submucosa é diferente da fissura de palato aberta, pois provavelmente, existe condição patológica isolada do músculo levantador do véu palatino que, normalmente, é essencial para a função velofaringea e não para a dilatação da tuba auditiva.

Dentre as curvas timpanométricas alteradas, encontramos, no grupo 1, maior ocorrência de curvas tipo B (53\%), seguida de curva tipo 
As $(21 \%)$, e curvas tipo C (5\%). No grupo 2 verificamos $17 \%$ de curvas tipo B, $14 \%$ de curvas do tipo As e $12 \%$ de curvas do tipo C. Para o grupo 3 as curvas alteradas foram 30\% do tipo B, resultados estes confirmando os estudos de Handizic-Cuk et al (2001), Fernandes et al (2001) e Feniman e Piazentin-Penna (2002).

As alterações timpanométricas encontradas no grupo 1 (79\%), confirmam a presença do componente condutivo, causado pelo mau funcionamento da tuba auditiva, provavelmente devido à inadequação da musculatura do véu palatino, principalmente, porque as crianças foram todas avaliadas anteriormente à correção cirúrgica do palato, realizada após os 12 meses de idade. Handzic-Cuk et al (1996) referiram que o completo restabelecimento da musculatura do palato, repercutindo em melhora na audição, dá-se após os 6 a 7 anos de idade. Piazentin (1989) verificou melhora na audição após a palatoplastia, porém a maioria dos casos não atingiu a normalidade. Pretendemos, desse modo, realizar o acompanhamento audiológico dessas crianças ao longo do tempo, a fim de verificar o efeito da palatoplastia na audição das mesmas, e caso ocorra a melhora, em que idade.

Considerando as crianças com fissura submucosa (grupo 3) com comportamento auditivo semelhante aos daquelas que não apresentam fissura de palato aberta, como no grupo 2 (fissura pré-forame incisivo), as alterações timpanométricas podem ser explicadas com base nos outros indicadores de risco citados anteriormente tais como os 
antecedentes familiares, infecções de vias aéreas superiores, presença de tonsilas palatinas e faringea e outros, contribuindo para a ocorrência de alterações do tipo condutivo (43\% no grupo 2 e $30 \%$ no grupo 3 ).

Em concordância com nosso estudo, Fernandes et al (2000) encontraram maior ocorrência de alteração timpanométrica em crianças com fissura labiopalatina de 9 a 15 meses de idade, quando comparadas com crianças de 3 a 6 meses de idade, provavelmente, devido à dificuldade de drenagem da secreção da cavidade timpânica associada à alteração da viscosidade da secreção que progride desde o nascimento e alcança um ponto crítico com 17 semanas de vida, como relatou Too Chung (1983) e Fria (1987), também, encontraram alta ocorrência de efusão na orelha média em crianças com fissura labiopalatina (98\%) e Helias et al (1988) observaram que esses problemas aparecem precocemente nessas crianças e estão diretamente relacionados à mal formaçãopalatina.

Realizando a associação dos dados da audiometria de observação comportamental entre os 3 grupos envolvidos no estudo, pudemos encontrar diferença estatisticamente significante entre as crianças de 3 a 6 meses de idade. A maior ocorrência de alteração (50\%) foi no grupo 1, seguida pelo grupo 2, com 14\% de alteração. No grupo 3, 100\% das crianças apresentaram resultados dentro dos padrões considerados de normalidade. 
Nas crianças de 6 a 9 meses de idade, quanto à associação descrita acima, não verificamos diferença estatisticamente significante entre os grupos 1 e 2 , ocorrendo $60 \%$ de alteração no grupo 1 e $62,5 \%$ no grupo 2. Para o grupo 1, na faixa etária de 9 a 12 meses de idade, encontramos $40 \%$ de alteração.

$\mathrm{Na}$ associação dos dados da audiometria de reforço visual entre os 3 grupos do estudo, encontramos diferença estatisticamente significante para a faixa etária de 3 a 6 meses. Entre as crianças de 6 a 9 meses de idade dos grupos 1 e 2 não houve diferença estatisticamente significante. Nas crianças de 3 a 6 meses de idade do grupo 1, ocorreu alteração nos resultados em $18 \%$ dos casos, enquanto as dos grupos 2 e 3 apresentaram resultados dentro dos padrões considerados de normalidade. Nas crianças de 6 a 9 meses verificamos maior ocorrência de alteração no grupo 2 (25\%), seguidas pelas grupo 1 com 10\%. Para as crianças de 9 a 12 meses de idade do grupo 1, verificamos alteração em $10 \%$ dos casos.

Piazentin (1989) estudando crianças maiores, encontrou alteração auditiva em todas as crianças antes da palatoplastia mas, com a cirurgia, houve melhora na audição, pois a ação da musculatura do palato se manifesta, propiciando melhor funcionamento da tuba auditiva e, conseqüentemente, melhores condições para a orelha média. Feniman et al (1999) sugeriram que a fissura palatina parece ser um importante fator a ser considerado, pois verificaram que sujeitos com fissura de palato apresentam limiares aéreos piores do que aqueles com 
fissura apenas de lábio. Handzic-Cuk et al (1996) enfatizaram que até os 6 anos de idade, as crianças com fissura de palato apresentam perda auditiva condutiva moderada à severa. A partir dessa idade, ocorre melhora nos resultados audiológicos porém, sem tendência à normalização. Quanto à fissura submucosa, Brandão e Genaro (1998) referiram que este tipo de fissura pode contribuir para a ocorrência de alteração auditiva devido ao mau funcionamento da tuba auditiva.

Quanto à ocorrência de EOAT verificamos diferença estatisticamente significante nos diferentes tipos de fissura e faixa etária que envolveram o estudo. Nas crianças do grupo 1 (3 a 6 meses e 6 a 9 meses de idade), que realizaram os exames bilateralmente, verificamos $100 \%$ de EOAT ausentes. Ainda neste mesmo grupo, nas crianças de 9 a 12 meses de idade observamos presença de EOAT em apenas $1(10 \%)$ das orelhas avaliadas.

Nas crianças do grupo 2, observamos presença de EOAT em $81 \%$ das orelhas de crianças de 3 a 6 meses e 50\% nas de crianças de 6 a 9 meses de idade. No grupo 3 a ocorrência de EOAT foi em $70 \%$ das crianças que realizaram os exames bilateralmente.

Nos trabalhos pesquisados, também encontramos maior ocorrência de EOAT em crianças com fissura de lábio do que naquelas com fissura de palato. Anteunis et al (1998) verificaram EOAT presente em todas as crianças com fissura de lábio e, naquelas com fissura de palato foi observado presença de EOAT em 6 das 24 orelhas testadas. 
No estudo de Piazentin-Penna e Fenimam (1999) a ocorrência de EOAT foi em $87 \%$ das orelhas de crianças com fissura de lábio entre 3 e 12 meses de idade. O restante das orelhas apresentou EOAT ausentes, com timpanometria alterada, indicando a presença de um componente condutivo levando à ausência das EOAT.

A literatura mostra ausência ou presença reduzida de EOAT em crianças com alterações da orelha média, sem a existência de fissura (Erwing et al 1991, Satoh 1992, Rogowski 1995, Mir Plana et al 1997). Esses resultados estão relacionados às efusões serosas e mucosas, dificultando, provavelmente, a transmissão da EOAT para o meato acústico externo (Erwing et al 1991). Amedee (1995) referiu que o tipo de efusão afeta a presença ou a ausência de EOAT em efusão crônica, uma vez que a efusão mucóide resulta em menor chance de se detectar as emissões. Em nosso estudo, o tipo de efusão não foi considerado.

No teste das EOAT existem alguns aspectos, como choro, sono agitado, respiração ruidosa, dentre outros, que interferem no registro do exame. Aidan et al (1999) mostraram que, quando as crianças não estão em sono profundo ou ruídos fisiológicos estão presentes, como movimentos de deglutição, podem influenciar no registro da EOAT. White et al (1994) referiram que em crianças a partir de 4 a 6 semanas de vida, a dificuldade em alcançar um estado apropriado, aumenta o tempo para a realização da avaliação das EOAT.

Os aspectos acima citados, além do sono agitado, choro, movimentação excessiva, ronco, sucção e/ou movimentos de língua na 
região da fissura não operada, dificultaram a realização das EOAT. Foram necessárias várias tentativas até o término do exame; mesmo assim, não foi possivel realizar o teste em 31 orelhas do grupo 1 e 15 orelhas do grupo 2. Em concordância com a literatura citada, acreditamos que os aspectos mencionados interferiram na realização do teste.

A realização do teste das EOAT foi mais dificil nos grupos 1 e 2, nos quais as cirurgias do lábio e/ou do palato ainda não tinham sido realizadas. Nos casos do grupo 3 (fissura submucosa), conseguimos realizar o teste em todas as crianças. Atribuímos esse fato à fissura de palato submucosa apresentar os planos mucosos oral e nasal íntegros, provavelmente, melhorando as condições para a realização do exame, pois não existe comunicação direta entre as cavidades oral e nasal devido à presença da mucosa recobrindo o palato, diminuindo a ocorrência de alguns fatores citados como interferentes no registro das EOAT, porém não encontramos citações na literatura a esse respeito. Anteunis et al (1998) defenderam o uso das EOAT em recém-nascidos com fissura isolada de lábio e observaram que em bebês com fissura de palato o PAETE poderia ser mais apropriado.

Como não encontramos trabalhos na literatura consultada de EOAT e fissura de lábio e/ou palato operados, sugerimos a realização de pesquisas futuras em crianças com fissura operada, a fim de verificar se, com a cirurgia, a eliminação ou a diminuição dos ruídos conseqüentes da fissura aberta facilitariam o registro das EOAT. 
Também, como parte dos objetivos do trabalho, verificamos a associação dos dados entre as EOAT e cada um dos outros testes realizados.

Quanto à associação entre os dados da EOAT e da entrevista audiológica, não encontramos diferença estatisticamente significante entre as idades e os tipos de fissura envolvidos no estudo.

$\mathrm{Na}$ literatura consultada, não encontramos trabalhos referentes à essa associação. No entanto, Piazentin (1989) estudando crianças com fissura labiopalatina, verificou que grande parte da população avaliada não apresentou nenhum tipo de queixa auditiva, mesmo com resultado alterado da avaliação audiológica. A autora salientou que uma perda auditiva leve pode, muitas vezes, passar despercebida pela família.

Observamos, em nossa rotina de trabalho, que vários pais e/ou responsáveis, quando vêm ao HRAC para a realização das cirurgias e passam por avaliações pré-cirúrgicas, incluindo a avaliação audiológica, omitem informações quanto à queixa auditiva. Por ocasião dos retornos pós-cirúrgicos, muitas vezes, são relatadas queixas referentes à épocas anteriores às cirurgias. Sendo assim, consideramos que no presente estudo os dados quanto à queixa auditiva podem ser maiores do que os referidos por ocasião da cirurgia, ou seja, na época em que realizamos este trabalho.

A associação entre os dados da EOAT e das medidas de imitância acústica, mostrou diferença estatisticamente significante entre as 
crianças de 3 a 6 meses de idade do grupos 2 e 3. Em relação a estes dados, observamos que 4 casos do grupo 1 apresentaram ausência de EOAT com curva timpanométrica normal. Analisando a audiometria de cada uma dessas crianças verificamos que as mesmas estavam alteradas. Nestes, descartamos a presença de um componente condutivo, pois os resultados das medidas de imitância acústica estavam normais. Esses resultados nos permitiram pensar na possibilidade de existir um problema neurossensorial levando à ausência das EOAT porém, os pacientes necessitam ser reavaliados, se necessário, encaminhados para a realização de PAETE, para a confirmação dos dados e encaminhamentos necessários. Como demonstrou a literatura, as EOAT estão ausentes quando existe uma perda auditiva superior a 30 dB (Bonfils e Narcy 1989, Gattaz e Cerruti 1994, Lopes Filho 1996, Kemp 1997, Lopes Filho e Carlos 1997 e Coube e Costa Filho 1998).

Observamos 5 casos do grupo 2 com EOAT presentes, audiometria dentro dos padrões considerados de normalidade e curva timpanométrica alterada.

Erwing et al (1991) analisaram a relação entre perda auditiva condutiva e registro das EOAT, referindo que, quando a perda auditiva condutiva é menor que 20dBNA, não é possivel predizer se a EOAT pode ser registrada ou não. Relacionaram tais achados às efusões serosas e mucosas, provavelmente impedindo a resposta da EOAT da cóclea para o meato acústico externo. 
Autores como Proschel e Eysholdt (1993), Amedee (1995) e Rogowski (1995), em concordância com nosso estudo, verificaram que EOAT presentes, ou com amplitude diminuída, quando na presença de alterações da orelha média e perda auditiva leve, podem afetar a presença ou a ausência das EOAT. Como mencionado anteriormente, de acordo com Amedee (1995), o tipo de efusão na orelha média afeta a presença ou a ausência da EOAT, contradizendo as noções de que as EOAT não são mensuráveis se a timpanometria é anormal ou se o fluído está presente na orelha média.

Quanto à associação entre os dados da EOAT e os dados da VRA e AOC, não encontramos diferença estatisticamente significante entre os os grupos e a faixa etária estudados. No entanto, verificamos EOAT ausentes e ARV e/ou AOC normais. Nos casos que apresentaram essa situação com resultado da imitância alterados, relacionamos a ausência de EOAT ao comprometimento condutivo, como relataram Fuse et al (1993), Mir Plana et al (1997), que observaram falhas no registro da EOAT na presença de anormalidades da orelha média.

Em três crianças do grupo 1, que estavam em boas condições para a realização dos exames, verificamos ausência de EOAT, com resultados normais da avaliação comportamental e das medidas de imitância acústica. A literatura também mostra a ocorrência desta situação. Bonfils et al (1990) verificaram 2\% de casos com EOAT ausentes e audição normal. Uziel e Piron (1991) e Satoh (1992) também referiram 
proporções semelhantes. Este fato pode indicar uma perda auditiva neurossensorial leve, pois de acordo com Bonfils e Narcy (1989), Gattaz e Cerruti (1994), Lopes Filho (1996), Kemp (1997), Lopes Filho e Carlos (1997), Coube e Costa Filho (1998), o exame das EOAT detecta perda a partir de $30 \mathrm{~dB}$. Fichino et al (2000) observaram que uma perda leve, poderia passar despercebida na avaliação comportamental, na qual a intensidade gerada por esses instrumentos ultrapassam a intensidade de $30 \mathrm{~dB}$.

Um outro aspecto a ser considerado quando na ausência de EOAT e medidas de imitância acústica e audiometria normais, é o fato da presença de ruídos provenientes da própria fissura labiopalatina, como respiração e deglutição ruidosas, movimentos de língua no local da fissura, interferindo no registro das EOAT.

Pialarissi e Gattaz (1997) e Gattaz (1999) mostraram que a ausência ocasional das emissões otoacústicas pode ocorrer devido às alterações anatômicas do MAE ou da orelha média, aos problemas relacionados ao equipamento, ou ao excesso de ruído ambiental.

Observamos, no grupo 2, duas crianças com EOAT presente, AOC alterada e curva timpanométrica normal. Para essas crianças, solicitou-se retorno para reavaliação audiológica para definição de conduta. 
O registro das EOAT é, universalmente, utilizado em crianças devido sua forma fácil, rápida e não invasiva de realização, porém na população estudada são necessários outros estudos, em diferentes faixas etárias, diferentes tipos de fissura e períodos após as cirurgias de lábio e palato, para um conhecimento de suas características e aprimoramento da técnica, para verificarmos a real aplicabilidade deste procedimento na população com fissura labiopalatina.

Após a análise critica dos resultados, verificamos maior ocorrência de alterações audiológicas nas crianças com fissura em que o palato está aberto, porém, em menor porcentagem; essas alterações também ocorreram nas crianças com fissura de lábio e fissura de palato submucosa.

Dessa forma, torna-se necessário enfatizar a importância da avaliação audiológica o mais cedo possível na vida dessas crianças. O acompanhamento otorrinolaringológico e audiológico deve ser aplicado rotineiramente a fim de se detectar as alterações otológicas e audiológicas, administrando-se tratamentos adequados, evitando-se, assim, a instalação da perda auditiva e, conseqüentemente, a privação sensorial, o que, provavelmente, acarretaria prejuízo no desenvolvimento da fala, da linguagem e do processamento auditivo. Deste modo, estaríamos visando à saúde auditiva da população com fissura labiopalatina. 


\section{CONCLUSÕES.}

Com base nos resultados obtidos no presente estudo foi possivel concluir:

y maior ocorrência de EOAT nas crianças com fissura em que os planos mucosos oral e nasal estão integros (fissura de palato submucosa e fissura pré-forame incisivo);

y que a associação entre os resultados da EOAT com os dos outros procedimentos realizados, mostrou diferença estatisticamente significante apenas no que diz respeito à associação das EOAT com as medidas de imitância acústica das crianças de 3 a 6 meses de idade dos grupos 2 e 3 ;

\ que o uso das EOAT não mostrou ser um método adequado para a avaliação da audição de bebês com fissura de palato não operada, entretanto, nas crianças com fissura de lábio e de palato submucosa sua aplicabilidade foi mais efetiva. 


\section{REFERÊNCIAS BIBLIOGRÁFICAS.}

Aidan D, Avan P, Bonfils P. Auditory screening in neonates by means of transient evoked otoacoustic emissions: a report of 2,842 recordings. Ann Otol Rhinol Laringol 1999; 108:525-31.

Alt A (1878) apud Heller JC. Hearing loss in patients with cleft palate. In: Bzoch KR, editor. Communicative disorders related to cleft lip and palate. 2nd ed. Boston: Little Brown, 1979. p.100-19.

Amedee RG. The effects of chronic otitis media with effusion on the measurement of transiently evoked otoacoustic emissions. Laryngoscope 1995; 105:589-95.

Aniansson G, Svensson H, Becker M, Ingvarsson L. Otitis media and feeding with breast milk of children with cleft palate. Scand J. Plast Reconstr Surg Hand Surg 2002; 36:9-15.

Anteunis LJC, Brienesse P, Schrander JJ. Otoacoustic emissions in screening cleft lip and/or palate children for hearing loss- a feasibility study. Int J Pediatr Otorhinolaryngol 1998; 44:259-66. 
Azevedo MF. Avaliação audiológica no primeiro ano de vida. In: Lopes Filho O, editor. Tratado de fonoaudiologia. São Paulo: Roca; 1997. p.239-63.

Azevedo MF, Vieira RM, Vilanova LCP. Desenvolvimento auditivo de crianças normais e de alto risco. São Paulo: Plexus; 1995

Beppu R, Hattori T, Yanagita N. Comparisom of TEOAE with play audiometry for screening hearing problems in children. Auris Nasus Larynx 1997; 24:367-71.

Bonfils P, Narcy P. Auditoy screening of infants using evoked otoacoustic emissions. Audiol Practic 1989; 6:4-6.

Bonfils P, Uziel A, Pujol R. Screening for auditory dysfunction in infants by evoked oto-acoustic emissions. Arch Otoloaryngol Head Neck Surg $1988 ; 114: 887-90$.

Bonfils P, Avan P, Francois M, Marie P, Trotoux J, Narcy P. Clinical significance of otoacoustic emissions: a perspective. Ear Hear 1990; $11: 155-8$ 
Brandão GR, Genaro KF. Fissura de palato submucosa e audição. Acta Awho 1998; 17:98-104.

Bray PJ. Click evoked otoacoustic emissions and the development of a clinical otoacoustic hearing test instrument [thesis]. London: University of London; 1989.

Broen PA, Moller KT, Carlstron J, Doyle SS, Devers M, Keeman KM. Comparison of the hearing histories of children with and without cleft palate. Cleft Palate Craniofac J 1996; 33:127-33.

Bütow KW, Louw B, Hugo SR, Grimbeeck RJ. Tensor veli palatini muscle tension sling for eustachian tube function in cleft palate: surgical technique and audiometric examination. $J$ Craniomaxillofac Surg 1991; 19:71-6.

Cantekin EI, Doyle WJ, Bluestone CD. Effect of levator veli palatini muscle excision on eustachian tube function. Arch Otolaryngol 1983; 109:281-4.

Cantekin EI, Phillips DC, Doyle WJ, Bluestone CD, Kimes KK. Effect of surgical alterations of the tensor veli palatini muscle on eustachian tube function. Ann Otol Rhinol Laryngol Suppl 1980; 89(3 Pt 2):47-53. 
Carvallo RMM, Ravagnani MP, Sanches SGG. Influência dos padrões timpanométricos na captação das emissões otoacústicas. Acta Awho 2000; 19:18-25.

Castro JC. Fisiologia da tuba auditiva. In: Caldas Neto S, Sih T. Otologia e audiologia em pediatria. Rio de Janeiro: Revinter; 1999. p.17-8.

Chapchap MJ, Segre CM. Universal newborn hearing screening and transient evoked otoacoustic emissions: new concepts in Brazil.In: III International Congress of Pediatric Audiology; 2000 9-12 maio; Dinamarca, Copenhagen; 2000.

Costa SMB, Costa Filho OA. Estudo das emissões otoacústicas evocadas em recém-nascidos pré-termo. Pró-fono 1998; 10:21-5.

Costa Filho OA, Piazentin SHA. Aspectos otológicos. In: Altmann EBC, editora. Fissuras labiopalatinas. Carapicuiba: Pró-Fono; 1997. p. 485-98.

Croft CB, Shprintzen RJ, Ruben RJ. Hypernasal speech following adenotonsillectomy. Otolaryngol Head Neck Surg 1981; 89:179-88. 
Coube CZV, Costa Filho OA. Emissões otoacústicas: uma visão geral. In: Frota S. Fundamentos de fonoaudiologia. Rio de Janeiro: Guanabara Koogan; 1998. p.95-106.

Doyle WJ, Cantekin EI, Bluestone CD. Eustachian tube function in cleft palate children. Ann Otol Rhinol Laryngol Suppl 1980; 89(3 Pt 2):34-40. Doyle WJ, Reilly JS, Jardini L, Rovnak S. Effect of palatoplasty on the function of the eustachian tube in children with cleft palate. Cleft Palate $J$ 1986; 23:63-8.

Doyle KJ, Burggraaff B, Fijikawa S, Kim J, Macarthur CJ. Neonatal hearing screening with otoscopy, auditory brain stem response, and otoacoustic emissions. Otolaryngol Head Neck Surg 1997; 116:597-603.

Duncan B, Ey J, Holberg CJ, Wright AL, Martinez FD, Taussig LM. Exclusive breast-feeding for at least 4 months protects against otitis media. Pediatrics 1993; 91:867-72.

Elberling C, Parbo J, Johnsen NJ, Bagi P. Evoked acoustic emission: clinical application. Acta Otolaryngol Suppl 1985; 421:77-85. 
Erwig H, Blomer R, Bauer HH. Zur evaluation transitorisch evozierter otoakustischer emissionen bei kindern mit tubenbeluftungsstorungen. Laryngorhinootologie 1991; 70:635-40.

Etzel RA, Pattishall EN, Haley NJ, Fletcher RH, Henderson FW. Passive smoking and middle ear effusion among children in day care. Pediatrics 1992; 90(2 Pt1): 228-32.

Feniman MR. Emissões otoacústicas evocadas por click em indivíduos com audição normal (tese). São Paulo. Escola Paulista de Medicina; 1993.

Feniman MR. Hearing and cleft lip. Braz $J$ Dysmorphol Speech Hear Disord 1998; 1:9-14.

Feniman MR, Piazentin-Penna SHA. Tympanometry in brasilians babies with cleft lip and palate. In: History in the making ; 2002 17-20; Philadelphia, Eua, Philadelphia: American Academy of Audiology; 2002 p.89.

Feniman MR, Donadon DR, Vieira JM. Audição de pacientes com fissura isolada de lábio e com fissura de palato: um estudo comparativo. J Bras Fonoaudiol 1999; 1:44-7. 
Fernandes DR, Piazentin-Penna SHA, Feniman MR. Achados timpanométricos em bebês com fissura transforame incisivo antes das restaurações precoces das lesões labial e palatina. In: Anais do $15^{\circ}$ Encontro Internacional de Audiologia; 2000 14-17 abr.; Bauru, Brasil. Bauru: Hospital de Reabilitação de Anomalias Craniofaciais, Universidade de São Paulo; 2000. p. 62.

Fernandes DR, Piazentin-Penna SHA, Feniman MR. Achados timpanométricos na pré-queiloplastia e pré-palatoplastia em bebês com fissura transforame incisivo. In: Anais do $3^{\circ}$ Encontro Científico da PósGraduação do HRAC, USP; 1999 3-5 dez.; Bauru, Brasil. Bauru: Hospital de Reabilitação de Anomalias Craniofaciais, USP; 1999. p. 36.

Fichino SN, Meyer EP, Lewis DR. Acompanhamento audiológico de crianças com indicadores de risco. Distúrb Comun 2000; 11:313-33.

Filkelstein Y, Talmi YP, Nachmani A, Hauben DJ, Zohar Y. Levator veli palatini muscle and eustachian tube function. Plast Reconstr Surg $1990 ; 85: 684-92$. 
Frable MA, Brandon GT, Theogaraj SD. Velar closure and ear tubings as a primary procedure in the repair of cleft palates. Laryngoscope 1985; 95(9Pt1):1044-6.

Freeland AP, Evans DM. Middle ear disease in the cleft palate infant: its effect on speech and language development. Br J Plast Surg 1981; 34:142-3.

Fria TJ Paradise JL, Sabo DL, Elster BA. Conductive hearing loss in infants and young children with cleft palate. J Pediatr 1987; 111:84-7.

Fuse T, Aoyagi M, Suzuki T, Koike Y. [Clinical application of transiently evoked otoacoustic emissions in screening for auditoy dysfunction]. Nippon Jibiinkoka Gakkai Kaiho 1993; 96:1125-32.

Garcia Velasco M, Yzunga A, Hernandez X, Marques C. Diagnosis and treatment of submucous cleft palate: a review of 108 cases. Cleft Palate $J$ 1988; 25:171-2.

Gattaz G. Registro das emissões otoacústicas evocadas e sua aplicação clinica na audiologia infantil. In: Caldas $\mathrm{N}$, Caldas Neto $\mathrm{S}$, Sih $\mathrm{T}$, editores. Otologia e audiologia em pediatria. Rio de Janeiro: Revinter; 1999. p. 211-5. 
Gattaz G, Cerruti VQ. O uso do registro de emissões otoacústicas evocadas para triagem auditiva em neonatos de risco para deficiência auditiva. Rev Paul Pediatr 1994, 12:291-4.

Goldman JL, Martinez SA, Ganzel TM. Eustachian tube dysfunction and its sequelae with cleft palate. South Med $J$ 1993; 86:1236-7.

Gopalakrishna A, Goleria KS, Raje A. Middle ear function in cleft palate. Br J Plast Surg 1984; 37:558-65.

Gould HJ. Hearing loss and cleft palate: the perspective of time. Cleft Palate J 1990; 27:36-9.

Gravel JS, Wallace IF. Effects of otitis media with effusion on hearing in the first 3 years of life. J Speech Lang Hear Res 2000; 43:631-44.

Gravel JS, Wallace IF, Ruben RJ. Auditory consequences of early mild hearing loss associated with otitis media. Acta Otolaryngol 1996; 116:219-21.

Güneren E, Özsoy Z, Ulay M, Eryilmaz E, Özkal H, Geary PM. A comparision of the effects of Veau-Wardill-kilner palatoplasty and 
Furlow double-opposing Z-platy operations on eustachian tube fuction. Cleft Palate Craniofac J 2000; 37:266-70.

Gutzmann H (1894) apud Hirschberg J. Velopharyngeal insufficiency. Folia Phoniatr 1986; 38:221-76.

Gutzmann A, Gutzmann H (1893) apud Hirschberg J. Velopharyngeal insufficiency. Folia Phoniatr 1986; 38:221-76.

Handzic-Cuk J, Cuk V, Risavi R, Katusic D, Stajner-Katusic. Hearing levels in cleft palate patients. Int $J$ Pediatr Otorhinolaringol 1996; $37: 227-42$.

Handzic-Cuk J, Cuk V, Gluhinic M, Risavi R, Stajner-Katusic S. Timpanometric findings in cleft palate patients: influence of age and cleft type. J Laryngol Otol 2001; 115:91-6.

Hanson LA et al. Breast-feeding, a complex support system for the offspring. Pediatric Int; 2002; 44:347-52.

Hayashi $\mathrm{H}$, Arai S, Yasuda $\mathrm{M}$, Arai $\mathrm{R}$, Fujii $\mathrm{H}$, Imai $\mathrm{T}$ et al. On the otological abnormities of cleft palate patients. Sapporo Igaku Zasshi $1961 ; 20: 64-72$. 
Helias J, Chobaut JC, Mourot M, Lafon JC. Ealrly detection of hearing loss in children with cleft palates by brain-stem auditory response. Arch Otolaryngol Head Neck Surg 1988; 114:154-6.

Hubbard TW, Paradise JL, McWillians BJ, Elster BA, Taylor FH. Consequences of unremitting middle-ear disease in early life: otologic, audiologic, and developmental findings in children with cleft palate. $N$ Engl J Med 1985; 312:1529-34.

Hubig DOC, Costa OA. Otite média: considerações em relação à população de creche. In: Lichitig I, Carvallo RMM, organizador. Audição: abordagens atuais. São Paulo: Pró-fono; 1997. p. 89-117.

Ilicali ÖC, Keles N, Deger K, Savas I. Relationship of passive cigarrette smoking to otitis media. Arch Otolaryngol Head Neck Surg 1999; 125:758-62.

Jerger J. Clinical experience with impedance audiometry. Arch Otolaryngol 1970; 92:311-24.

Johnsen NJ, Bagi P, Elberling, C. Evoked acoustic emissions from the human ear. III. Findings in neonates. Scand Audiol 1983; 12:17-24. 
Joint Committee on Infant Hearing year 1994 position statement. ASHA 1994.

Jury SC. Prevention of severe mucosecretory ear disease and its complications in patients with cleft lip and palate malformations. Folia Phoniatr Logop 1997; 49:177-80.

Katz J. Tratado de audiologia clinica. 3a ed. São Paulo: Manole; 1989.

Kemker FJ. Audiological management of patients with cleft palate and related disorders. In: Bzoch $\mathrm{KR}$, editor. Communicative disorders related to cleft lip and palate. 4th ed. Austin: Pro-Ed; 1997. p.245-60.

Kemp DT. Otoacoustic emission in perspective. In: Robinete, MS, Glatkke TJ. Otoacoustic emissions clinical applications. Stuttgart: Thieme; 1997. p.1-21.

Kemp DT. Stimulated acoustic emissions from within the human auditory system. J Acoust Soc Am 1978; 64:1386-91.

Kemp DT, Ryan S, Bray P. A guide to the effective use of otoacoustic emissions. Ear Hear 1990; 11:93-105. 
Kinnebrew MC, Mc Tigue $\mathrm{Dj}$. Submucous cleft palate: review and two clinical reports. Pediatr Dent 1984; 6:252-8.

Kitajiri M, Sando J, Hashida Y, Doyle WJ. Histopathology of otitis media in infants with cleft and high-arched palates. Ann Otol Rhinol Laryngol 1985; 94(1 Pt 1):44-50.

Koivunen P, Uhari M, Laitakari K, Alho OP, Luotonen J. Otoacoustic emission and tympanometry in children with otitis media. Ear Hear 2000; 21:212-7.

Kono D, Young L, Holtmann B. The association of submucous cleft palate and clefting of the primary palate. Cleft Palate $J 1981 ; 18: 207-9$.

Kós AOA, Soares YCMM. Otite média aguda. In: Caldas N, Caldas Neto S, Sih T. Otologia e audiologia em pediatria. Rio de Janeiro: Revinter; 1999. p.49-52.

Lannois M (1901) apud Heller JC Hearing loss in patients with cleft palate. In: Bzoch KR, editor. Communicative disorders related to cleft lip and palate. 2nd ed. Boston: Little Brown; 1979. p. 100-19. 
Lidén G, Kankkunen A. Visual reinforcement audiometry. Acta Otolaryngol 1969; 67:281-92.

Lopes Filho O, Carlos RC. Emissões otoacústicas. In: Lopes Filho O, editor. Tratado de fonoaudiologia. São Paulo: Roca, 1997. p.221-37.

Lopes Filho O, Carlos R, Thomé D, Eckley C. Emissões otoacústicas transitórias e produtos de distorção na avaliação da audição em recémnascidos com poucas horas de vida. Rev Bras Otorrinolaringol 1996; $62: 220-8$

Lubianca Neto JF, Arrarte JLF, Brinkmann CA, Facco SR, Martins WM. A exposição ambiental ao fumo e o risco de otite média em crianças: avaliação das evidências. Rev Bras Otorrinolaringol 1996; 62:280-93.

Matsune S, Sando I, Takahashi H. Insertion of the tensor veli palatini muscle into the eustachian tube cartilage in cleft palate cases. Ann Otol Rhinol Laryngol 1991; 100:439-46.

Mattucci KF. Cleft palate patient: otologic management. N Y State $J$ Med $1979 ; 79: 333-9$. 
Miguel H, Trindade I, Yamashita R, Genaro K, Marques I, PegoraroKrook M, et al. Pressão intra-oral durante a sucção nutritiva em bebês normais e com fissura de lábio e de palato. In: Anais do II Encontro Científico da Pós-Graduação do HRAC-USP; 1998 4-6 dez; Bauru, Brasil. Bauru: Hospital de Reabilitação de Anomalias Craniofaciais, Universidade de São Paulo; 1998. p.17.

Mir Plana B, Sequi Canet JM, Paredes Cencillo C, Brines Solanes J. [Influence of middle ear on the measurement of otoacoustic emissions]. An Esp Pediatr 1997; 47:162-6.

Molini E, Simoncelli C, Ricci G Capolunghi B, Alunni N, Von Garrel C. Die evoziertn otoakustischen emissionem (EOE) als padaudiologische screenigmethode. Laryngorhinootologie 1991; 70:412-6.

Moller P. Hearing, middle ear pressure and otopathology in a cleft palate population. Acta Otolaryngol 1981; 92:521-8.

Moss ALH, Jones KJ, Piggot RW. Submucous cleft palate in the differential diagnosis of feeding difficulties. Arch Dis Child 1990; $65: 182-4$ 
Northern JL, Downs MP. Behavioral hearing testing of children. In: Northern JL, Downs MP. Hearing in children. 4th. ed. Baltimore: Willians Wilkins; 1991. p.139-87.

Norton SJ, Widen JE. Evoked otoacoustic emissions in normal-hearing infants and children: emerging data and issues. Ear Hear 1990; $11: 121-7$

Nunn DR, Derkay CS, Darrow DH, Magee W, Strasnick B. The effect of very early cleft palate closure on the need for ventilation tubes in the first years of life. Laryngoscope 1995; 105(9 Pt 1):905-8.

Oliveira RP. Relação entre os sinais clínicos da fissura de palato submucosa e a sintomatologia especifica: uma abordagem preventiva (dissertação). Bauru: Hospital de Reabilitação de Anomalias Craniofaciais, Universidade de São Paulo; 2002.

Paradise JL, Elster BA. Evidence in infants with cleft palate that breast milk protects against otitis media. Pediatrics 1994; 94:853-60.

Pialarissi PR, Gattaz G. Emissões otoacústicas: conceitos básicos e aplicações clínicas. Arq Fund Otorrinolaringol Fac Med Universidade de São Paulo 1997; 1:41-3. 
Piazentin SHA. A influência da palatoplastia primária nas alterações do ouvido médio (dissertação). São Paulo: Pontificia Universidade Católica; 1989.

Piazentin-Penna SHA, Feniman MR. Avaliação audiológica em bebês com fissura de lábio (estudo preliminar). In: Anais da $5^{a}$ Jornada de Fonoaudiologia da Unesp de Marília; 1999 12-15 ago; Marília, Brasil. Marília: Fundação para o Desenvolvimento do Ensino, Pesquisa e Extensão; 1999. p.31.

Proschel U, Eysholdt U. Evoked otoacoustic emissions in children in relation to middle ear impedance. Folia Phoniatr 1993; 45:288-94.

Ribeiro M. Achados otoscópicos e audiométricos nos portadores de fissura pós-forame incisivo (dissertação). São Paulo: Escola Paulista de Medicina; 1987.

Roberts JE, Burchinal MR, Medley LP, Zeizel SA, Mundy M, Roush J, et al. Otitis media, hearing sensitivity, and maternal responsiveness in relation to language during infancy. J Pediatr 1995; 126:481-9. 
Robinson PJ, Lodje S, Jones BM, Walker CC, Grant HR. The effect of palate repair on otitis media with effusion. Plast Reconstr Surg 1992; 89: 640-5.

Rogowski M. WywoLane otoakustyczne emisjen (TEOAE) u dzieci $z$ zaburzeniami czynnosci trabki sLuchowej. Otolaryngol Pol 1995; 49:238-42.

Rynnel-Dagöö B, Linderberg K, Bagger-Sjöbäck D, Larson O. Middle ear disease in cleft palate children at three years old of age. Int $J$ Pediatr Otorhinolaryngol 1992; 23:201-9.

Sataloff J, Fraser, M. Hearing loss in children cleft palates. Arch Otolaryngol 1952; 55:61-4.

Satoh N. [A study of auditory screening in infant by rvoked otoacoustic emission (EOAE)]. Hokkaido Igaku Zasshi 1992; 67:259-71.

Schonweiler R, Lisson JA, Schonweiler B, Eckardt A, Ptok M, Trankmann J, et al. A retrospective study of hearing, speech, and language function in children with clefts following palatoplaty and veloplasty procedures at 18-24 months of age. Int $J$ Pediatr Otorhinolaryngol 1999; 50:205-17. 
Seagle MB, Nackashi JA, Kemker FJ, Marks RG, Willians WN, Frolova LE, et al. Otologic and audiologic status of Russian children with cleft lip and palate. Cleft Palate Craniofac J 1998; 35:495-9.

Shimo G. Middle ear problems associated with cleft palate. Can $J$ Otolaryngol 1972; 1:9-15.

Shprintzen RJ, Croft CB. Abnormalities of the eustachian tube orifice in individuals with cleft palate. Int $J$ Pediatr Otorhinolaryngol 1981; 3:15-23.

Sih T. Otite média recorrente. In: Caldas N, Caldas Neto S, Sih T. Otologia e audiologia em pediatria. Rio de Janeiro: Revinter; 1999. p.53-7.

Soares E, Guerrero SMA, Azevedo MF. Estudo comparativo das triagens auditivas por emissões otoacústicas transientes, observação comportamental e medidas de imitância acústica em crianças com e sem risco para a deficiência auditiva. Rev Bras Otorrinolaringol 1998; 64(3Pt1):221-7. 
Spina V, Psillaks JM, Lapa FS, Ferreira MC. Classificação das fissuras lábio- palatinas: sugestão de modificação. Rev Hosp Clin Fac Med São Paulo 1972; 27:5-6.

Stockard-Pope, JE. Auditory development and hearing evaluation in children. Advances in Pediatrics 2001; 273-99.

Stenströn C, Ingvarsson L. Late effects on ear disease in otitis-prone children: a long-term follow-up study. Acta Otolaryngol 1995; 115:65863.

Strupler W. Middle ear deafness in infants with cleft palate. Int $J$ Pediatr Otorhinolaryngol 1980; 1:279-83.

Suzuki T, Ogiba Y. Conditioned orientation reflex audiometry. Arch Otolaryngol 1961; 74:192-8.

Takasaki K, Sando I, Balaban CD, Ishijima K. Postnatal development of eustachian tube cartilage: a study of normal and cleft palate cases. Int $J$ Pediatr Otorhinolaryngol 2000; 52:31-6.

Thomé S. Estudo da prática do aleitamento materno em crianças portadoras de malformação congênita de lábio e/ou de palato (mestrado). 
Ribeirão Preto: Escola de Enfermagem de Ribeirão Preto, Universidade de São Paulo; 1990.

Thorington J (1892) apud Heller JC. Hearing loss in patients with cleft palate. In: Bzoch KR, editor. Communicative disorders related to cleft lip and palate. 2nd ed. Boston: Little Brown; 1979. p.100-19.

Todd NW, Krueger BL. Minuscule submucous cleft palate cadaver study. Ann Otol Rhinol Laryngol 1992; 5:417-22.

Too-Chung MA. The assessment of middle ear function and hearing by tympanometry in children before and after early cleft palate repair. $\mathrm{Br} J$ Plast Surg 1983; 36:295-9.

Trindade IEK, Miguel HC, Yamashita RP, Genaro KF, Marques IL, Pegoraro-Krook MI, et al. Nutritive sucking characteristics of infants with cleft lip and palate. In: Proceedings of the $56^{\text {th }}$ Annual Meeting of American Cleft Palate-Craniofacial Association (ACPA);1999; USA Scottsdale;1999. p. 74.

Uziel A, Piron JP. Evoked otoacoustic emissions from normal newborns and babies admitted to an intensive care baby unit. Acta Otolaryngol Suppl 1991; 482:85-91. 
Velasco MG, Ysunza A, Hernandez X, Marques C. Diagnosis and treatment of submucous cleft palate: a review of 108 cases. Cleft Palate $J$ 1988; 25:171-3.

Vernon-Feagans L, Manlove EE, Volling BL. Otitis media and the social behavior of day-care-attending children. Child Dev 1996; 67:1528-39.

Wallace IF Gravel JS, McCarton CM, Stapells DR, Bernstein RS, Ruben RJ. Otitis media, auditory sensitivity, and language outcomes at one year. Laryngoscope 1988; 98:64-70.

Webster JC. Middle ear fuction in the cleft palate. J Laryngol Otol 1980; $94: 31-7$.

White KR, Vohr BR, Maxon AB, Behrens TR, McPherson MG, Mauk GW. Screening all newborns for hearing loss using transient evoked otoacoustic emissions. Int J Pediatr Otorhinolaringol 1994; 29:203-17. 


\section{FONTES CONSULTADAS.}

Universidade se São Paulo. Hospital de Reabilitação de Anomalias Craniofaciais. Guia de orientação para elaboração de dissertações e teses: Curso Pós- Graduação- HRAC- USP. Bauru: Hospital de Reabilitação de Anomalias Craniofaciais, Universidade de São Paulo, 2002. 
Anexo 1 - Aprovação do trabalho pelo comitê de ética em pesquisa

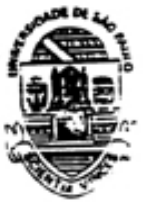

\section{UNIVERSIDADE DE SÃO PAULO \\ HOSPITAL DE REABILTTAÇ̃O DE ANOMALIAS CRANIOFACIAIS}

Ru Hostal. 620. Teletone (0142) 24-317-, EEP 17043.90

BAURU - S.P. - Brasi

Of. Ne 73/98-CEP-UEP

Bauru, 17 de novembro de 1998.

Prezada Senhora

Comunicamos que em reunião do Comitê de Ética em Pesquisa realizada em 30/9/98, o projeto de pesquisa abaixo:

Titulo: Identificação auditiva precoce em bebês com fissura labiopalatina. Pesquisadora: Silvia Helena Alvarez Piazentin Penna

Curso: Doutorado

Após análise, o projeto de pesquisa foi aprovado, pois o mesmo enquadra-se dentro dos principios de ética que orientam as pesquisas em seres humanos.

Atenciosamente

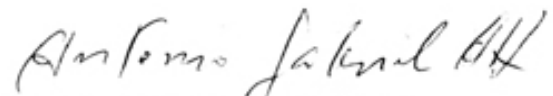

PROF. DR. ANTONIO GABRIEL ATTA

Presidente do Comitê de Ėtica em Pesquisa

IIma. S $r^{\mathrm{a}}$.

Profa. Dra. INGE ELLY KIEMLE TRINDADE

DD. Presidente da Comissăo de Pós-Graduaçăo do HRACF-USP 
Anexo 2 - Protocolo da entrevista audiológica

\section{HOSPITAL DE REABILITAÇÃO DE ANOMALIAS CRANIOFACIAIS UNIVERSIDADE DE SÃO PAULO SETOR DE FONOAUDIOLOGIA}

\section{Identificação}

Nome:

RG: Tipo de fissura:

DN: Idade atual:

Entrevista Audiológica

1- Antecedente familiar de DA

( ) $\operatorname{sim}$ ( ) não

2- Infecções intra- uterinas

( ) $\operatorname{sim}$ ( )não

Citomegalovirus( ) idade gestacional

Rubéola ( ) idade gestacional

Herpes ( ) idade gestacional

Toxoplasmose ( ) idade gestacional

3- Peso ao nascimento menor que $1500 \mathrm{~g}$ ou PIG
4- Hiperbilirrubinenia
( ) $\operatorname{sim}$
( ) não
( ) $\operatorname{sim}$
( ) não

Nivel

5- Meningite bacteriana, especialmente haemofilus influenzae
( ) $\operatorname{sim}$
( ) não

6- Condições de nascimento :

( ) boa ( ) ruim.

Descrever:

7- Incubadora

8- Medicação ototóxica

9- Drogas ou alcoolismo materno

10- Consanguinidade

11- Aleitamento artificial

12- Alergia

13- Tabagismo dos pais

14- Queixa atual

Qual:

15- Doenças otológicas

Qual, quando:

16- IVAS

17- Deficiências imunológicas

18- Creche, berçário, família numerosa

19- Reações a sons

20- Outros

$\begin{array}{ll}\text { ( ) } \operatorname{sim} & \text { ( ) não Tempo__ horas / dia } \\ \text { ( ) } \operatorname{sim} & \text { ( ) não } \\ \text { ( ) } \operatorname{sim} & \text { ( ) não } \\ \text { ( ) } \operatorname{sim} & \text { ( ) não } \\ \text { ( ) } \operatorname{sim} & \text { ( ) não } \\ \text { ( ) } \operatorname{sim} & \text { ( ) não Qual: } \\ \text { ( ) } \operatorname{sim} & \text { ( ) não } \\ \text { ( ) } \operatorname{sim} & \text { ( ) não }\end{array}$
( ) $\operatorname{sim}$
( ) não Quando:

( ) $\operatorname{sim}$ ( ) não

( ) sim ( ) não sons ambientais sons de fala despertar
( ) sim ( ) não

( ) $\operatorname{sim}$ ( ) não

( ) $\operatorname{sim}$ ( ) 
Anexo 3 - Protocolo da avaliação audiológica

\section{HOSPITAL DE REABILITAÇÃO DE ANOMALIAS CRANIOFACIAIS UNIVERSIDADE DE SÃO PAULO SETOR DE FONOAUDIOLOGIA}

Avaliação de Observação Comportamental (AOC)

\begin{tabular}{|l|l|}
\hline $\begin{array}{l}\text { Sons não } \\
\text { calibrados }\end{array}$ & $\begin{array}{c}\text { Reaçõe } \\
\text { s }\end{array}$ \\
\hline Guizo & \\
\hline Sino & \\
\hline $\begin{array}{l}\text { Black- } \\
\text { black }\end{array}$ & \\
\hline Agogô & \\
\hline
\end{tabular}

Avaliação de Reforço Visual (VRA)

\begin{tabular}{|l|l|l|l|l|}
\hline $\begin{array}{l}\text { Sons } \\
\text { calibrados }\end{array}$ & $500 \mathrm{~Hz}$ & $1000 \mathrm{~Hz}$ & $2000 \mathrm{~Hz}$ & $4000 \mathrm{~Hz}$ \\
\hline OD & & & & \\
\hline $\mathrm{OE}$ & & & & \\
\hline
\end{tabular}

Emissão Otoacústica Evocada por Estímulo Transiente (EOAT)

OD ( ) presente ( ) ausente

$\mathrm{OE} \quad($ ) presente ( ) ausente

Medidas de Imitância Acústica (IMIT)

Curva Timpanométrica

OD

$\mathrm{OE}$

Tipo A

Tipo B

( )

( )

Tipo C

( )

( )

Tipo Ad

( )

( )

Tipo As

( )

( )

Compliância Estática

OD $\mathrm{ml}$

$\mathrm{OE}$ $\mathrm{ml}$

OBS 
Anexo 4 - Distribuição da presença ou ausência de indicadores de risco, referidos pelos pais ou responsáveis, além da fissura labiopalatina, nas crianças do grupo 1

\begin{tabular}{|c|c|c|}
\hline Criança & $\begin{array}{l}\text { Idade } \\
\text { Meses }\end{array}$ & Indicadores de risco, além da fissura labiopalatina \\
\hline 1 & $7 \mathrm{~m} 3 \mathrm{~d}$ & Aleitamento artificial \\
\hline 2 & $3 \mathrm{~m} 16 \mathrm{~d}$ & Aleitamento artificial, pais tabagistas \\
\hline 3 & $4 \mathrm{~m} 7 \mathrm{~d}$ & Ausência de indicador de risco \\
\hline 4 & $11 \mathrm{~m} 21 \mathrm{~d}$ & Aleitamento artificial, IVAS \\
\hline 5 & $8 \mathrm{~m} 13 \mathrm{~d}$ & Antecedente familiar de DA, aleitamento artificial, IVAS \\
\hline 6 & $3 \mathrm{~m} 4 \mathrm{~d}$ & Cianose, pais tabagistas \\
\hline 7 & $11 \mathrm{~m} 21 \mathrm{~d}$ & Aleitamento artificial, pais tabagistas \\
\hline 8 & $3 \mathrm{~m} 2 \mathrm{~d}$ & Ausência de indicador de risco \\
\hline 9 & $6 \mathrm{~m} 5 \mathrm{~d}$ & Ausência de indicador de risco \\
\hline 10 & $3 \mathrm{~m} 1 \mathrm{~d}$ & Ausência de indicador de risco \\
\hline 11 & $3 \mathrm{~m} 6 \mathrm{~d}$ & Aleitamento artificial \\
\hline 12 & $12 \mathrm{~m} 7 \mathrm{~d}$ & Aleitamento artificial \\
\hline 13 & $12 \mathrm{~m} 17 \mathrm{~d}$ & OMS, aleitamento artificial \\
\hline 14 & $12 \mathrm{~m} 20 \mathrm{~d}$ & OMS, aleitamento artificial \\
\hline 15 & $4 \mathrm{~m} 11 \mathrm{~d}$ & Pais tabagistas \\
\hline 16 & $6 \mathrm{mOd}$ & Aleitamento artificial, perda auditiva, OMS, \\
\hline 17 & $8 \mathrm{~m} 16 \mathrm{~d}$ & OMS, aleitamento artificial \\
\hline 18 & $6 \mathrm{~m} 1 \mathrm{~d}$ & Incubadora, aleitamento artificial \\
\hline 19 & $3 \mathrm{mOd}$ & Aleitamento artificial, creche \\
\hline 20 & $8 \mathrm{~m} 5 \mathrm{~d}$ & Aleitamento artificial, incubadora \\
\hline 21 & $5 \mathrm{~m} 10 \mathrm{~d}$ & Ausência de indicador de risco \\
\hline 22 & $3 \mathrm{~m} 14 \mathrm{~d}$ & Aleitamento artificial \\
\hline 23 & $3 \mathrm{~m} 8 \mathrm{~d}$ & Aleitamento artificial \\
\hline 24 & $6 \mathrm{~m} 14 \mathrm{~d}$ & Aleitamento artificial, consangüinidade \\
\hline 25 & $3 \mathrm{~m} 13 \mathrm{~d}$ & Ausência de indicador de risco \\
\hline 26 & $12 \mathrm{~m} 5 \mathrm{~d}$ & Aleitamento artificial, pais tabagistas \\
\hline 27 & $12 \mathrm{~m} 11 \mathrm{~d}$ & OMS, aleitamento artificial, cianose, IVAS \\
\hline 28 & $9 \mathrm{~m} 7 \mathrm{~d}$ & IVAS, aleitamento artificial \\
\hline 29 & $9 \mathrm{~m} 7 \mathrm{~d}$ & Aleitamento artificial \\
\hline 30 & $6 \mathrm{~m} 2 \mathrm{~d}$ & Aleitamento artificial \\
\hline 31 & $3 \mathrm{~m} 28 \mathrm{~d}$ & Ausência de indicador de risco \\
\hline 32 & $3 \mathrm{~m} 26 \mathrm{~d}$ & Antecedente familiar de DA, pais tabagistas \\
\hline 33 & $6 \mathrm{~m} 20 \mathrm{~d}$ & Aleitamento artificial \\
\hline 34 & $4 \mathrm{~m} 10 \mathrm{~d}$ & Ausência de indicador de risco \\
\hline 35 & $12 \mathrm{~m} 3 \mathrm{~d}$ & Aleitamento artificial \\
\hline 36 & $12 \mathrm{~m} 10 \mathrm{~d}$ & Aleitamento artificial, pais tabagistas \\
\hline 37 & $6 \mathrm{~m} 8 \mathrm{~d}$ & Aleitamento artificial, pais tabagistas, consangüinidade \\
\hline 38 & $7 \mathrm{~m} 23 \mathrm{~d}$ & Aleitamento artificial, IVAS \\
\hline 39 & $3 \mathrm{~m} 17 \mathrm{~d}$ & Aleitamento artificial \\
\hline 40 & $8 \mathrm{~m} 7 \mathrm{~d}$ & Aleitamento artificial, adotivo \\
\hline 41 & $9 \mathrm{~m} 11 \mathrm{~d}$ & OMSco \\
\hline 42 & $5 \mathrm{~m} 10 \mathrm{~d}$ & Aleitamento artificial \\
\hline 43 & $3 \mathrm{~m} 25 \mathrm{~d}$ & Incubadora \\
\hline 44 & $3 \mathrm{~m} 15 \mathrm{~d}$ & Pais tabagistas \\
\hline 45 & $3 \mathrm{mOd}$ & Pais tabagistas \\
\hline 46 & $3 \mathrm{~m} 15 \mathrm{~d}$ & Aleitamento artificial \\
\hline 47 & $5 \mathrm{~m} 26 \mathrm{~d}$ & Ausência de indicador de risco \\
\hline 48 & $11 \mathrm{~m} 16 \mathrm{~d}$ & Otalgia \\
\hline
\end{tabular}


Anexo 5 - Distribuição da presença ou ausência de indicadores de risco, referidos pelos pais ou responsáveis, além da fissura labiopalatina, nas crianças do grupo 2

\begin{tabular}{cll} 
Criança & $\begin{array}{l}\text { Idade } \\
\text { meses }\end{array}$ & Indicadores de risco, além da fissura labiopalatina \\
1 & $3 \mathrm{~m} 18 \mathrm{~d}$ & Pais tabagistas, otalgia \\
2 & $3 \mathrm{~m} 23 \mathrm{~d}$ & Otalgia \\
3 & $5 \mathrm{~m} 11 \mathrm{~d}$ & Otalgia \\
4 & $3 \mathrm{~m} 5 \mathrm{~d}$ & Ausência de indicador de risco \\
5 & $7 \mathrm{~m} 10 \mathrm{~d}$ & Ausência de indicador de risco \\
6 & $4 \mathrm{~m} 9 \mathrm{~d}$ & Ausência de indicador de risco \\
7 & $5 \mathrm{~m} 12 \mathrm{~d}$ & Ausência de indicador de risco \\
8 & $3 \mathrm{~m} 3 \mathrm{~d}$ & Pais tabagistas, otalgia \\
9 & $3 \mathrm{~m} 14 \mathrm{~d}$ & Otalgia \\
10 & $3 \mathrm{~m} 3 \mathrm{~d}$ & Ausência de indicador de risco \\
11 & $3 \mathrm{~m} 7 \mathrm{~d}$ & Pais tabagistas \\
12 & $3 \mathrm{~m} 15 \mathrm{~d}$ & Pais tabagistas \\
13 & $9 \mathrm{~m} 17 \mathrm{~d}$ & OMS, aleitamento artificial \\
14 & $5 \mathrm{~m} 8 \mathrm{~d}$ & Ausência de indicador de risco \\
15 & $9 \mathrm{~m} 25 \mathrm{~d}$ & Ausência de indicador de risco \\
16 & $3 \mathrm{~m} 3 \mathrm{~d}$ & Ausência de indicador de risco \\
17 & $8 \mathrm{~m} 7 \mathrm{~d}$ & Aleitamento artificial, adotivo \\
18 & $3 \mathrm{~m} 2 \mathrm{~d}$ & Ausência de indicador de risco \\
19 & $4 \mathrm{~m} 19 \mathrm{~d}$ & Cianose \\
20 & $6 \mathrm{~m} 3 \mathrm{~d}$ & Ausência de indicador de risco \\
21 & $8 \mathrm{~m} 14 \mathrm{~d}$ & Pais tabagistas, OMS \\
22 & $5 \mathrm{~m} 11 \mathrm{~d}$ & Ausência de indicador de risco \\
23 & $8 \mathrm{~m} 21 \mathrm{~d}$ & Ausência de indicador de risco \\
24 & $6 \mathrm{~m} 20 \mathrm{~d}$ & Pais tabagistas \\
25 & $4 \mathrm{~m} 4 \mathrm{~d}$ & Pais tabagistas \\
26 & $4 \mathrm{~m} 6 \mathrm{~d}$ & Ausência de indicador de risco \\
27 & $9 \mathrm{~m} 11 \mathrm{~d}$ & Ausência de indicador de risco \\
28 & $4 \mathrm{~m} 4 \mathrm{~d}$ & Aleitamento artificial \\
29 & $4 \mathrm{~m} 16 \mathrm{~d}$ & Ausência de indicador de risco \\
\hline & &
\end{tabular}

OMS - Otite Média Secretora 
Anexo 6- Distribuição da presença ou ausência de indicadores de risco, referidos pelos pais ou responsáveis, além da fissura labiopalatina, nas crianças do grupo 3

\begin{tabular}{|c|c|c|}
\hline Criança & $\begin{array}{l}\text { Idade } \\
\text { meses }\end{array}$ & Indicadores de risco, além da fissura labiopalatina \\
\hline 1 & $3 \mathrm{~m} 5 \mathrm{~d}$ & Pais tabagistas \\
\hline 2 & $3 \mathrm{~m} 15 \mathrm{~d}$ & Ausência de indicadores de risco \\
\hline 3 & $3 \mathrm{~m} 3 \mathrm{~d}$ & Ausência de indicadores de risco \\
\hline 4 & $6 \mathrm{~m} 5 \mathrm{~d}$ & Pais tabagistas \\
\hline 5 & $6 \mathrm{~m} 10 \mathrm{~d}$ & Ausência de indicadores de risco \\
\hline
\end{tabular}


Anexo 7 - Distribuição da ocorrência dos tipos de curvas timpanométricas, nas crianças do grupo 1

Criança

$\begin{array}{ll}1 & 7 \mathrm{~m} 3 \mathrm{~d} \\ 2 & 3 \mathrm{~m} 16 \mathrm{~d} \\ 3 & 4 \mathrm{~m} 7 \mathrm{~d} \\ 4 & 11 \mathrm{~m} 21 \mathrm{~d} \\ 5 & 8 \mathrm{~m} 13 \mathrm{~d} \\ 6 & 3 \mathrm{~m} 4 \mathrm{~d} \\ 7 & 11 \mathrm{~m} 21 \mathrm{~d}\end{array}$

$83 \mathrm{~m} 2 \mathrm{~d}$

$96 \mathrm{~m} 5 \mathrm{~d}$

$10 \quad 3 \mathrm{~m} 1 \mathrm{~d}$

$113 \mathrm{~m} 6 \mathrm{~d}$

12

13

14

15

16

17

18

19

20

21

22

23

24

25

26

27

28

29

30

31

32

33

34

35

36

37

38

39

40

41

42

43

44

45

46

47

48
Idade

meses

$12 \mathrm{~m} 1 \mathrm{~d}$

$12 \mathrm{~m} 17 \mathrm{~d}$

$12 \mathrm{~m} 20 \mathrm{~d}$

$4 \mathrm{~m} 11 \mathrm{~d}$

$6 \mathrm{mod}$

$8 \mathrm{~m} 16 \mathrm{~d}$

$6 \mathrm{~m} 1 \mathrm{~d}$

$3 \mathrm{mod}$

$9 \mathrm{~m} 5 \mathrm{~d}$

$5 \mathrm{~m} 10 \mathrm{~d}$

$3 \mathrm{~m} 14 \mathrm{~d}$

$3 \mathrm{~m} 8 \mathrm{~d}$

$6 \mathrm{~m} 14 \mathrm{~d}$

$3 \mathrm{~m} 13 \mathrm{~d}$

$12 \mathrm{~m} 5 \mathrm{~d}$

$12 \mathrm{~m} 11 \mathrm{~d}$

$9 \mathrm{~m} 7 \mathrm{~d}$

$9 \mathrm{~m} 7 \mathrm{~d}$

$6 \mathrm{~m} 2 \mathrm{~d}$

$3 \mathrm{~m} 28 \mathrm{~d}$

$3 \mathrm{~m} 26 \mathrm{~d}$

$6 \mathrm{~m} 20 \mathrm{~d}$

$4 \mathrm{~m} 10 \mathrm{~d}$

$12 \mathrm{~m} 3 \mathrm{~d}$

$12 \mathrm{~m} 10 \mathrm{~d}$

$6 \mathrm{~m} 8 \mathrm{~d}$

$7 \mathrm{~m} 23 \mathrm{~d}$

$3 \mathrm{~m} 17 \mathrm{~d}$

$8 \mathrm{~m} 7 \mathrm{~d}$

$9 \mathrm{~m} 11 \mathrm{~d}$

$5 \mathrm{~m} 10 \mathrm{~d}$

$3 \mathrm{~m} 25 \mathrm{~d}$

$3 \mathrm{~m} 15 \mathrm{~d}$

$3 \mathrm{mod}$

$3 \mathrm{~m} 15 \mathrm{~d}$

$5 \mathrm{~m} 26 \mathrm{~d}$

$11 \mathrm{~m} 16 \mathrm{~d}$
Tipo de curva timpanométrica

OD

As

As

As

As

B

A

As

A

A

B

As

B

B

B

As

As

B

B

As

As

B

C

As

A

B

A

B

C

B

B

A A

As As

A B

As As

B $B$

$\mathrm{B} \quad \mathrm{B}$

B $\mathrm{B}$

B B

B B

$\mathrm{B} \quad \mathrm{C}$

$\mathrm{B} \quad \mathrm{B}$

A B

A A

A A

A A

B B

B B

OD-orelha direita; OE-orelha esquerda; A-curva timpanométrica tipo A B-curva timpanométrica tipo B; C-curva timpanométrica tipo C;

As-curva timpanométrica tipo As 
Anexo 8 - Distribuição da ocorrência dos tipos de curvas timpanométricas, nas crianças do grupo 2

\begin{tabular}{|c|c|c|c|}
\hline \multirow[t]{2}{*}{ Criança } & \multirow[t]{2}{*}{$\begin{array}{l}\text { Idade } \\
\text { meses }\end{array}$} & \multicolumn{2}{|c|}{ Tipo de curva timpanométrica } \\
\hline & & OD & OE \\
\hline 1 & $3 \mathrm{~m} 18 \mathrm{~d}$ & A & A \\
\hline 2 & $3 \mathrm{~m} 23 \mathrm{~d}$ & A & A \\
\hline 3 & $5 \mathrm{~m} 11 \mathrm{~d}$ & A & A \\
\hline 4 & $3 \mathrm{~m} 5 \mathrm{~d}$ & A & A \\
\hline 5 & $7 \mathrm{~m} 10 \mathrm{~d}$ & A & A \\
\hline 6 & $4 \mathrm{~m} 9 \mathrm{~d}$ & A & A \\
\hline 7 & $5 \mathrm{~m} 12 \mathrm{~d}$ & A & A \\
\hline 8 & $3 \mathrm{~m} 3 \mathrm{~d}$ & $\mathrm{C}$ & A \\
\hline 9 & $3 \mathrm{~m} 14 \mathrm{~d}$ & A & A \\
\hline 10 & $3 \mathrm{~m} 3 \mathrm{~d}$ & A & A \\
\hline 11 & $3 \mathrm{~m} 7 \mathrm{~d}$ & A & A \\
\hline 12 & $3 \mathrm{~m} 15 \mathrm{~d}$ & A & A \\
\hline 13 & $9 \mathrm{~m} 17 \mathrm{~d}$ & B & B \\
\hline 14 & $5 \mathrm{~m} 8 \mathrm{~d}$ & B & $\mathrm{C}$ \\
\hline 15 & $9 \mathrm{~m} 25 \mathrm{~d}$ & As & A \\
\hline 16 & $3 \mathrm{~m} 3 \mathrm{~d}$ & A & A \\
\hline 17 & $8 \mathrm{~m} 7 \mathrm{~d}$ & B & B \\
\hline 18 & $3 \mathrm{~m} 2 \mathrm{~d}$ & As & B \\
\hline 19 & $4 \mathrm{~m} 19 \mathrm{~d}$ & B & C \\
\hline 20 & $6 \mathrm{~m} 3 \mathrm{~d}$ & B & B \\
\hline 21 & $8 \mathrm{~m} 14 \mathrm{~d}$ & $\mathrm{~A}$ & As \\
\hline 22 & $5 \mathrm{~m} 11 \mathrm{~d}$ & As & As \\
\hline 23 & $8 \mathrm{~m} 21 \mathrm{~d}$ & $\mathrm{C}$ & As \\
\hline 24 & $6 \mathrm{~m} 20 \mathrm{~d}$ & A & A \\
\hline 25 & $4 \mathrm{~m} 4 \mathrm{~d}$ & A & A \\
\hline 26 & $4 \mathrm{~m} 6 \mathrm{~d}$ & A & A \\
\hline 27 & $9 \mathrm{~m} 11 \mathrm{~d}$ & B & $\mathrm{C}$ \\
\hline 28 & $4 \mathrm{~m} 4 \mathrm{~d}$ & $\mathrm{C}$ & $\mathrm{C}$ \\
\hline 29 & $4 \mathrm{~m} 16 \mathrm{~d}$ & As & As \\
\hline
\end{tabular}

OD - orelha direita; OE - orelha esquerda;

A- curva timpanométrica tipo A; B-curva timpanométrica tipo B

C- curva timpanométrica tipo C; As- curva timpanométrica tipo As 
Anexo 9 - Distribuição da ocorrência dos tipos de curvas timpanométricas, nas crianças do grupo 3

$\begin{array}{cccc}\text { Criança } & \begin{array}{l}\text { Idade } \\ \text { meses }\end{array} & \text { Tipo de curva timpanométrica } \\ & & \text { OD } & \text { OE } \\ 1 & 3 m 5 d & \mathrm{~A} & \mathrm{~B} \\ 2 & 3 \mathrm{~m} 15 \mathrm{~d} & \mathrm{~A} & \mathrm{~A} \\ 3 & 3 \mathrm{~m} 3 \mathrm{~d} & \mathrm{~B} & \mathrm{~B} \\ 4 & 6 \mathrm{~m} 5 \mathrm{~d} & \mathrm{~A} & \mathrm{~A} \\ 5 & 6 \mathrm{~m} 10 \mathrm{~d} & \mathrm{~A} & \mathrm{~A}\end{array}$

OD - orelha direita; OE - orelha esquerda;

A- curva timpanométrica tipo A; B- curva timpanométrica tipo B 
Anexo 10- Distribuição da ocorrência de respostas a sons instrumentais, nas crianças do grupo 1

\begin{tabular}{|c|c|c|c|c|c|}
\hline \multirow[t]{2}{*}{ Criança } & \multirow{2}{*}{$\begin{array}{l}\text { Idade } \\
\text { meses }\end{array}$} & \multicolumn{4}{|c|}{$\mathrm{AOC}$} \\
\hline & & GUIZO & SINO & $B L A C K$ & AGOGÔ \\
\hline 1 & $7 \mathrm{~m} 3 \mathrm{~d}$ & LL & LL & LL & $\mathrm{RCP}$ \\
\hline 2 & $3 \mathrm{~m} 16 \mathrm{~d}$ & A & A & A & A \\
\hline 3 & $4 \mathrm{~m} 7 \mathrm{~d}$ & $\mathrm{PF}$ & $\mathrm{PF}$ & $\mathrm{PF}$ & $\mathrm{PF}$ \\
\hline 4 & $11 \mathrm{~m} 21 \mathrm{~d}$ & LL & LL & LL & LL \\
\hline 5 & $8 \mathrm{~m} 13 \mathrm{~d}$ & LL & LL & LL & LL \\
\hline 6 & $3 \mathrm{~m} 4 \mathrm{~d}$ & A & $\mathrm{A}$ & $\mathrm{A}$ & A \\
\hline 7 & $11 \mathrm{~m} 21 \mathrm{~d}$ & LL & LL & LL & $\mathrm{RCP}$ \\
\hline 8 & $3 \mathrm{~m} 2 \mathrm{~d}$ & A & A & A & $\mathrm{RCP}$ \\
\hline 9 & $6 \mathrm{~m} 5 \mathrm{~d}$ & LL & LL & LL & $\mathrm{RCP}$ \\
\hline 10 & $3 \mathrm{~m} 1 \mathrm{~d}$ & A & A & A & A \\
\hline 11 & $3 m 6 d$ & A & A & A & $\mathrm{RCP}$ \\
\hline 12 & $12 \mathrm{~m} 7 \mathrm{~d}$ & LL & LL & LL & LL \\
\hline 13 & $12 \mathrm{~m} 17 \mathrm{~d}$ & LL & LL & LL & $\mathrm{RCP}$ \\
\hline 14 & $12 \mathrm{~m} 20 \mathrm{~d}$ & LL & LL & LL & $\mathrm{RCP}$ \\
\hline 15 & $4 \mathrm{~m} 11 \mathrm{~d}$ & $\mathrm{PF}$ & $\mathrm{A}$ & $\mathrm{PF}$ & $\mathrm{RCP}$ \\
\hline 16 & $6 \mathrm{mOd}$ & LL & LL & LL & $\mathrm{RCP}$ \\
\hline 17 & $8 \mathrm{~m} 16 \mathrm{~d}$ & LL & LL & LL & LL \\
\hline 18 & $6 \mathrm{~m} 1 \mathrm{~d}$ & LL & LL & LL & $\mathrm{RCP}$ \\
\hline 19 & $3 \mathrm{mOd}$ & A & A & A & $\mathrm{RCP}$ \\
\hline 20 & $8 \mathrm{~m} 5 \mathrm{~d}$ & LL & LL & LL & $\mathrm{RCP}$ \\
\hline 21 & $5 \mathrm{~m} 10 \mathrm{~d}$ & LL & LL & LL & $\mathrm{RCP}$ \\
\hline 22 & $3 \mathrm{~m} 14 \mathrm{~d}$ & A & A & A & A \\
\hline 23 & $3 \mathrm{~m} 8 \mathrm{~d}$ & A & A & $\mathrm{PF}$ & $\mathrm{RCP}$ \\
\hline 24 & $6 \mathrm{~m} 14 \mathrm{~d}$ & LL & LL & LL & LL \\
\hline 25 & $3 \mathrm{~m} 13 \mathrm{~d}$ & A & A & A & A \\
\hline 26 & $12 \mathrm{~m} 5 \mathrm{~d}$ & $\mathrm{LL}$ & LL & LL & $\mathrm{RCP}$ \\
\hline 27 & $12 \mathrm{~m} 11 \mathrm{~d}$ & LL & LL & LL & LL \\
\hline 28 & $9 \mathrm{~m} 7 \mathrm{~d}$ & LL & LL & LL & LL \\
\hline 29 & $9 \mathrm{~m} 7 \mathrm{~d}$ & LL & LL & LL & LL \\
\hline 30 & $6 \mathrm{~m} 2 \mathrm{~d}$ & $\mathrm{PF}$ & $\mathrm{PF}$ & $\mathrm{PF}$ & $\mathrm{PF}$ \\
\hline 31 & $3 \mathrm{~m} 28 \mathrm{~d}$ & A & A & A & A \\
\hline 32 & $3 \mathrm{~m} 26 \mathrm{~d}$ & A & A & A & $\mathrm{RCP}$ \\
\hline 33 & $6 \mathrm{~m} 20 \mathrm{~d}$ & LL & LL & LL & $\mathrm{RCP}$ \\
\hline 34 & $4 \mathrm{~m} 10 \mathrm{~d}$ & $\mathrm{PF}$ & $\mathrm{PF}$ & $\mathrm{PF}$ & A \\
\hline 35 & $12 \mathrm{~m} 3 \mathrm{~d}$ & LL & LL & LL & $\mathrm{RCP}$ \\
\hline 36 & $12 \mathrm{~m} 10 \mathrm{~d}$ & LL & LL & LL & $\mathrm{RCP}$ \\
\hline 37 & $6 \mathrm{~m} 8 \mathrm{~d}$ & $\mathrm{LL}$ & LL & LL & $\mathrm{RCP}$ \\
\hline 38 & $7 \mathrm{~m} 23 \mathrm{~d}$ & LL & LL & LL & $\mathrm{RCP}$ \\
\hline 39 & $3 \mathrm{~m} 17 \mathrm{~d}$ & $\mathrm{PF}$ & $\mathrm{PF}$ & $\mathrm{PF}$ & $\mathrm{PF}$ \\
\hline 40 & $8 \mathrm{~m} 7 \mathrm{~d}$ & LL & LL & LL & LL \\
\hline 41 & $9 \mathrm{~m} 11 \mathrm{~d}$ & LL & LL & LL & LL \\
\hline 42 & $5 \mathrm{~m} 10 \mathrm{~d}$ & $\mathrm{PF}$ & $\mathrm{PF}$ & $\mathrm{PF}$ & $\mathrm{PF}$ \\
\hline 43 & $3 m 25 d$ & A & A & A & RCP \\
\hline 44 & $3 \mathrm{~m} 15 \mathrm{~d}$ & $\mathrm{PF}$ & $\mathrm{PF}$ & $\mathrm{PF}$ & $\mathrm{RCP}$ \\
\hline 45 & $3 \mathrm{mOd}$ & A & A & A & $\mathrm{RCP}$ \\
\hline 46 & $3 \mathrm{~m} 15 \mathrm{~d}$ & A & A & A & A \\
\hline 47 & $5 \mathrm{~m} 26 \mathrm{~d}$ & A & A & A & A \\
\hline 48 & $11 \mathrm{~m} 16 \mathrm{~d}$ & LL & LL & LL & LL \\
\hline
\end{tabular}

AOC- Audiometria de observação comportamental; BLACK- Black-black; A- Atenção; PF- Procura da fonte; LL- Localização lateral; RCP- Reflexo cocleopalpebral 
Anexo 11 - Distribuição da ocorrência de respostas a sons instrumentais, nas crianças do grupo 2

\begin{tabular}{|c|c|c|c|c|c|}
\hline \multirow[t]{2}{*}{ Criança } & \multirow[t]{2}{*}{$\begin{array}{l}\text { Idade } \\
\text { meses }\end{array}$} & \multicolumn{4}{|c|}{$\mathrm{AOC}$} \\
\hline & & GUIZO & SINO & $B L A C K$ & AGOGÔ \\
\hline 1 & $3 \mathrm{~m} 18 \mathrm{~d}$ & $\mathrm{PF}$ & $\mathrm{PF}$ & $\mathrm{PF}$ & A \\
\hline 2 & $3 \mathrm{~m} 23 \mathrm{~d}$ & $\mathrm{PF}$ & $\mathrm{PF}$ & $\mathrm{A}$ & $\mathrm{RCP}, \mathrm{S}$ \\
\hline 3 & $5 \mathrm{~m} 11 \mathrm{~d}$ & $\mathrm{~A}$ & A & $\mathrm{A}$ & $\mathrm{RCP}$ \\
\hline 4 & $3 \mathrm{~m} 5 \mathrm{~d}$ & $\mathrm{PF}$ & $\mathrm{PF}$ & $\mathrm{PF}$ & $\mathrm{RCP}$ \\
\hline 5 & $7 \mathrm{m10d}$ & LL & LL & LL & LL \\
\hline 6 & $4 \mathrm{~m} 9 \mathrm{~d}$ & $\mathrm{~A}$ & $\mathrm{~A}$ & $\mathrm{PF}$ & $\mathrm{RCP}, \mathrm{S}$ \\
\hline 7 & $5 \mathrm{~m} 12 \mathrm{~d}$ & LL & LL & LL & RCP \\
\hline 8 & $3 \mathrm{~m} 3 \mathrm{~d}$ & A & A & A & RCP \\
\hline 9 & $3 \mathrm{~m} 14 \mathrm{~d}$ & $\mathrm{PF}$ & A & $\mathrm{PF}$ & RCP \\
\hline 10 & $3 \mathrm{~m} 3 \mathrm{~d}$ & $\mathrm{~A}$ & A & $\mathrm{PF}$ & $\mathrm{RCP}$ \\
\hline 11 & $3 \mathrm{~m} 7 \mathrm{~d}$ & A & A & $\mathrm{A}$ & $\mathrm{RCP}$ \\
\hline 12 & $3 \mathrm{~m} 15 \mathrm{~d}$ & A & A & A & $\mathrm{RCP}$ \\
\hline 13 & $9 \mathrm{~m} 17 \mathrm{~d}$ & LL & LL & LL & $\mathrm{RCP}$ \\
\hline 14 & $5 \mathrm{~m} 8 \mathrm{~d}$ & LL & LL & LL & $\mathrm{RCP}$ \\
\hline 15 & $9 m 25 d$ & LL & LL & LL & $\mathrm{RCP}$ \\
\hline 16 & $3 \mathrm{~m} 3 \mathrm{~d}$ & A & A & A & $\mathrm{RCP}$ \\
\hline 17 & $8 \mathrm{~m} 7 \mathrm{~d}$ & LL & LL & LL & LL \\
\hline 18 & $3 \mathrm{~m} 2 \mathrm{~d}$ & A & A & A & $\mathrm{RCP}$ \\
\hline 19 & $4 \mathrm{~m} 19 \mathrm{~d}$ & $\mathrm{PF}$ & $\mathrm{PF}$ & $\mathrm{PF}$ & $\mathrm{RCP}$ \\
\hline 20 & $6 \mathrm{~m} 3 \mathrm{~d}$ & LL & LL & LL & $\mathrm{RCP}$ \\
\hline 21 & $8 \mathrm{~m} 14 \mathrm{~d}$ & LL & LL & LL & LL \\
\hline 22 & $5 \mathrm{~m} 11 \mathrm{~d}$ & $\mathrm{PF}$ & $\mathrm{PF}$ & $\mathrm{PF}$ & PF \\
\hline 23 & $8 \mathrm{~m} 21 \mathrm{~d}$ & LL & LL & LL & LL \\
\hline 24 & $6 \mathrm{~m} 20 \mathrm{~d}$ & LL & LL & LL & $\mathrm{RCP}$ \\
\hline 25 & $4 \mathrm{~m} 4 \mathrm{~d}$ & $\mathrm{PF}$ & A & A & $\mathrm{RCP}$ \\
\hline 26 & $4 \mathrm{~m} 6 \mathrm{~d}$ & $\mathrm{PF}$ & $\mathrm{PF}$ & $\mathrm{PF}$ & $\mathrm{PF}$ \\
\hline 27 & $9 \mathrm{~m} 11 \mathrm{~d}$ & LL & LL & LL & LL \\
\hline 28 & $4 \mathrm{~m} 4 \mathrm{~d}$ & $\mathrm{PF}$ & A & A & $\mathrm{RCP}$ \\
\hline 29 & $4 \mathrm{~m} 16 \mathrm{~d}$ & A & A & A & $\mathrm{RCP}$ \\
\hline
\end{tabular}

AOC - Audiometria de observação comportamental; BLACK - Black-black; A - Atenção; PF - Procura da fonte; LL - Localização lateral; RCP - Reflexo cocleopalpebral; S Reação de Startle 
Anexo 12 - Distribuição da ocorrência de respostas a sons instrumentais, nas crianças do grupo 2

\begin{tabular}{clcccc} 
Criança & \multicolumn{1}{l}{$\begin{array}{l}\text { Idade } \\
\text { meses }\end{array}$} & \multicolumn{4}{c}{ AOC } \\
& & GUIZO & SINO & BLACK & AGOGô \\
1 & $3 \mathrm{~m} 5 \mathrm{~d}$ & $\mathrm{~A}$ & $\mathrm{~A}$ & $\mathrm{~A}$ & $\mathrm{RCP}$ \\
2 & $3 \mathrm{~m} 15 \mathrm{~d}$ & $\mathrm{PF}$ & $\mathrm{PF}$ & $\mathrm{A}$ & $\mathrm{RCP}$ \\
3 & $3 \mathrm{~m} 3 \mathrm{~d}$ & $\mathrm{~A}$ & $\mathrm{~A}$ & $\mathrm{~A}$ & $\mathrm{RCP}$ \\
4 & $6 \mathrm{~m} 5 \mathrm{~d}$ & LL & LL & LL & RCP \\
5 & $6 \mathrm{~m} 10 \mathrm{~d}$ & LL & LL & LL & RCP
\end{tabular}

AOC - Audiometria de observação comportamental; BLACK - Black-black; A - Atenção; PF - Procura da fonte; LL - Localização lateral; RCP - Reflexo cocleopalpebral 
Anexo 13 - Distribuição dos niveis de respostas para tons puros (VRA), nas diferentes freqüências $(\mathrm{Hz})$, nas crianças do grupo 1

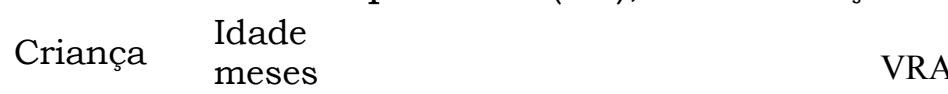

OD

$\mathrm{OE}$

\begin{tabular}{|c|c|c|c|c|c|c|c|c|}
\hline & 000 & 1000 & 2000 & 4000 & 500 & 1000 & 2000 & 4000 \\
\hline $7 \mathrm{~m} 3 \mathrm{~d}$ & 45 & 45 & 45 & 45 & 45 & 45 & 45 & 45 \\
\hline $3 \mathrm{~m} 16 \mathrm{~d}$ & 60 & 60 & 60 & 60 & 60 & 60 & 60 & 60 \\
\hline $4 \mathrm{~m} 7 \mathrm{~d}$ & 60 & 60 & 60 & 60 & 60 & 60 & 60 & 60 \\
\hline $11 \mathrm{~m} 21 \mathrm{~d}$ & 70 & 70 & 70 & 70 & 70 & 70 & 70 & 70 \\
\hline $8 \mathrm{~m} 13 \mathrm{~d}$ & 30 & 30 & 30 & 30 & 30 & 30 & 30 & 30 \\
\hline $3 \mathrm{~m} 4 \mathrm{~d}$ & 70 & 70 & 70 & 70 & 70 & 70 & 70 & 70 \\
\hline $11 \mathrm{~m} 21 \mathrm{~d}$ & 30 & 30 & 30 & 30 & 30 & 30 & 30 & 30 \\
\hline $3 \mathrm{~m} 2 \mathrm{~d}$ & 70 & 70 & 70 & 70 & 70 & 70 & 70 & 70 \\
\hline $6 \mathrm{~m} 5 \mathrm{~d}$ & 50 & 50 & 50 & 50 & 50 & 50 & 50 & 50 \\
\hline $3 \mathrm{~m} 1 \mathrm{~d}$ & 60 & 60 & 60 & 60 & 60 & 60 & 60 & 60 \\
\hline $3 \mathrm{~m} 6 \mathrm{~d}$ & 60 & 60 & 60 & 60 & 60 & 60 & 60 & 60 \\
\hline $12 \mathrm{~m} 7 \mathrm{~d}$ & 30 & 30 & 30 & 30 & 30 & 30 & 30 & 30 \\
\hline $12 \mathrm{~m} 17 \mathrm{~d}$ & 35 & 35 & 35 & 35 & 35 & 35 & 35 & 35 \\
\hline $12 \mathrm{~m} 20 \mathrm{~d}$ & 35 & 35 & 35 & 35 & 35 & 35 & 35 & 35 \\
\hline $4 \mathrm{~m} 11 \mathrm{~d}$ & 60 & 60 & 60 & 60 & 60 & 60 & 60 & 60 \\
\hline $6 \mathrm{mOd}$ & 50 & 50 & 50 & 50 & 50 & 50 & 50 & 50 \\
\hline $8 \mathrm{~m} 16 \mathrm{~d}$ & 30 & 30 & 30 & 30 & 30 & 30 & 30 & 30 \\
\hline $6 \mathrm{~m} 1 \mathrm{~d}$ & 50 & 50 & 50 & 50 & 50 & 50 & 50 & 50 \\
\hline $3 \mathrm{mOd}$ & 70 & 70 & 70 & 70 & 70 & 70 & 70 & 70 \\
\hline $8 \mathrm{~m} 5 \mathrm{~d}$ & 30 & 30 & 30 & 30 & 30 & 30 & 30 & 30 \\
\hline $5 \mathrm{~m} 10 \mathrm{~d}$ & 50 & 40 & 40 & 40 & 40 & 40 & 40 & 40 \\
\hline $3 \mathrm{~m} 14 \mathrm{~d}$ & 60 & 60 & 60 & 60 & 60 & 60 & 60 & 60 \\
\hline $3 \mathrm{~m} 8 \mathrm{~d}$ & 50 & 50 & 50 & 50 & 50 & 50 & 50 & 50 \\
\hline $6 \mathrm{~m} 14 \mathrm{~d}$ & 60 & 60 & 60 & 60 & 60 & 60 & 60 & 60 \\
\hline $3 \mathrm{~m} 13 \mathrm{~d}$ & 60 & 60 & 60 & 60 & 60 & 60 & 60 & 60 \\
\hline $12 \mathrm{~m} 5 \mathrm{~d}$ & 25 & 25 & 25 & 25 & 25 & 25 & 25 & 25 \\
\hline $12 \mathrm{~m} 11 \mathrm{~d}$ & 25 & 30 & 35 & 35 & 30 & 30 & 30 & 30 \\
\hline $9 \mathrm{~m} 7 \mathrm{~d}$ & 30 & 30 & 30 & 30 & 30 & 30 & 30 & 30 \\
\hline $9 \mathrm{~m} 7 \mathrm{~d}$ & 30 & 30 & 30 & 30 & 35 & 35 & 35 & 35 \\
\hline $6 \mathrm{~m} 2 \mathrm{~d}$ & 60 & 60 & 60 & 60 & 55 & 60 & 55 & 55 \\
\hline $3 \mathrm{~m} 28 \mathrm{~d}$ & 50 & 50 & 50 & 50 & 50 & 50 & 50 & 50 \\
\hline $3 \mathrm{~m} 26 \mathrm{~d}$ & 50 & 50 & 50 & 50 & 50 & 50 & 50 & 50 \\
\hline $6 \mathrm{~m} 20 \mathrm{~d}$ & 50 & 50 & 50 & 50 & 50 & 50 & 50 & 50 \\
\hline $4 \mathrm{~m} 10 \mathrm{~d}$ & 50 & 50 & 60 & 60 & 60 & 60 & 60 & 60 \\
\hline $12 \mathrm{~m} 3 \mathrm{~d}$ & 35 & 35 & 35 & 35 & 35 & 35 & 35 & 35 \\
\hline $12 \mathrm{~m} 10 \mathrm{~d}$ & 25 & 25 & 25 & 25 & 35 & 35 & 35 & 35 \\
\hline $6 \mathrm{~m} 8 \mathrm{~d}$ & 40 & 40 & 40 & 40 & 40 & 40 & 40 & 40 \\
\hline $7 \mathrm{~m} 23 \mathrm{~d}$ & 40 & 40 & 40 & 40 & 40 & 40 & 40 & 40 \\
\hline $3 \mathrm{~m} 17 \mathrm{~d}$ & 60 & 60 & 60 & 60 & 60 & 60 & 60 & 60 \\
\hline $8 \mathrm{~m} 7 \mathrm{~d}$ & 30 & 30 & 30 & 30 & 30 & 30 & 30 & 30 \\
\hline $9 \mathrm{~m} 11 \mathrm{~d}$ & 30 & 30 & 30 & 40 & 30 & 30 & 30 & 40 \\
\hline $5 \mathrm{~m} 10 \mathrm{~d}$ & 50 & 50 & 50 & 50 & 50 & 50 & 50 & 50 \\
\hline $3 \mathrm{~m} 25 \mathrm{~d}$ & 70 & 70 & 70 & 70 & 70 & 70 & 70 & 70 \\
\hline $3 \mathrm{~m} 15 \mathrm{~d}$ & 70 & 70 & 70 & 70 & 70 & 70 & 70 & 70 \\
\hline $3 \mathrm{mOd}$ & 60 & 60 & 60 & 60 & 60 & 60 & 60 & 60 \\
\hline $3 \mathrm{~m} 15 \mathrm{~d}$ & 55 & 55 & 50 & 50 & 50 & 55 & 60 & 60 \\
\hline $5 \mathrm{~m} 26 \mathrm{~d}$ & 40 & 40 & 40 & 40 & 40 & 40 & 40 & 40 \\
\hline $11 \mathrm{~m} 16 \mathrm{~d}$ & 25 & 25 & 25 & 25 & 25 & 25 & 25 & 25 \\
\hline
\end{tabular}

VRA - Audiometria de reforço visual; OD - Orelha direita; OE - Orelha esquerda; $\mathrm{Hz}$ - Hertz 
Anexo 14 - Distribuição dos niveis de respostas para tons puros (VRA), nas diferentes freqüências $(\mathrm{Hz})$, nas crianças do grupo 2

\begin{tabular}{|c|c|c|c|c|c|c|c|c|c|}
\hline \multirow{3}{*}{ Criança } & \multirow{3}{*}{$\begin{array}{l}\text { Idade } \\
\text { meses }\end{array}$} & \multicolumn{8}{|c|}{ VRA } \\
\hline & & \multicolumn{4}{|c|}{ OD } & \multicolumn{4}{|c|}{$\mathrm{OE}$} \\
\hline & & 500 & 1000 & 2000 & 4000 & 500 & 1000 & 2000 & 4000 \\
\hline 1 & $3 \mathrm{~m} 18 \mathrm{~d}$ & 50 & 50 & 50 & 50 & 50 & 50 & 50 & 50 \\
\hline 2 & $3 \mathrm{~m} 23 \mathrm{~d}$ & 60 & 60 & 60 & 60 & 60 & 60 & 60 & 60 \\
\hline 3 & $5 \mathrm{~m} 11 \mathrm{~d}$ & 50 & 50 & 50 & 50 & 50 & 50 & 50 & 50 \\
\hline 4 & $3 \mathrm{~m} 5 \mathrm{~d}$ & 50 & 50 & 50 & 50 & 50 & 50 & 50 & 50 \\
\hline 5 & $7 \mathrm{~m} 10 \mathrm{~d}$ & 40 & 40 & 40 & 40 & 40 & 40 & 40 & 40 \\
\hline 6 & $4 \mathrm{~m} 9 \mathrm{~d}$ & 50 & 50 & 50 & 50 & 50 & 50 & 50 & 50 \\
\hline 7 & $5 \mathrm{~m} 12 \mathrm{~d}$ & 40 & 40 & 40 & 40 & 40 & 40 & 40 & 40 \\
\hline 8 & $3 \mathrm{~m} 3 \mathrm{~d}$ & 60 & 60 & 60 & 60 & 60 & 60 & 60 & 60 \\
\hline 9 & $3 \mathrm{~m} 14 \mathrm{~d}$ & 50 & 50 & 50 & 50 & 50 & 50 & 50 & 50 \\
\hline 10 & $3 \mathrm{~m} 3 \mathrm{~d}$ & 50 & 50 & 50 & 50 & 50 & 50 & 50 & 50 \\
\hline 11 & $3 \mathrm{~m} 7 \mathrm{~d}$ & 50 & 50 & 55 & 55 & 50 & 55 & 55 & 50 \\
\hline 12 & $3 \mathrm{~m} 15 \mathrm{~d}$ & 55 & 50 & 55 & 55 & 55 & 50 & 50 & 60 \\
\hline 13 & $9 \mathrm{~m} 17 \mathrm{~d}$ & 30 & 30 & 30 & 30 & 30 & 30 & 30 & 30 \\
\hline 14 & $5 \mathrm{~m} 8 \mathrm{~d}$ & 40 & 45 & 45 & 45 & 50 & 50 & 50 & 50 \\
\hline 15 & $9 \mathrm{~m} 25 \mathrm{~d}$ & 40 & 40 & 40 & 40 & 40 & 40 & 40 & 40 \\
\hline 16 & $3 \mathrm{~m} 3 \mathrm{~d}$ & 50 & 55 & 50 & 55 & 50 & 50 & 50 & 50 \\
\hline 17 & $8 \mathrm{~m} 7 \mathrm{~d}$ & 45 & 40 & 45 & 45 & 45 & 45 & 45 & 40 \\
\hline 18 & $3 \mathrm{~m} 2 \mathrm{~d}$ & 50 & 50 & 55 & 55 & 55 & 50 & 55 & 60 \\
\hline 19 & $4 \mathrm{~m} 19 \mathrm{~d}$ & 40 & 40 & 40 & 40 & 40 & 40 & 40 & 40 \\
\hline 20 & $6 \mathrm{~m} 3 \mathrm{~d}$ & 40 & 50 & 45 & 40 & 40 & 45 & 45 & 45 \\
\hline 21 & $8 \mathrm{~m} 14 \mathrm{~d}$ & 30 & 30 & 30 & 30 & 30 & 30 & 30 & 30 \\
\hline 22 & $5 \mathrm{~m} 11 \mathrm{~d}$ & 40 & 40 & 40 & 40 & 40 & 40 & 40 & 40 \\
\hline 23 & $8 \mathrm{~m} 21 \mathrm{~d}$ & 30 & 30 & 30 & 30 & 35 & 35 & 35 & 35 \\
\hline 24 & $6 \mathrm{~m} 20 \mathrm{~d}$ & 60 & 60 & 60 & 60 & 60 & 60 & 60 & 60 \\
\hline 25 & $4 \mathrm{~m} 4 \mathrm{~d}$ & 50 & 60 & 60 & 50 & 50 & 50 & 50 & 50 \\
\hline 26 & $4 \mathrm{~m} 6 \mathrm{~d}$ & 60 & 60 & 60 & 60 & 60 & 60 & 60 & 60 \\
\hline 27 & $9 \mathrm{~m} 11 \mathrm{~d}$ & 30 & 30 & 30 & 30 & 30 & 30 & 30 & 30 \\
\hline 28 & $4 \mathrm{~m} 4 \mathrm{~d}$ & 50 & 50 & 50 & 50 & 50 & 50 & 50 & 50 \\
\hline 29 & $4 \mathrm{~m} 16 \mathrm{~d}$ & 60 & 60 & 60 & 60 & 60 & 60 & 60 & 60 \\
\hline
\end{tabular}


Anexo 15 - Distribuição dos niveis de respostas para tons puros (VRA), nas diferentes freqüências $(\mathrm{Hz})$, nas crianças do grupo 3

\begin{tabular}{cccccccccc} 
Criança & Idade & \multicolumn{9}{c}{ VRA } \\
& & \multicolumn{9}{c}{ OD } & & \multicolumn{5}{c}{ OE } \\
& & 500 & 1000 & 2000 & 4000 & 500 & 1000 & 2000 & 4000 \\
1 & $3 m 5 d$ & 50 & 50 & 55 & 60 & 55 & 50 & 60 & 60 \\
2 & $3 m 15 d$ & 60 & 50 & 60 & 55 & 50 & 55 & 60 & 55 \\
3 & $3 m 3 d$ & 55 & 55 & 50 & 55 & 55 & 55 & 60 & 55 \\
4 & $6 m 5 d$ & 45 & 45 & 50 & 50 & 50 & 50 & 45 & 45 \\
5 & $6 m 10 d$ & 30 & 30 & 30 & 35 & 35 & 35 & 30 & 30
\end{tabular}

VRA - audiometria de reforço visual; OD - orelha direita; OE - orelha esquerda; $\mathrm{Hz}-$ Hertz 
Anexo 16 - Distribuição dos dados quanto a presença ou ausência de Emissão otoacústica evocada por estímulo transiente, nas crianças do grupo 1

\begin{tabular}{|c|c|c|c|}
\hline \multirow{2}{*}{ Criança } & \multirow{2}{*}{$\begin{array}{l}\text { Idade } \\
\text { Meses }\end{array}$} & \multicolumn{2}{|c|}{ EOAT } \\
\hline & & OD & $\mathrm{OE}$ \\
\hline 1 & $7 \mathrm{~m} 3 \mathrm{~d}$ & - & - \\
\hline 2 & $3 \mathrm{~m} 16 \mathrm{~d}$ & - & - \\
\hline 3 & $4 \mathrm{~m} 7 \mathrm{~d}$ & - & - \\
\hline 4 & $11 \mathrm{~m} 21 \mathrm{~d}$ & - & - \\
\hline 5 & $8 \mathrm{~m} 13 \mathrm{~d}$ & - & - \\
\hline 6 & $3 \mathrm{~m} 4 \mathrm{~d}$ & - & - \\
\hline 7 & $11 \mathrm{~m} 21 \mathrm{~d}$ & - & - \\
\hline 8 & $3 \mathrm{~m} 2 \mathrm{~d}$ & - & - \\
\hline 9 & $6 \mathrm{~m} 5 \mathrm{~d}$ & - & - \\
\hline 10 & $3 \mathrm{~m} 1 \mathrm{~d}$ & - & - \\
\hline 11 & $3 \mathrm{~m} 6 \mathrm{~d}$ & - & - \\
\hline 12 & $12 \mathrm{~m} 7 \mathrm{~d}$ & - & - \\
\hline 13 & $12 \mathrm{~m} 17 \mathrm{~d}$ & - & - \\
\hline 14 & $12 \mathrm{~m} 20 \mathrm{~d}$ & - & - \\
\hline 15 & $4 \mathrm{~m} 11 \mathrm{~d}$ & - & - \\
\hline 16 & $6 \mathrm{mOd}$ & - & - \\
\hline 17 & $8 \mathrm{~m} 16 \mathrm{~d}$ & - & - \\
\hline 18 & $6 \mathrm{~m} 1 \mathrm{~d}$ & - & - \\
\hline 19 & $3 \mathrm{mOd}$ & - & - \\
\hline 20 & $8 \mathrm{~m} 5 \mathrm{~d}$ & - & - \\
\hline 21 & $5 \mathrm{~m} 10 \mathrm{~d}$ & - & - \\
\hline 22 & $3 \mathrm{~m} 14 \mathrm{~d}$ & - & - \\
\hline 23 & $3 \mathrm{~m} 8 \mathrm{~d}$ & - & - \\
\hline 24 & $6 \mathrm{~m} 14 \mathrm{~d}$ & - & - \\
\hline 25 & $3 \mathrm{~m} 13 \mathrm{~d}$ & - & - \\
\hline 26 & $12 \mathrm{~m} 5 \mathrm{~d}$ & + & - \\
\hline 27 & $12 \mathrm{~m} 11 \mathrm{~d}$ & NR & NR \\
\hline 28 & $9 \mathrm{~m} 7 \mathrm{~d}$ & - & - \\
\hline 29 & $9 \mathrm{~m} 7 \mathrm{~d}$ & - & - \\
\hline 30 & $6 \mathrm{~m} 2 \mathrm{~d}$ & - & - \\
\hline 31 & $3 \mathrm{~m} 28 \mathrm{~d}$ & NR & - \\
\hline 32 & $3 \mathrm{~m} 26 \mathrm{~d}$ & NR & - \\
\hline 33 & $6 \mathrm{~m} 20 \mathrm{~d}$ & - & - \\
\hline 34 & $4 \mathrm{~m} 10 \mathrm{~d}$ & - & NR \\
\hline 35 & $12 \mathrm{~m} 3 \mathrm{~d}$ & - & NR \\
\hline 36 & $12 \mathrm{~m} 10 \mathrm{~d}$ & NR & NR \\
\hline 37 & $6 \mathrm{~m} 8 \mathrm{~d}$ & NR & NR \\
\hline 38 & $7 \mathrm{~m} 23 \mathrm{~d}$ & NR & NR \\
\hline 39 & $3 \mathrm{~m} 17 \mathrm{~d}$ & NR & NR \\
\hline 40 & $8 \mathrm{~m} 7 \mathrm{~d}$ & NR & NR \\
\hline 41 & $9 \mathrm{~m} 11 \mathrm{~d}$ & NR & NR \\
\hline 42 & $5 \mathrm{~m} 10 \mathrm{~d}$ & NR & NR \\
\hline 43 & $3 \mathrm{~m} 25 \mathrm{~d}$ & NR & NR \\
\hline 44 & $3 \mathrm{~m} 15 \mathrm{~d}$ & NR & NR \\
\hline 45 & $3 \mathrm{mOd}$ & NR & NR \\
\hline 46 & $3 \mathrm{~m} 15 \mathrm{~d}$ & NR & NR \\
\hline 47 & $5 \mathrm{~m} 26 \mathrm{~d}$ & NR & - \\
\hline 48 & $11 \mathrm{~m} 16 \mathrm{~d}$ & NR & NR \\
\hline
\end{tabular}

EOAT - Emissão otoacústica evocada por estímulo transiente;+ Presença de EOAT; - Ausência de EOAT; NR - Exame não realizado 
Anexo 17 - Distribuição dos dados quanto a presença ou ausência de Emissão otoacústica evocada por estímulo transiente, nas crianças do grupo 2

\begin{tabular}{clcc} 
Criança & \multicolumn{1}{c}{ Idade } & \multicolumn{2}{c}{ EOAT } \\
& meses & OD & OE \\
1 & $3 \mathrm{~m} 18 \mathrm{~d}$ & + & + \\
2 & $3 \mathrm{~m} 23 \mathrm{~d}$ & + & + \\
3 & $5 \mathrm{~m} 11 \mathrm{~d}$ & + & + \\
4 & $3 \mathrm{~m} 5 \mathrm{~d}$ & + & + \\
5 & $7 \mathrm{~m} 10 \mathrm{~d}$ & + & + \\
6 & $4 \mathrm{~m} 9 \mathrm{~d}$ & + & + \\
7 & $5 \mathrm{~m} 12 \mathrm{~d}$ & + & + \\
8 & $3 \mathrm{~m} 3 \mathrm{~d}$ & + & - \\
9 & $3 \mathrm{~m} 14 \mathrm{~d}$ & + & + \\
10 & $3 \mathrm{~m} 3 \mathrm{~d}$ & + & + \\
11 & $3 \mathrm{~m} 7 \mathrm{~d}$ & + & + \\
12 & $3 \mathrm{~m} 15 \mathrm{~d}$ & + & + \\
13 & $9 \mathrm{~m} 17 \mathrm{~d}$ & + & - \\
14 & $5 \mathrm{~m} 8 \mathrm{~d}$ & - & + \\
15 & $9 \mathrm{~m} 25 \mathrm{~d}$ & - & + \\
16 & $3 \mathrm{~m} 3 \mathrm{~d}$ & + & + \\
17 & $8 \mathrm{~m} 7 \mathrm{~d}$ & - & - \\
18 & $3 \mathrm{~m} 2 \mathrm{~d}$ & - & - \\
19 & $4 \mathrm{~m} 19 \mathrm{~d}$ & + & + \\
20 & $6 \mathrm{~m} 3 \mathrm{~d}$ & - & - \\
21 & $8 \mathrm{~m} 14 \mathrm{~d}$ & + & $\mathrm{NR}$ \\
22 & $5 \mathrm{~m} 11 \mathrm{~d}$ & $\mathrm{NR}$ & + \\
23 & $8 \mathrm{~m} 21 \mathrm{~d}$ & $\mathrm{NR}$ & - \\
24 & $6 \mathrm{~m} 20 \mathrm{~d}$ & $\mathrm{NR}$ & $\mathrm{NR}$ \\
25 & $4 \mathrm{~m} 4 \mathrm{~d}$ & $\mathrm{NR}$ & $\mathrm{NR}$ \\
26 & $4 \mathrm{~m} 6 \mathrm{~d}$ & $\mathrm{NR}$ & $\mathrm{NR}$ \\
27 & $9 \mathrm{~m} 11 \mathrm{~d}$ & $\mathrm{NR}$ & $\mathrm{NR}$ \\
28 & $4 \mathrm{~m} 4 \mathrm{~d}$ & $\mathrm{NR}$ & $\mathrm{NR}$ \\
29 & $4 \mathrm{~m} 16 \mathrm{~d}$ & $\mathrm{NR}$ & $\mathrm{NR}$
\end{tabular}

EOAT - Emissão otoacústica evocada por estímulo transiente; + Presença de EOAT; - Ausência de EOAT;

NR - exame não realizado 
Anexo 18 - Distribuição dos dados quanto a presença ou ausência de Emissão otoacústica evocada por estímulo transiente, nas crianças do grupo 3

\begin{tabular}{clcc} 
& & \multicolumn{2}{c}{ EOAT } \\
Criança & $\begin{array}{l}\text { Idade } \\
\text { meses }\end{array}$ & OD & OE \\
1 & $3 \mathrm{~m} 5 \mathrm{~d}$ & + & - \\
2 & $3 \mathrm{~m} 15 \mathrm{~d}$ & + & + \\
3 & $3 \mathrm{~m} 3 \mathrm{~d}$ & - & - \\
4 & $6 \mathrm{~m} 5 \mathrm{~d}$ & + & + \\
5 & $6 \mathrm{~m} 10 \mathrm{~d}$ & + & +
\end{tabular}

EOAT - Emissão otoacústica evocada por estímulo transiente; + Presença de EOAT; - Ausência de EOAT;

NR - Exame não realizado 